\title{
Expanding men's participation in reproductive health in Kenya
}

Bolaji M. Fapohunda

Naomi Rutenberg

Population Council

Follow this and additional works at: https://knowledgecommons.popcouncil.org/departments_sbsr-rh

Part of the Demography, Population, and Ecology Commons, Family, Life Course, and Society Commons, International Public Health Commons, and the Sociology of Culture Commons How does access to this work benefit you? Let us know!

\section{Recommended Citation}

Fapohunda, Bolaji M. and Naomi Rutenberg. 1999. "Expanding men's participation in reproductive health in Kenya." Nairobi: African Population Policy Research Center. 


\title{
Expanding Men's Participation in Reproductive Health in Kenya
}

\author{
Bolaji M. Fapohunda
}

Naomi Rutenberg

(C) 1999, APPRC

Recommended citation

Fapohunda, Bolaji M. and Naomi Rutenberg, 1999, Expanding MenÌs Participation in Reproductive Health in Kenya, Nairobi, Kenya, African Population Policy Research Center 


\section{Contents}

Acknowledgments $\quad$ v

Executive summary

1 Introduction 1

Background 1

Objectives 7

Research design and methodology

Organization $\quad 23$

$2 \quad$ What do men think about family planning? $\quad 24$

Knowledge of family planning $\quad 24$

Prevalence of family planning among men $\quad 27$

Use and non-use of family planning $\quad 29$

How to increase menÌs use of family planning 37

The dynamics of contraceptive use 38

Family planning and sexual behavior $\quad 45$

$\begin{array}{ll}\text { Summary } & 47\end{array}$

$3 \quad$ Knowledge, perceptions, and concerns about STDs 49

Types, symptoms, and transmission of STDs

Prevalence of STDs and concerns about risk $\quad 52$

Knowledge about management of STDs $\quad 54$

Prevention and behavior change $\quad 55$

Summary $\quad 56$

$4 \quad$ Knowledge, perceptions, and concerns about HIV/AIDS $\quad 58$

What is HIV/AIDS? $\quad 58$

Beliefs about origin and cause $\quad 60$

Knowledge of transmission $\quad 62$

$\begin{array}{ll}\text { Concerns about risks } & 64\end{array}$

HIV/AIDS infection management and behavioral change 66

$\begin{array}{ll}\text { Summary } & 68\end{array}$

$5 \quad$ Spousal roles in reproductive health $\quad \mathbf{7 0}$

$\begin{array}{ll}\text { Family planning } & 70\end{array}$

STI/HIV/AIDS prevention and management $\quad 78$

Summary $\quad 89$

$6 \quad$ Perspectives on male-friendly reproductive health services 93

Type and sources of services offered to men $\quad 93$

Are men satisfied with the services provided? 95

Men and womenİs perspectives on male-friendly services 98

Provider perspectives on menÌs service needs $\quad 107$

$\begin{array}{ll}\text { Summary } & 114\end{array}$

$7 \quad$ Policy and program implications $\quad 117$

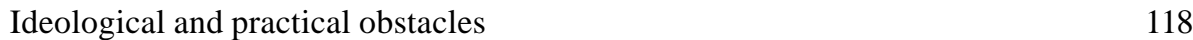

Expand Information about family planning $\quad 119$

Improve mens physical access to services $\quad 120$

Introduce interventions to promote gender equity 120

Promote male interests in supporting family planning $\quad 122$

$\begin{array}{ll}\text { Target youth } & 123\end{array}$

Promote individual and community responsibility 123 
Offer male-friendly services $\quad 125$

Implications for further research $\quad 125$

Bibliography

127

\section{Acknowledgments}

This study was undertaken with significant input from many people and institutions. The Division of Primary Health Care of the Ministry of Health provided supportive environment and technical assistance. In particular, the authors are grateful to Drs Achola Ominde, Margaret Makumi and Jane Asila for their assistance. This study would not have been possible without the collaboration of the FPAK Male Involvement Project Staff. They authors are grateful, in particular, to Steven Mucheke, Peter Mwarogo, Godwin Mzenge, Massibo Wamalwa for their contributions to the success of this study. Special thanks go to Pamela Lynam of AVSC International-Nairobi for reviewing study instruments and providing references which significantly improved the quality of this work.

The authors acknowledge the support of their colleagues at the Population Council-Nairobi and the African Population Policy Research Center (APPRC) for reviewing study proposal and draft reports. In particular, they are grateful to Ayo Ajayi, Ian Askew, Evasius Bauni, Jane Chege, Francis Dodoo, Alex Ezeh, Baker Maggwa, Esther Muia, Lewis Ndhlovu, Cathy Toroitich-Ruto, Samson Wasao, and Eliya Zulu for their assistance. In addition, they thank John Kekovole, former colleague at APPRC, for his input into this study.

They also acknowledge the assistance of Priscilla Akwara in the analysis of data and preparation of drafts of the report; Eva Ndavu for editing the report; Violet Bukusi, Peter Gaiku, and Carolyn Libamira for administrative assistance; members of the research team: Jane Kweyu, Peter Ofware, Paul Oluru, Rena Otieno, Mashetti Masinjila, Odylia Muhenje, Salome Mulehi, Ben Mulemi, Patrick Rapando, Ruth Waswa, whose dedication and hard work contributed to the successful implementation of the field work.

Last but not least, the authors thank the people of Kakamega District, the Divisional Officers and community leaders of the places visited for their hospitality. 



\section{Executive Summary}

\section{Objective of Study}

The studyİs ultimate objective is to improve the effectiveness of family planning (FP) and reproductive health services by providing information that could increase acceptance, continuation and consistency of use by men or their full support and cooperation for use by their female partners, which in turn should enhance the reproductive health $(\mathrm{RH})$ of men and women. The immediate objectives were to:

$\hat{O}$ recommend a list of qualitative characteristics of a service delivery model which incorporates the perspectives and preferences of men, their partners, and service providers regarding the appropriate constellation and organization of FP and STDs/HIV services that would encourage greater participation by men as both clients and supportive partners.

Ô investigate menİs understanding, perceptions, beliefs, and practices regarding family planning, STDs, and HIV/AIDS; the social and cultural context of these beliefs; and the impact of the above on reproductive preferences and behavior.

Ô describe menİs perceived susceptibility to and strategies for avoiding disease and unwanted pregnancy; and responsibility towards their own well being and that of their partners.

\section{Research Design}

The study was conducted in three sites in Kakamega District: Kabras, Mumias, and Kakamega municipality. Data were collected in both the community and in health facilities. Data collection in the communities used a combination of methods, including transect walk, focus group discussions, narratives, stories, listing, ranking/scoring, and scripting. A total of 48 focus groups were conducted. The focus groups consisted of 266 men 15 Oे59 years and 218 women 15 Oे 49 years. The participants were a purposive sample of community members. They were stratified by age, sex, marital status, and sector of employment in order to enhance synergy, reduce distraction, and enable participants to discuss freely.

The research in five health facilities was conducted as a sequel to the community-based study; the aim was to determine how health providers perceive menİs reproductive health $(\mathrm{RH})$ needs and to investigate health workersÌ readiness to address menÌs RH needs within their facilities. Data collection at the facilities was conducted using an adaptation of COPE (AVSC International 1995).

\section{Findings}

The key findings are discussed under themes dealing with perceptions, concerns, and knowledge of family planning; STDs; HIV/AIDS; spousal discussion about reproductive health, responsibility and roles for FP and STD prevention; characteristics of male-friendly FP services; and ways of enhancing menÌs participation in reproductive health services. The study concludes with policy and program implications.

Perceptions, Concerns, and Knowledge of Family Planning

Awareness of family planning (FP) is high. Almost all participants know at least one modern method of FP. However, the two male methodsÛ́condom and vasectomyÛare stigmatized. The condom is perceived as an instrument of immorality used mostly for illicit sex although there is widespread knowledge of its contraceptive role. Vasectomy, locally described as Ïcutting the veinÓ, Ïblocking the seedsÓ, or Ïclosing completelyÓ, is associated with loss of manhood and is unpopular as a method of family planning.

There is widespread belief that FP is womenİs business and this notion may account for lack of concern by men. Use of condom is more widespread in urban areas, among persons with higher education and among those in formal employment. Lack of information and conviction regarding the advantages of FP, and misconceptions of contraceptive methods and condoms may account for their limited use in rural areas and among persons of lower educational statuses.

Other reasons for non-use of FP include: misconceptions emanating from local beliefs and practices that have flourished due to the lack of adequate proven information in the area; divergent preferences 
for the number and composition of children; disparities among spouses in the cost and benefits of children; low education levels; womenİs dependency on their husbands; persistence of beliefs and practices that promote male domination such as naming practices, pressure from parents-in-law and polygyny; and gender division of labor which promotes womenÌs reproductive roles at the expense of their productive roles.

There is widespread belief that contraception affects sexual behavior by making a womanÌs body hot or cold, depending on the method. Neither of these effects is acceptable to men. If cold, the woman will be unresponsive. If hot, there is the fear that she will engage in illicit sex. Hence the limited support for FP. Men also believe that women who use contraceptives are able to retain physical beauty and youthfulness instead of being aged by pregnancy and childbearing and that this increases the chances that a wife can be ÏgrabbedÓ by another man.

Family planning is also perceived to take away worries of unwanted pregnancies and provide opportunity for women to have extramarital relationships. Consequently, some husbands block their wivesİ access to contraceptives. Some wives circumvent their husbands by using FP covertly.

Men associate FP with the prevention of unwanted pregnancy, but use remains low. Abortion, though not a method of contraception, is considered a pragmatic solution to unwanted pregnancy, although the sentiments differ depending on whether it is a wife/regular friend or a casual partner who is pregnant. In general, husbands are not supportive of unwanted pregnancies among their wives. Many husbands abandon their wives, deny the pregnancy, or use violence because they believe that the wife should have known better. Yet, they seldom use FP or initiate such action with their spouses. To avoid problems and violence, many women secretly use abortion or adopt a contraceptive method after the delivery of the child.

\section{Knowledge, Perceptions, Concerns About STDS}

The data reveals differential knowledge about STDs by sex and residence. In general, women and rural residents are less knowledgeable about types and symptoms of STDs. Most respondents believe that all STDs, with the exception of HIV/ AIDs, are curable, a belief that has led to a lack of concern about acquiring infections.

There are differences in perceptions and concerns about risk of STDs. Men in urban areas are more likely to perceive little risk to themselves than women or men in rural areas. However, younger men of reproductive age who are not in union are perceived by all categories of participants to have the highest risk of contracting STDs in both rural and urban areas. The risk of STDs in both rural and urban areas is equally high among men and women though for different reasons. While promiscuity, money, and power were identified as factors increasing menÌs risk of STDs, poverty and structural inequity to opportunities were identified as the major factors in womenİs risk status.

Opinions regarding availability of services and information strongly influence concerns about risk. Men and women who live in areas with better access to health facilities and information are more likely to say that STDs constitute a minor threat to them than those who live in areas with minimal access. Men are aware of places from which to obtain STD services and do take advantage of them when the need arises. However, utilization of services is constrained by poor accessibility to information and facilities, shortage of essential supplies and service providers, lack of space, unfriendly provider behavior, and the constellation of services which deny confidentiality, comfort, or privacy.

\section{Knowledge, Perceptions, Concerns About HIV/AIDS}

There is limited overall knowledge of symptoms, prevalence, and transmission routes in both urban and rural areas, with the latter being more deficient. Areas with better access to health facilities and information are more likely to have residents who possess correct information about transmission and prevalence. Gaps in peopleÌs knowledge regarding prevalence, origin of HIV/AIDS, and symptoms, and poor access to services (including screening, care, and counseling), enhance the risk of HIV/AIDS in the area.

There is evidence of behavioral change in the area. A few men have begun to engage in practices (safe sex, Ïzero grazingÓ, etc) that reduce their risk of STDs and HIV/AIDS infection. However, the 
awareness of HIV/AIDS has not translated into profound or widespread changes in behavior. Some of the reasons for the limited change in behavior include frustration, the fear of dying alone, suspicion of seropositivity status, alcoholism, poverty, and peer influence. Other reasons are the persistence of beliefs which contribute to the tamsmission of HIV/AIDS such as divine causation and practices such as witchcraft and widow inheritance as well as the perception that Ïdeath is deathÓ whether by AIDS, İstage coachÓ (motor accident) or lightning. Because people believe that all STDs (excluding HIV/AIDS) are treatable, knowledge has limited effects on behavior.

\section{Spousal Discussion of FP and STDs/HIV/AIDS}

While FP issues are sometimes broached, though with considerable difficulty, STDs including HIV/AIDS risks and prevention are rarely mentioned among married spouses. Both men and women contribute to the difficulties in broaching subjects of FP. Women are not receptive to discussions about FP if they have not achieved their desired family size and composition because they are worried about the implication of such discussions on their own social status, marital security, well being, and relationship. Men are concerned that they could be suspected of infidelity, desire to marry another wife, extramarital relationships or raising children from Ïoutside partnersó. Spousal discussion of FP is more likely when both spouses are well educated, have achieved desired family size, and have access to FP services and information.

Spousal discussion of the risk of STDs, including HIV/AIDS, is inhibited by the desire to avoid accusations or counter accusations of marital infidelity between spouses. There is a belief that discussing STDs presents an opportunity for the wife to accuse the husband of infidelity, behavior both the wife and the husband are reluctant to acknowledge. Men fear that such suspicions could spur the wife to retaliatory behavior. The persistent culture of silence makes sexual matters taboo even for spousal discussion, and male sexual transgressions, for the same reason, go unpunished. Other factors include low education levels, educational gaps between spouses, lack of information about STDs, and menİs prevailing desire to control or be in control.

Circumstances under which topics of STDs and HIV/AIDS are broached include: when there is love, respect and trust between spouses; couples are well educated and have access to information about STDs; there is strong knowledge/suspicion that one of the spouses (mostly the husband/male partner) is engaged in extramarital relationships; and spouses are worried about their risk of STDs/HIV/AIDS.

Perception of Spousal Roles and Responsibilities for FP and STDs, HIV/AIDS Prevention

Both men and women stated that FP should be the joint responsibility of husband and wife. In reality, joint spousal responsibility is often difficult to achieve. Because of gender inequalities in decision making and differentials in reproductive goals, marital reproductive agenda tend to be characterized by significant conflict. Common sources of conflict include: divergent preferences for the number and sex composition of children; disagreement over using FP and particular contraceptive method; deception, suspicious motivation, and lack of commitment by husband to uphold mutual FP decisions; and covert contraceptive use by the wife.

Various mechanisms are used to resolve spousal conflict over FP. These include third-party intervention, persuasion, passive acceptance of husbandİs decision, and/or covert use. Coercion in the form of separation or divorce can be used if a wife refuses to acknowledge the husbandİs authority over her sexuality.

Men show little commitment to prevent risk of STDs, but there is considerable commitment to initiate treatment in their wives if they know or suspect that they themselves have acquired a disease; men take this action in order to prevent re-infection. However, most men and women said that they would not notify their partners if they find or suspect that they have STDs or HIV/AIDS but would seek treatment covertly. In the case of an STD, men were worried that their sexual autonomy, pride, or integrity could be challenged. In the case of HIV/AIDS, men are worried that their wives could desert them, go into shock, or lose control. Similarly, women said that they would not notify their husbands about an STD because husbands could become violent; regarding HIV/AIDS, most women said that they would inform their husbands so that they could plan for their children.

Participants described both positive and negative responses if they suspect or discover that they have acquired STDs or HIV/AIDS. The positive ones include seeking care, counselling, and blood screening. Most men said that if they learn that they have HIV/AIDS, they would stay in the marriage 
and find ways of coping. Most women said that they would stay to take care of a seropositive husband even if they themselves were seronegative. The participants stated that women mainly plan for the family, support their spouses, readjust to the new condition, pretend that all is well, and wait for death.

The participants reported that most negative responses to HIV/AIDS are by men and include deliberate transmission through commercial sex in order to create company in death. Some thought that a few women also turned to this avenging strategy (though women tended to have more positive responses). Many men increase the number of partners and frequency of sex in order to get the ÏfluidÓ (virus) out of the body, hide STDs/HIV/AIDS status, and avoid societal suspicions and knowledge of HIV status. Some men adopt new dressing attire and styles in order to hide status. Another negative response is to end the relationship. Younger persons in non-marital relationships said that they would end it if they found that their partner had an STD or HIV/AIDS. Similarly, most married men said that they would divorce their wives if they themselves were seronegative but spouses had HIV/AIDS. With STDs, most married men would beat the wife, abandon her, seek extramarital sexual gratification, send wife to her parentsì home, or seek divorce. Other negative responses in case of HIV/AIDS include sinking into a state of shock, hopelessness, mental torture, self-denial, self-rejection, withdrawal from society, and suicidal thoughts.

Qualitative Characteristics of Male-Friendly Reproductive Health Services

To elicit greater participation of men in reproductive health, including FP, study data indicate that health facilities should have certain characteristics. For example, such facilities should offer predominantly FP and STD services, a range of methods beyond condom and vasectomy, and guarantee confidentiality, privacy, and comfort. There should be adequate access to information on choice, merits of FP, and method side effects. Flexible hours and short waiting times are helpful. Services should be affordable; FP should be free or minimally priced, but STD services should be priced higher to encourage the practice of safe sexual behavior. There is a need for more male providers to serve male clients. Providers should be knowledgeable, friendly, helpful, patient, polite, persuasive, warm, discreet, and trustworthy; they should demonstrate good communication skills.

There are other ways to encourage men to use FP services. Respondents include some innovative ideas in their suggestions. For example, they said to take services to men at their work-places and recreation centers (using mobile clinics) and use multiple fora to communicate information about FP and HIV/AIDS, including the mass media, funeral ceremonies, chiefİs barazas (meetings), and health talks at hospitals. There is a need for more information on condom disposal. FP services could be more aggressively advertised on T-shirts, bags, and caps. Some men suggest that incentives and even legislation could encourage men to seek services. Study participants suggest that it is very important to focus on youth; this critical group is not currently being served by any program.

Summary of Policy and Program Recommendations

In order to expand menÌs participation in reproductive health, FP policy and programs should increase menÌs access to information on benefits of FP, range of methods, side effects and method contraindications. The aim is to improve service quality and make services male friendly. Service delivery outlets should be increased to provide more health care and information in rural areas. Massive education campaigns can minimize misinformation and misconceptions regarding FP and specific methods. A responsive policy would reduce gender disparity in access to resources and opportunities, both productive and reproductive; this would eliminate obstacles to spousal discussion of reproductive health issues and improve womenÌs objective condition (including access to higher education and income-generating opportunities) and improve womenÌs ability to negotiate their partnerÌs cooperation and support for reproductive health.

The data further revealed low overall knowledge and capacity to evaluate risk and prevalence of HIV/AIDS in the communities. Consequently, awareness of the existence of the disease has not translated into widespread change in behavior. Added to this laissez-faire attitude is the persistence of some harmful practices and beliefs that enhance the transmission of HIV/AIDS: deliberate transmission, widow inheritance, risky health practices, belief in divine causation, and the notion of AIDS safe 
havens. Efforts to curtail the epidemic must include massive community education campaigns to change beliefs and harmful practices that increase an individualìs exposure to infection.

The study result points to an opportunity for improving womenÌs and menÌs reproductive health through strengthening STD services for men and their partners. Most men do seek treatment for STDs, either in the formal sector or clinics, both for themselves and for their partners if they discover that they have acquired an infection. Reproductive health programs could explore this opportunity to expand coverage of services, particularly for women who have traditionally been hard to reach with STD services.

Specific recommendations include:

Ô Expand information about family planning to men in order to reduce misconceptions;

Ô Improve menÌs physical access to male-friendly reproductive health sevices;

Ô Introduce interventions to promote gender equity;

Ô Promote menİs interest in supporting family planning;

Ô Promote individual and community responsibility for STDs and HIV/AIDS prevention;

- Target youth through specialized youth-friendly services; 


\section{The Population Council}

The Population Council seeks to help improve the well being and reproductive health of current and future generations around the world and to help achieve a humane, equitable, and sustainable balance between people and resources. The Council analyzes population issues and trends; conducts biomedical research to develop new contraceptives; works with public and private agencies to improve the quality and outreach of family planning and reproductive health services; helps governments to influence demographic behavior; communicates the results of research in the population field to appropriate audiences; and helps build research capacities in developing countries. The Council, a nonprofit, non-governmental research organization established in 1952, has a multinational Board of Trustees; its New York headquarters supports a global network of regional and country offices.

\section{The African Population Policy Research Center (APPRC)}

The African Population Policy Research Center, a program of the Population Council, aims to strengthen the professional capacity of scholars from sub-Saharan Africa by allowing them to explore population issues relevant to formulating policies, allocating resources, and improving programs in the region. The core of the CenterÌs Research Agenda comprises four themes:

Ô explaining the fertility decline in Kenya;

$\hat{O}$ enhancing the pace of fertility transition through family planning programs and socio-economic development;

Ô investigating sexual and fertility behavior in the era of AIDS;

Ô understanding the changing environment of the transition to adulthood.

\section{Africa OR/TA Project II}

The overall objective of the Africa OR/TA Project II is to broaden understanding of how to improve family planning services in sub-Saharan Africa, and to apply operations research and technical assistance to improve services by:

Ô increasing access to a full range of family planning services and methods;

Ô developing service delivery strategies that are client-oriented and acceptable to various population groups;

Ô improving the operations of programs to make them more efficient and financially sustainable;

Ô improving the quality of services;

Ô strengthening the capabilities of family planning program managers to use operations research to diagnose and solve service delivery problems.

This project was supported by the Population Council's Operations Research and Technical Assistance Project II, Contract No. CCP-3030-C-00-3008-00 funded by the United States Agency for International Development (USAID). 



\section{Chapter 1}

\section{Introduction}

\section{Background}

In an attempt to enhance our understanding of how to increase menÌs participation in family planning and reproductive health both for their own well being and as gatekeepers to womenİs health, the African Population Policy Research Center (APPRC) and Population Councills OR/TA Project II launched a study designed to explore the best practices for delivering services to men. The study examined menİs knowledge, perceptions, concerns about reproductive health issues, including family planning, and the social context of their knowledge Ûtopics which are very unclear to leaders in policy and program arena.

In sub-Saharan Africa, family planning and reproductive health care research and interventions place a disproportionate emphasis on women and largely ignore the role of men (Mbizvo and Adamchak 1991; Fakeye and Babaniyi 1989; Odhiambo 1992; Ringheim 1993). As a result, male participation in family planning and reproductive health has been low (WHO 1995).

Men in Africa, who are heads of their households, are often key figures in domestic decision making, particularly about fertility behavior and preferences (Isiugo-Abanihe 1994), and that authority is supported by tradition. They are also the main link between the family and the prevailing culture and are the major players in bringing development to the home. Fapohunda and Todaro (1988) observed that African family structure shapes spousal perceptions of fertility and that men and women do not necessarily have the same views about family planning and reproduction because their interests are shaped by expectations which are determined by the social structure of their households and community. Therefore, the failure to include men in reproductive research could reduce coverage, bias findings, and undermine applicability of findings for policy and programs.

Indeed, an understanding of menİs perspectives on family planning and reproductive health could provide more insights than are possible by studying women because men have more power than women in reproductive decision making, including number of children and whether or not to use family planning. As such, their views need more careful and systematic analysis (see also Isiugo-Abanihe 1994), especially since those views are important determinants of womenİs reproductive attitude and behavior (Rutenberg and Watkins 1997; Ezeh 1993; Renne 1993). Additionally, men dominate decisions and policies in the public domain. Therefore, an understanding of their reproductive perspectives could identify program interventions to promote the use of services by men (both as FP clients and as partners to women clients) and this, in turn, would influence family planning and reproductive health policies.

Studies about male involvement indicate that an understanding of menÌs perspectives on family planning and reproductive health could increase use of RH services among men. For instance, Mbizvo and Basset (1996) found that when given adequate counsel, men are likely to change initial biases against family planning. Similarly, a controlled experiment conducted in Addis Ababa, Ethiopia, to determine the relative efficacy of home visitation with and without husbandİs participation on the use of modern contraception found greater and consistent contraceptive use among couples when husbands were included in the interventions than among those whose husbands were excluded (Terefe and Larson 1993). Another study revealed a significant increase in the use of condoms and hormonal contraceptives in Zaire and urban Rwanda when both partners participated in the HIV antibody testing and counseling program (Kamenga et al. 1991; Allen et al. 1993). The failure to include men could inhibit use of reproductive health services by women (Ryder et al. 1991). Although the importance of male participation to the effectiveness and coverage of reproductive health programs has been challenged (e.g., King et al. 1995), ${ }^{10}$ there is need to design and test strategies to reach men as a part of the global strategy for achieving reproductive health for all. It is necessary to understand menİs perspectives, beliefs, and practices in order to develop such interventions.

These objectives are underlined by the paucity of information about menİs perspectives on reproductive health. Also, there is scant systematic research documenting menİs reproductive attitudes, behaviors, and perceptions of their spouseÌs reproductive well being and rights. Until such 
information is available, fertility and reproductive health policies and services will continue to be limited both in coverage and effectiveness. The study goals were to collect information on menİs views and perspectives on reproductive health including FP, in order to expand services to encompass men as family planning users and supportive partners.

This study explores a number of dimensions of menÌs perspectives, beliefs, and practices. It first of all looks at menİs perceptions of family planning Ûwhat does it mean to them, what do they understand by it, who should use, who should decide use, and in which context is use appropriate? A second concern is menİs knowledge and attitudes about existing and preferred family planning and STD services. These lead to menİs understanding of their own reproductive health, their partnerÌs health, and their responsibility towards their partnerÎs well being, specifically regarding family planning and the treatment and prevention of STDs.

Many interventions, especially service delivery models, in the area of reproductive health ${ }^{2 \ddot{U}}$ are topdown; i.e., they are adaptations of successful or promising models but are not necessarily based on an assessment of target community perspectives and definitions. This study employs qualitative methods to investigate local definitions, perspectives, preferences, responsibilities, and socio-cultural contexts of male reproductive health as well as to elicit proposals for appropriate delivery of health services that include men. Such information is a key to understanding the problem and formulating interventions that could bring about behavior change in both men and women; such change includes consistent use of family planning and prompt and appropriate treatment of sexually transmitted diseases.

\section{Male Involvement Initiatives in Kenya}

The concentration of reproductive health policies and programs, especially family planning, on women is partly responsible for the limited utilisation of services by men. They have become suspicious, uninterested, and non-supportive, even when wives experience difficulties in using contraceptive methods. Consistent international endorsement from the mid-1980s of the need to increase menİs participation in reproductive health led to several efforts by both public and private sectors to bring men back into programs. A selected review of these initiatives in Kenya is presented below.

The main organization implementing programs targeting men in Kenya is the Family Planning Association of Kenya (FPAK), established in 1967. This national association began to implement programs for men in the late 1980s. This initiative came out of the need to rectify gender imbalance in the delivery of reproductive health services in Kenya given the key role of men in family life.

The first male initiative undertaken by FPAK was in 1987. In an attempt to encourage men to come to the Phoenix House clinic, an additional, exclusive menÌs entrance was established. However, due to congestion by female clients at this Nairobi venue, it was not possible to provide privacy for male clients. In 1988, the Association produced posters and brochures to promote vasectomy services. This was followed in 1994 with a large communications program with the theme ÏReaching out to men: The forgotten 50 percent,Ó which addressed the problem of inadequate male involvement and participation in reproductive health, especially family planning, in Kenya. The goals are to redesign family planning programs to include the needs and concerns of men, develop special programs to change menİs negative attitudes regarding family planning, promote spousal communication and support for female contraception, and increase the involvement of men aged 18 Ò59 (FPAK 1996).

The FPAK initiatives to reach men have clinical and non-clinical components. The clinical components are male-only and male-friendly clinics. The non-clinical component consists of a multimedia IEC campaign, service provider training, and interventions to reach men through work place motivators.

The clinical component consists of a major intervention to provide FP and moderate STD prevention and treatment services to men in a clinic environment. This intervention is based on the assumption that conventional clinics that primarily serve women are inappropriate for meeting the reproductive health needs of men. Therefore, the establishment of male-only and male-friendly clinics was considered necessary for providing FP and STD services to men. By 1996, there were male-only clinics in three districtsÛKakamega, Kisumu, and Nakuru. These operate like conventional FP clinics but cater only to men and all service providers at the site are men. The male-friendly clinic is a conventional clinic redesigned to give attention to menİs privacy and time constraints. The FPAK male initiatives are funded by International Planned Parenthood Federation (IPPF). Other organizations have also 
contributed to the goal of reaching men with reproductive health services. Population Health Services/Marie Stopes opened male-only clinics in Nairobi, Mombasa, Meru, Kisii, and Kisumu with technical support from Association for Vasectomy and Surgical Contraception (AVSC). These clinics provide vasectomy services and counselling. These facilities are also used by AVSC to train Kenyan surgeons in vasectomy procedure (Tour»1996).

The non-clinical components consist of three interventions: work place motivators, multimedia IEC campaign (MIEC), and service provider training. The work place motivator service delivery model is based on the philosophy of the community-based distribution (CBD) model and provides reproductive health information, organizes motivational education sessions, educates men about STDs (including HIV/AIDS), recruits and counsels potential FP clients, distributes non-prescription contraceptives, and makes follow-up visits to FP clients. FPAK has recruited and trained work place motivators in the three pilot districtsÛKakamega, Kisumu, and Nakuru (Mwarogo and Achwal 1997).

The MIEC seeks to increase knowledge and spousal communication of family planning among married men who do not practice family planning. A variety of media sources are used for this purpose, including, radio, television, print, puppet shows, and community meetings. The Program for Appropriate Technology in Health (PATH) has also designed a program for hard-to-reach though vulnerable work groups. The first was the incorporation of reproductive health education into the orientation and refresher training for security guards in Nairobi. Four of the five security firms included in the intervention have begun implementation by training security officers on reproductive issues (PATH 1997b). Other organizations that have been involved in IEC campaigns are AVSC, Population and Health Services (PHS) and Marie Stopes. Marie Stopes instituted a İvasectomy weekÓ during which vasectomy adverts were placed in newspapers and medical personnel were trained in procedures and the delivery of services to clients. Marie Stopes and PATH have also developed programs to reach men in their work places. PATH involvement has been primarily in AIDS Control and Prevention Project (AIDSCAP) and Family Planning Private Sector (FPPS) project areas in Eldoret, Nairobi, and Mombasa. PATH prepared and distributed an assortment of STIs/HIV/AIDS education materials to work place motivators in FPPS project sites. These motivators are expected to use the materials to educate their work mates as well as peers and teenage boys in their communities (PATH 1997a).

The service provider training initiative is meant to equip non-clinical service providers with necessary skills in client management, counselling, client-provider interaction, and knowledge of menİs health needs. It also aims to reduce provider bias in delivering services to men (Juma 1996).

Some Achievements

There is no known empirical study on the impact of these Kenyan initiatives. However, some qualitative work conducted in parts of Rift Valley and Western provinces indicates that the FPAK initiative is yielding positive results in that men are becoming aware of the Ïmale-only clinicÓ, although use was found to be low (BQR 1995). Data from companies which kept records of the activities of their work place motivators indicate that the program has been successful. For example, Rivatex, a textile company in Eldoret, reported that the peer educators had reached 2,077 workers between September 1995 and June 1996. Employees are reported as seeking additional information on such topics as cures for AIDS, care for AIDS sufferers, and problems and myths associated with condoms and how to use them properly (PATH 1997a). These records are not systematic but are based mainly on reports by workplace motivators, and their quality is unknown.

The main weakness in most of the initiatives reviewed above is that they are based on knowledge, attitude, and practice studies which do not permit in-depth examination of male-friendly services. Sometimes, the data are not analyzed. This study was designed to fill these gaps and shed light on the types of service delivery best suited to menİs needs and which incorporate the perspectives and preferences of men, their partners and service providers. The study also provides in-depth information on menİs perceptions, concerns, knowledge, and views about two key components of reproductive health: family planning and sexually transmitted diseases.

\section{Objectives}

The overall objective is to increase the effectiveness of family planning and reproductive health services by providing information that could increase acceptance, continuation, and consistency of use 
by men or their full support and cooperation for use by their female partners. This would, in turn, enhance the reproductive health of both men and women.

The immediate objectives are to:

Ô recommend a list of qualitative characteristics of a service delivery model which incorporates the perspectives and preferences of men, their partners, and service providers regarding the appropriate constellation and organization of FP and STD/HIV services for men that would encourage greater participation by men as both clients and supportive partners;

Ô investigate menÌs understanding, perceptions, beliefs, and practices regarding FP, STDs, and HIV/AIDS; the social and cultural context of these beliefs and the impact on reproductive preferences and behavior;

Ô describe menÌs perceived susceptibility, preventive strategies, and responsibility towards their own well being and that of their partners.

\section{Research Design and Methodology}

Qualitative Analysis in the Communities

The study applied a variety of qualitative research methods to collect data from men and women on menÌs perceptions and understanding of STDs/HIV/AIDS and family planning, their reproductive behavior, and demand for reproductive health services, including STD services, condoms, and family planning. The qualitative approach allows creativity, learning, and sharing of information between researchers and participants. Such flexibility with data collection is useful in exploring the socio-cultural and economic contexts of behavior. The techniques are particularly beneficial for use in developing countries where individualsì activities are interwoven in a complex web of family and community relationships (Chambers 1992).

\section{Study Setting}

The research was conducted in three divisions of Kakamega DistrictÛKakamega Municipality, Mumias and Kabras. It is intended to have direct programmatic effect by contributing directly to the FPAK male involvement initiative. These divisions were deliberately chosen to represent a cross-section of FPAKÌs program as well as variations in access to health information and services and their impact on perceptions of reproductive health needs.

Kakamega District, located in western Kenya, is predominantly rural with only 2.5 percent of its population living in urban areas; this rate is much lower than the national average of 18 percent (based on the 1989 census, CBS 1996). In the labor force, 70 percent are employed in agriculture, and 49 percent of the adult population are illiterate (Brass and Jolly 1993). The districtİs estimated population size is 1,321,496 (projections based on 1989 census) with an annual growth rate of 2.98 percent (GOK 1998). It has the second highest fertility rate in Western Province (an average parity of 8.4 children among women 45Oे49 years old) which, according to CBS (1996), has the highest fertility rate (with a total fertility rate of 8.1) of all provinces in the country. The contraceptive prevalence rate is 28.3 percent, which is below the national average of 33 percent (GOK 1998). Kakamega is one of the districts worst hit by the AIDS pandemic in Kenya: $10 \mathrm{O} 20$ percent of the population are believed to be carrying the virus that causes AIDS (NASCOP 1996).

\section{Kakamega Division}

Kakamega municipality is situated in the center of the district; as the Provincial Headquarters, it has the best network of health facilities in the district. This includes the Provincial General Hospital, two government dispensaries, six private hospitals and two private clinics, and the only male clinic in the district (opened in 1996). The economy of the division is diverse although the formal sector is relatively small. Its inclusion in the study is useful for understanding the rural-urban differences in local definitions of FP, menİs STD needs, and perceptions of reproductive health services which best meet the needs of men.

Three residential areas of Kakamega municipalityÛKambi Somali, Amalemba, and LurambiÛare covered by this study. These areas represent the different socio-economic subgroups in Kakamega Division, namely, upper middle class (mainly civil servants and professionals), lower middle class and lower class populations. categorized by type of work and income level. 
Kambi Somali is a slum area to the west of the town center. The houses are mainly old Swahili type with mud walls and cemented floors. The roofs are old iron sheets that have rusted over the years. Some houses have old iron sheets as walls. The doors are wooden. The houses are crowded around the estate.

Kambi Somali literally translates as ÏCamp of SomalisÓ. The name was derived from the first occupants of the slum area who were predominantly Somali settling in a Luhya ethnic area. Many of the early residents were Somali in various Ïmixesó as they have intermarried or had relationships with other ethnic groups. The current population reflects an ethnic mix but with a predominant Luhya presence. The main religions are Christianity and Islam.

The residents of Kambi Somali are engaged mainly in small-scale business activities such as running kiosks and shops, charging car batteries, making furniture, repair work, and selling local brew, changİa. Women constitute the majority of the changİaa traders while their clients are mainly men from within and without the slum. Residents also keep livestock such as chicken, ducks, and goats. Some of the men are commuter bus conductors. The Kambi Somali residents are generally poor. Many are unemployed idlers. The sight of drunken men is not uncommon. Children are poorly dressed and do not look healthy.

The area has limited access to modern facilities. There is no health center or FP clinic within the immediate boundaries of the slum. However, residents live within close proximity to the main government health facility and other private clinics, including the FPAK family planning clinics. Community-based distributors visit residents to disseminate information on family planning and to provide services such as dispensing condoms.

Residents have access to piped water that is collected from taps in front of the houses. Water from a nearby stream serves as a backup when there is a shortage. The area has about five pit latrines that are made of old rusty iron sheets, but it is not uncommon to see people relieving themselves in the open.

There are two schools within the vicinity of Kambi Somali, a private nursery school and a public primary school. Since the area is adjacent to a major road (MumiasÒKakamega), residents have access to matatus (mini-buses), and bicycles for transportation. Donkeys are used to carry heavy luggage. Apart from the main road, a network of footpaths links houses, and a dirt road leads to adjacent estates and facility.

Amalemba estate is located to the south of the town center. It is a planned residential area, mainly inhabited by middle income people. Most of the residents are engaged in formal employment as skilled civil servants, nurses, teachers, and NGO workers. The rest are engaged in non-formal private sector sales and services.

Most of the houses are permanent structures with corrugated iron sheets or asbestos roofs. Some houses are well fenced (with cypress) secured with iron gates. A few of the houses are semi-permanent. The area houses the Kakamega General Hospital and at least two private health centers. Most homes have piped water and electricity; however, there is no street lighting. The roads are good murram save for the KisumuÒKakamega tarmac road. Some houses have telephones but there is no post office in the area. Some residents drive private cars or are seen being transported by employerÌs vehicle. The majority travel by commuter buses or bicycles. The residents are well dressed and the children look well fed and healthy.

Lurambi is a residential area for both low and lower-middle income groups. It is located to the west of the town centre. The area is not formally planned by the Municipal Council but is spontaneously expanding. While some of the houses are permanent buildings on enclosed plots, the majority are semipermanent structures with cemented floors, mud walls, and corrugated iron sheet roofs. Lurambi features a variety of people ranging from lower cadre civil servants, clerical staff in private businesses, business proprietors to small traders and original landowners. Most children are well dressed and appear healthy.

The area has no government clinic or health centers. The nearest hospital is Nala Nursing Home which is situated about $2 \mathrm{~km}$ away. There are no family planning clinics, but the area is served by CBDs 
who advise on family planning and offer contraceptives. Residents have access to health facilities in town such as the general hospital and the FPAK clinics.

There is no post office in Lurambi but the area has telephone services. There is one public call box and a few houses and shops have telephones. Most of the houses have electricity. The area is served by one major tarmac road (the KakamegaÒWebuye road). There is also a relatively busy murram road to Ingotse. On both roads, there are buses, matatus, and bicycles for private and public commuting. The area has access to piped water, but many households depend on water from a nearby stream.

\section{Mumias Division}

Mumias is located in the eastern part of the district. The division occupies an area of $309 \mathrm{sq} \mathrm{km}$. Mumias has a population of 165,907 and a population density of 527 people per sq $\mathrm{km}$. It is the largest and fastest growing division in the district because of the sugar factory and the general economic prosperity of the area. Administratively, Mumias has three locations and 20 sub-locations. This study was conducted in Ekero sub-location.

Mumias is predominantly agricultural and sugarcane is the main cash crop. The local economy revolves around the sugar factory which supports a large population of permanent workers and casual employees. Just as many people have set up businesses that depend on incomes from factory staff and farmers who are paid by the factory. Apart from sugarcane, the inhabitants of Mumias grow maize, beans, groundnuts, sorghum, cassava, and keep livestock primarily for domestic consumption. Mumias town has a small but growing formal business that is mainly service oriented. Informal business sector activities include vegetable and fruit selling, hawking of consumer products, bicycle repairs, and tailoring.

Family living arrangements are relatively unstable; many of the men working in the area come from other parts of the district and have left their partners in their home area. Polygamy is prevalent and there is a high incidence of concubinage and cohabitation of variable duration. Families tend to be big with members of the extended family staying with the nuclear family. Children appear malnourished and poorly clothed.

Family planning is not very popular among the men. Most of the resistance is attributable to traditional attitudes and the influence of the Catholic Church and Islam, both of which have a large following among the people. The division has one church-supported hospital. Other health facilities include four health centers, two dispensaries, four private hospitals/clinics and work place motivators.

The residents of Ekero benefit from the general economic prosperity of the division because of close proximity to Mumias town $(6 \mathrm{~km})$ and to the major paved road to Kakamega. As in other rural areas of the district, most families live in semi-permanent structures with mud walls, floors levelled with cow dung, and corrugated iron roofs. Some families live in temporary structures with grass-thatched roofs. A few rich farmers live in permanent houses with concrete walls and corrugated iron sheets. Nearly all the houses tend to be surrounded by sugarcane farms such that it is often difficult to spot them from the roadside.

The men produce cane for the sugar factory and, therefore, are subject to the vagaries of income due to fluctuations in demand. The majority of the women assist their husbands on the farm in addition to small-scale trading in vegetables and other farm products, but the income from these activities is quite small. A few of the inhabitants work in the formal sector as teachers, civil servants, and urban council workers.

With regard to health facilities, the area is served by one private hospital, two private clinics at the shopping center, a dispensary, and CBDs, all of which are located a few kilometers away from the Ekero community. The area has a busy rural market center where farm inputs, food (including vegetables, fruits, cereals), and clothing (predominantly second-hand) are sold. The community does not have a post office but relies on that in nearby Mumias town. There are telephone services and at least one public telephone booth in the market center. Apart from the main KakamegaÒMumias tarmac road, a good network of murram roads maintained by the sugar factory serves Ekero. Most residents depend on bicycles for short distances, and matatus and buses are available for long-distance travels. Clean drinking water is available from boreholes maintained by the communities but some residents get their water from nearby springs. The market center has electricity connected to many of the shops; however, very few houses have electricity. 


\section{Kabras Division}

Kabras Division is located in western Kakamega and has four locations and 17 sub-locations. This study was conducted in two of these sub-locationsÛKakunga and Mahira. Two of the focus groups were conducted at the Malava Urban Council, the administrative office for the division, because very few local residents of Kakunga and Mahira work in the formal sector. The division has a population of 147,621 people and a density of 347 people per sq km (GOK 1998), making it one of the most sparsely populated divisions in the district.

Like Mumias Division, Kabras is predominantly an agricultural community. The local economy is heavily dependent on subsistence farming. The area has a small sugar factoryÛWest Kenya Sugar Factory. However, the lack of electricity in the area constrains industrial activities. The division has a vibrant informal sector that includes hawking, bicycle repair, and retail trading in fruits, vegetables, and second-hand clothes.

Family size is large, with members of the extended family living with the nuclear family. There is a belief that land is plentiful so couples do not see the need for family planning. Because it is expected that children are likely to die young, many children are seen as insurance against child loss. Men and women marry at a young age, lengthening the reproductive span and increasing the likelihood of having large families.

Kabras Division has five government dispensaries and one NGO dispensary which are centrally located but not within easy access to the dispersed communities. There are no hospitals. A good number of the residents depend on traditional practitioners for their health care needs. Kabras lacks FPAK presence which makes it an interesting component of this comparative study.

The two communities studied in Kabras are Kakunga and Mahira, both relatively sparsely populated. Most of the homesteads are temporary structures with grass-thatched roofs, mud walls, and floors that are smoothened with cow dung. The walls of the houses often contain local artwork consisting of murals in different coloured clay and chalk. Huts are either traditionally round or square. There are few semi-permanent houses but permanent structures are rare.

The homesteads are generally large as they accommodate the extended family. Quite a number of men are also polygamous which further increases the number of houses in homesteads. There are, on average, four houses in each homestead providing residence to families that include two or three generations. The houses are most likely to be found near streams which provide drinking water for the livestock, an essential part of life in each homestead.

The residents of Mahira and Kakunga are of low socio-economic status compared to residents of Ekero. The area is rural and has no major shopping center. Agriculture is the major employer in the area although most residents are subsistence farmers. Sugarcane is the main cash crop but it has not led to prosperity due to the low demand for cane by the local sugar factory. This has tended to have an adverse effect on the rural economy since cane farms are overgrown and the expected income from sugarcane does not always come on time. Children appear unhealthy as they are thin with protruding stomachs and are most likely to be seen naked around the homesteads. Unlike other parts of Kabras Division, Kakunga does not produce a lot of maize. Maize is grown on small plots for home consumption alongside other crops such as cassava, sweet potatoes, pineapples, tomatoes, and assorted vegetables and fruits.

There are no telephone or postal services within these two sub-locations. The road network is poor. Apart from the main KakamegaÒWebuye road which forms part of the boundary of the sub-location, there are no other paved roads. Most of the accessible roads are grated dirt and in a poor state of maintenance. The road problems are intensified by gully erosion that is a result of heavy rains, lack of soil conservation, and steep slopes. People use commuter matatus and buses to travel to the major centers along the paved road; however, most travel within the sub-locations is either on foot or by bicycle. Donkeys are used to transport goods and farm produce.

Neither Kakunga nor Mahira has any health facilities such as clinics or dispensaries. Residents have to seek treatment in Kakamega, $20 \mathrm{kms}$ away or Malava, $11 \mathrm{kms}$ away. Accessibility to these facilities is complicated by the poor condition of the roads. Two CBD agents serve the communities with family planning information, condoms, and other primary health care services.

Data Collection in the Communities 
Data collection was carried out using a combination of qualitative techniques which encourage participation by research subjects. These included transect walk, mapping, focus group discussions (FGDs), narratives, stories, case studies, lists, ranking/scoring, theater/scripting, diagrams, and a short questionnaire. These techniques are described below.

\section{Transect Walk}

Transect walk consists of systematically walking with informants through the community, observing and gathering socio-economic data, including prevalent settlement patterns, residential structures, availability of services (such as health care, transportation, and communication), types of crops grown, market and type of products sold, roads, and type of vehicles. Some random interviews were conducted with key informants as a follow up to some of the observations recorded during the transect walk. Also, casual conversations were held with community people during this walk in order to establish rapport and gain acceptance. The walk was guided by community facilitators who most often were women leaders, headmasters and village elders. In two communities, our team of informants included the subchief. ${ }^{3}$ The data collected at this stage helped the research teams determine how to inquire about relevant community perspectives.

\section{Mapping}

A social map describing residential structures and the availability and location of facilities was drawn by a cross-section of the members of the community at the end of each transect walk. Participants were provided with flip chart papers, pencils, and rulers for the exercise. They indicated boundaries; names of villages, sub-villages; roads, water sites and sources; industrial areas; facilities of health, education, religion; water points; market place; churches; special places such as post office, parks, and community halls. This information helped the research team understand participants, location, size, boundaries, and social markers of the territory; it expanded their view of the communities. The participants in each community determined all markers on each map, and the maps were later reproduced to facilitate copying and storage.

\section{Focus Group Discussion}

FGD was the principal method used to gather information in the communities. It systematically provides answers to research questions through unstructured interviews with groups of men and women. FGD facilitates the gathering of carefully targeted data within a short period of time and provides a great deal of community experiences and opinions than can be learned from any individual interview. FGD engages participants in active comparisons of their opinions and experiences and in so doing creates lines of communication that connect the participants to one another and the research team (Kruger 1998). Each focus group was facilitated by a team of four field assistants of the same sex as the participants. Each team consisted of a facilitator, two note takers, and a rapporteur. In addition to the notes, all discussions were captured on electronic tapes. The study included 48 focus groups (23 female and 25 male) in the three divisions. The data were transcribed, translated, and coded in the Population Council office in Nairobi. Both the coding and analysis were performed using NUD*IST, a computer software program which provides qualitative data analysis. One major weakness of FGD is that it primarily elicits group norms rather than individual experiences. In order to correct this weakness, FGD was supplemented with other qualitative approaches that are well suited for gathering data on individual experiences. These include narratives, stories, lists, ranking/scoring, and theater/scripting.

\section{Narratives and Stories}

Using this technique, individual participants narrated relevant experiences such as managing a particular STD condition or dealing with the side effects of contraception. With respect to service utilization, for instance, some male participants narrated an experience during their last visit to a family planning clinic. These narratives and stories provided individual experiences on relevant subjects of the research.

\section{Theater/Scripting}

In selected focus groups, some volunteers acted short plays using scripts that captured several dimensions of the research problem. Some of the scripts centered around how decisions to use family planning services are made in day-to-day life while others centered around spousal role and responsibilities for STD/HIV and related problems. The theater was particularly useful in re-enacting real-life situations, refreshing a participantİs memory, and helping to put subject matter into focus. It also helped participants objectively discuss complex questions regarding experiences in contraceptive use and STDs without feeling that they were inappropriately discussing private matters in public. 


\section{Listing, Ranking, and Scoring}

Participants listed the type of FP methods that they or others in the village had used, were using, or experimented with and then ranked/scored these methods in terms of criteria they developed. In this approach, both the list and the criteria for ranking/scoring them were developed by the participants, making them particularly meaningful and relevant to the residents of the study area. Participants listed and ranked (in order of prevalence and/or seriousness) the different STDs they knew, types that attack people in the area, different modes of transmission and most likely channels. These lists provided data on prevalence, proportion, and degree of seriousness attached to each disease or transmission source and laid the groundwork for identifying serious STD problems and areas where interventions hold the greatest promise. ${ }^{4}$

\section{Questionnaire}

A short questionnaire was used to gather basic demographic and socio-economic information, including education, place of residence, type of work, income status, personal and household assets. The research assistants administered the questionnaire to those who participated in the FGDs.

Participants in the focus group interviews consisted of men aged $150 े 59$ and women aged 15 Oे49. The groups were stratified by age, sex, marital status, and sector of employment (formal and informal) in order to enhance synergy, reduce distraction, and enable participants to discuss freely within their groups. Each focus group had $8 \mathrm{O} 12$ participants.

\section{Participants}

Participants in the focus group discussions were selected with the help of community facilitators, including local school headmasters, youth leaders, elected village elders, women leaders, and subchief. ${ }^{\ddot{A}}$ A few days before data collection, the facilitators went from house to house to publicize the study and elicit community participation in the FGDs. These visits were repeated when the fieldwork began and throughout the period of the FGDs. The transect walk also served as a forum to inform people and to enlist their participation. On the day of the FGDs, those who showed up were randomly assigned to groups on the basis of age, sex, marital status, and employment. Four FGDs were usually conducted per day. Participants who could not be accommodated in the morning groups were asked to join the afternoon groups or come back the next day. The community facilitators kept a comprehensive list of names and addresses of potential participants and were always on standby to follow up persons who have been assigned to groups but failed to show up for discussions. One notable observation is the readiness of both men and women to participate in the FGDs. This cooperation is attributed to the fact that the facilitators were community leaders who enjoy tremendous respect among their peers and because the community at large were very supportive. Many thought that the team had come to teach them about reproductive health matters which also contributed to their willingness to participate.

Group discussions took place in relatively quiet locations so that the participants could hear one another easily. Venues like schools, government buildings, and churches, were used where available.

A total of 484 respondents participated in the FGDs and these were distributed almost equally among the three divisionsÛKakamega Municipality (33.9 percent), Mumias (33.7 percent), and Kabras (32.4 percent). Over half of the participants were male (55 percent) and the majority were rural (66 percent; see Table 1). The men were older than the women with minimal rural-urban differences. The mean number of living children is higher in rural than in urban areas and among men than women. The differences in family sizes between men and women are probably due to polygynous unions and out-ofwedlock childbearing (see Table 2).

Table 1 reveals that over 90 percent of the participants in both rural and urban areas said they had attended school with minimal differences between men and women in the proportion that had achieved some schooling. In rural areas, higher literacy levels were observed among males than females. The literacy level in the study area compares with the provincial levels, and gross enrollment in primary school for the province was 98 percent in 1993 (CBS 1994). Over 60 percent of the men were married, with most reporting monogamous unions. The majority of the participants were Christians although there are more Protestants than Catholics.

Participants have lived in their current location for varying durations; urban residents and women are more likely to have recently migrated (see Table 2). The shorter duration of residence observed 
among the women is due to the fact that many of them may have moved from their home areas to live with their husbands in the urban area or other villages in the district.

In terms of social and economic activities and amenities, almost all categories of respondents (over 97 percent) said they listen to the radio at least once a week and over two thirds belong to a social organization. For work status, 92 percent of the women in the rural areas and 85 percent in urban areas were currently working and most say that they earned income for their work. A greater percentage of men than women appeared to be unemployed at the time of this study, but men who were working were more likely to receive income for their work than women who were working. ${ }^{5}$

The commonest household asset was the radio in both rural and urban areas. Less than 20 percent of the participants from urban areas and 6 percent of residents in rural areas said that their houses had electricity. A majority of the respondents said that they or their spouses (in case of women) or parents (in case of the younger participants who were not in union) owned land, animals, and cash crops but there were significant rural-urban differences in the proportion owning these assets.

Participatory Research in the Clinics

The facility-based research was conducted as a sequel to the community-based study in health facilities that served the four communities selected for the study. The facility-based research had two objectives: to determine how the health providers perceive menÌs reproductive health needs and to investigate health provider readiness to address those needs within their facilities. The research was an adaptation of COPE a Ïdo-it-yourself approachÓ to research developed by AVSC International to help health facilities focus on improving the quality of their family planning services and use their resources more efficiently (AVSC International 1995). COPE is flexible, interactive, participatory, and allows both researchers and participants to learn by doing. Therefore, it is an appropriate technique for exploring complex subjects such as service delivery to men.

This COPE modification entailed self-assessment by clinic staff, client interviews, and preparation of an action plan. Self-assessment entails using a checklist based on the rights of clients and needs of providers to assess the quality of services provided at a facility, identify problems confronting quality, and how staffs plan to solve or minimize those problems within their facilities. Client interviews use a checklist of relevant questions to elicit clientsì opinions on quality of services and necessary improvements. The providerÌs action plan outlines how to solve the identified problems.

Data collection at each facility involved a number of activities. The facilitator made an initial visit to the facility to talk to staff, review records, become acquainted with the services provided at the site (for both men and women), and encourage staff to participate in the research. An introductory meeting introduced the objectives and rationale of the research to staff participants and trained them in the application of basic COPE tools.

The self-assessment was performed by teams of staff members who used guides to look at the adequacy and quality of services at their site. The questions included those adapted from the standard COPE checklist guide and others based on the results of the community study. The COPE guide covered clientsİ rights for services and providersÌ needs for meeting those rights. Clientsİ rights pertain to information, access to services, client-provider interaction, counseling, choice, opinion, confidentiality, and safety. Other clientsİ rights are privacy, dignity, comfort, and continuity. The team also gathered data on the needs of providers as they affect their capacity to deliver services. Needs covered in this study include management, supervision, information, training and orientation.

Providers applied self-assessment to the challenge of providing family planning as well as STD/HIV/AIDS services to male clients and couples. Their responses constitute the main data gathered at each location. Rights and needs which are not adequately met at each location are written into the action plan. The action plan is a statement of how staffs plan to solve identified problems at each location. The self-assessment was performed during scheduled meetings so that intrusion into normal duties was minimized.

Five health facilities were visited. ProvidersÌ perspectives regarding menÌs reproductive health needs were obtained from the self-assessment process. Facility 1 in Kakamega Municipality is an NGO facility. It is a relatively small clinic providing predominantly family planning services, vasectomy, condoms, STD diagnosis and treatment, treatment of infertility, male circumcision, and counseling. Six 
health providers participated. Facility 2, also in Kakamega Municipality, is the Government Hospital serving the whole of Western Province. It provides curative, preventive, and promotive health care for men, women, and children. Family planning and RH services include counseling on contraceptives, issuance of all FP methods, counseling and treatment of STIs, counseling and management of infertility, and counseling for marital problems related to FP and STDs. There were 13 participants in the selfassessment. Facility 3 was in Malava, the main government health facility serving over 147,000 people resident in Kabras Division. It provides MCH/FP services, child immunization and ORT, maternity, curative, and dental services. It also provides FP counseling, issuance of methods, diagnosis and treatment of STIs to men, women, and adolescents. There were six participants. Facility 4 is a government health center serving the large population of Mumias Division. The center provides $\mathrm{MCH} / \mathrm{FP}$ services, child immunization and ORT, maternity, curative, and dental services. It provides FP counseling, issuance of methods, diagnosis and treatment of STIs to men, women, and adolescents. Eight staff members participated. Facility 5 in Mumias Division is a relatively small dispensary providing curative services for minor illnesses such as malaria. FP and STI counseling are provided to both men and women. There is issuance of modern non-surgical FP methods and child immunization. It serves predominantly the people of Mwiboma and Ekero sub-locations. Seven staff members participated in the self-assessment.

\section{Organization}

This report is written in seven chapters. Chapter 1 gives background on FP and RH perspectives in Kenya as well as a demographic description of the three geographical study areas in Kakamega District, Kenya. The qualitative methodology used in both communityand facility-based research is described. Chapter 2 examines men's knowledge of FP methods, their reasons for use and non-use, how to increase men's use, the dynamics of unwanted pregnancy and patterns of contraceptive use, and how FP influences sexual behavior. Chapters 3 and 4 discuss knowledge, perceptions, and concerns about STDs, HIV/AIDS. Chapter 5 investigates spousal roles and responsibilities in reproductive health issues of FP, STDs, and HIV/AIDS. These are described in terms of spousal discussion, decision making, disagreement, responses, notification, and conflict resolution. Chapter 6 tries to determine whether existing RH services are male-friendly by considering responses by men, women, and service providers. Concerns are documented regarding choice of FP methods, availability of information, confidentiality, time factors, provider attitudes and gender, time, and space. The last chapter presents the implications of the study findings for policy and program development. 


\title{
Chapter 2
}

\section{What Do Men Think About Family Planning?}

\author{
Knowledge of Family Planning
}

We know a lot about what women think about family planning (FP) services but very little about what men think. Yet menís knowledge, perceptions, and concerns about FP methods are likely to inform their behavior. This point is important since men are the heads of their households and their views are the key to service utilization by both men and their spouses. In this study, we investigated menís knowledge, perceptions, beliefs, and concerns about FP and implications for service utilization. We also examined the patterns and dynamics of contraceptive use and the assumption held by individuals that contraceptive use influences sexual behavior. This association has been a major reason why some husbands and other stakeholders oppose family planning efforts and contraceptive methods. We hypothesized that knowledge influences attitude and behavior. Therefore, an understanding of menís knowledge, beliefs, and worries about FP and specific methods of contraception is important for designing messages and programs. Improving the utilization of services among men can reduce the obstacles women meet when trying to implement their reproductive goals.

Data revealed that awareness knowledge of contraception was overwhelmingly high among all the categories of respondents. Family planning was defined by the participants as a set of actions that allow a family to raise the number of children they can feed, clothe, shelter, and educate. It is matching family size with family resources. All respondents knew of at least one modern or traditional method, including condoms, vasectomy, periodic abstinence or rhythm, and withdrawal. Female oriented methods such as the pill, IUD (coil), injectable, tubal ligation, Norplant, and foaming tablets were spontaneously mentioned. Use of traditional herbs and breastfeeding were mentioned in only two groups. There were no major differences in knowledge among the various FGD groups. However, young unmarried groups gave more spontaneous responses than the married ones.

Modern Methods

Condom

Condoms are generally referred to as ìsocksî, ìshieldî, or ìrubberî (mpira). The respondents knew it as a male method that is easily available from health facilities, bars, shops, and CBDs. Almost all groups were able to identify the TRUST condoms. For married men and women, condoms were mostly associated with outside partners. This was evident from almost all the groups in rural and urban areas.

Vasectomy

To the respondents, vasectomy is synonymous with castration or loss of manhood. It is generally referred to as ìcutting the veinî, ìblocking the seedsî, ìoperation for menî or ìclosing completelyî. It is the least understood method. Most participants know that it is a permanent method for men, it is not reversible, and it can be obtained from health facilities, specifically Kakamega Provincial Hospital or the FPAK male clinic at Kholera House in Kakamega town. It was also obvious that many people do not have adequate knowledge of vasectomy. For 
example, one married man said: iÖ the problem is that many men have not yet got the information to know that when one is cut Ö youill just be normal Ö many think that when he goes to cut the vein they cannot accomplish sexual intercourse as usualî (from Kakamega, married, male, informal). A married female in Mumias said, ìI donít think they have knowledge because if they had, all people could be doing it [vasectomy].î

Tubal Ligation (TL)

Most categories of discussants knew TL as a permanent FP method for women. It is literally described as iturning the uterus and tying the fallopian tubesî. Some call it an ìoperation for women, closing completely or sterilization.î They know that this is obtained from specific health facilities like Kakamega Provincial Hospital.

Pill

The pill is another commonly cited method, generally referred to as ìtabletsî. Most respondents knew that it is an oral contraceptive involving swallowing of itabletsî daily by women. They said it is available in health facilities and sometimes distributed by CBDs. They also knew it as a temporary method.

Injectable

The injectable was also commonly mentioned by most discussants. They referred to it as the iinjectionî. They knew that it is a female method available in health facilities and a woman goes for an injection after every three months. They knew that it is a temporary method because they said ìwhen the woman wants a pregnancy she stops going for the injection.î

Intra-uterine Device (IUD)

The IUD was commonly referred to as the ìcoilî or ìcopper Tî. Discussants knew that it is a female method that is inserted through the womanís vagina and is available from health facilities. It is a temporary method which is ìremoved when a woman wants to get pregnant.î Norplant

Respondents mentioned Norplant only after probing. The respondents described it as ìsticks which are inserted on the upper left arm of the woman and they are left for $3 \tilde{n} 5$ years.î Whereas most married male respondents did not know this method, the unmarried youth knew about it from FP literature.

\section{Spermicides}

Only a few male respondents from the formally employed and married groups in Kakamega mentioned foaming tablets. However, the knowledge of this method was high among unmarried youth. The respondents knew that these tablets are inserted into the womanís vagina before sexual intercourse. Most women said that they have heard of this method at the $\mathrm{MCH} / \mathrm{FP}$ clinics but never used it.

Diaphragm

The diaphragm as another modern method was mentioned mostly by educated unmarried youth although they did not say how it works.

Traditional Methods

Rhythm/Safe Days and Periodic Abstinence

There was confusion of rhythm versus periodic abstinence among the respondents because they would mention rhythm and give a description of abstinence. Rhythm and abstinence were mentioned and highly supported by all respondents. Kakamega and Mumias respondents particularly indicated that the Catholic Church teaches them about the rhythm method. They 
knew that both men and women use rhythm and that it is highly dependent upon the womanís menstrual cycle and the cooperation of both partners.

Most of the respondents said that postpartum abstinence is an old tradition practiced long ago following childbirth in order to ensure a reasonable interval between births. During this period the new parents slept in different houses in order to avoid intercourse; they would return to each other when the baby was old enough to be sent to bring ì cup of water for the father,̂ indicating that the mother is ready for another pregnancy. Others said that the man used to sleep on a top floor (level, or bed) and would ìdrop some mudî to signal the woman that it was time to resume intercourse. Thus, sleeping arrangements that allowed the use of separate buildings, rooms and/or beds and polygyny facilitated the practice of abstinence in the past. Today, sleeping arrangements have changed, making abstinence difficult to practice.

Withdrawal

This method of FP elicited the most interesting responses of all. It was a widely known method by almost all the respondents especially the married and unmarried male youth, and yet it was the most unwanted and least desirable method. Only the young unmarried girls in Kabras had not heard of it. The respondents were able to describe the method as ithe man pouring out the seeds instead of ejaculating inside the womanís body.î It is described as a male method but one that needs a lot of discipline and determination on the part of the men. Most men are not willing to assume such responsibility.

Prevalence of Family Planning Among Men

The study also investigated the prevalence of family planning. When asked if men use modern FP methods, all the groups in both urban and rural areas agreed that very few men use FP with the intention of spacing or stopping childbearing. Some respondents said that most men believe that FP is for women only. The few men who use FP are urban or engaged in formal sector jobs or businesses. The rural majority does not use FP.

The methods used by men include condoms, vasectomy, abstinence, and withdrawal. A few participants said that some men have undergone vasectomy but that it is difficult to know who and how many have undergone the operation. Those who obtained a vasectomy did it secretly from their wives and are also reluctant to tell other men due to the stigma attached to the method. One group of married men in informal employment in Kakamega mentioned masturbation as another method used to avoid pregnancy. This is also practiced secretly without the wifeís knowledge and used mainly to avoid extramarital relationships that could increase the risk of pregnancy or HIV/AIDS. Condoms are used by some men but mostly for disease prevention rather than for FP, and use is mainly in casual sex encounters with ioutside partnersî.

Young unmarried men, though sexually active, were also characterized by minimal contraceptive use. Data revealed that about eight out of every ten young men aged $15 \tilde{n} 24$ were sexually active. However, respondents from the rural areas (Kabras and Mumias) stated that use (mainly of condoms) is higher among young urban men who are highly educated or currently in school. These groups are aware of the risks of unprotected sex; this awareness has not resonated with other categories of men, especially older ones in rural areas. With minimal use of contraceptives, a large number of sexually active men are increasingly exposed to disease or unwanted pregnancy. 
Participants in all the focus groups were asked to estimate how many men out of ten were using FP methods in the area. Most groups estimated that three out of ten would be using any method of FP. Only two groups (one in Kakamega and another in Mumias) gave an average of four men who could be practicing FP with their spouses. There were notable differences in these estimates by age, residence, or employment. However, a greater proportion of younger men were estimated to be using condoms in order to minimize their risk of disease and unwanted pregnancies. The respondents agreed that information on FP is lacking among men, especially in rural areas. The youth from Kabras and Mumias indicated that they were not as enlightened on FP methods as their counterparts in Kakamega (urban area). Ways of enhancing menís acceptance of FP are therefore imperative in order to relieve women from the sole responsibility of fertility regulation as is shown by these findings.

Use and Non-use of Family Planning

Four broad reasons for using FP were articulated from the data. Apart from the prevention of unwanted pregnancies, the reasons were economic, health, emotional, and sociopsychological. Prevention of unwanted pregnancies was a major consideration for using contraceptives among younger men who were not in union at the time of the study. According to the participants, unwanted pregnancy could disrupt schooling and career and compromise a manís plans to marry someone he loves. The latter is important because a man could be forced (against his own wishes) to marry a girl he had impregnated. They argued that it was important that they protect both themselves and their partners since they were not ready for parenthood. However, disease prevention takes precedence over pregnancy prevention when methods are used with casual sex partners. In this context, vasectomy was discussed in terms of its role to prevent unwanted pregnancies. The participants said that vasectomy offers maximum protection against pregnancy but that it is appropriate only for older men who may have achieved desired family size. Vasectomy is also unpopular in the area because of the fear of its side effects. Some married men said it is acceptable for wives to undergo TL if they have the number of children their husbands wanted. In general, most men do not consider FP their responsibility, and it is rare to find married men using methods with the intent to prevent unwanted pregnancies.

The respondents argued that FP offers some economic advantages for users. Most participants argued that the cost of living is high; therefore, families who use contraceptives are able to raise the number of children they can afford to care for. With fewer children, families are able to provide adequate food, clothing, education, and shelter, and parents can afford better quality of life for their offspring. Economic considerations constituted the most important reasons for using FP among married men.

Another economic reason is the declining land holdings of many households. In the past, land was wealth and almost all families could pass some to their offspring. Changes in land ownership laws and population pressure have led to significant decline in land holdings per family and the amount of land that each family can pass on to their children. To an average Kenyan male, it is a shame to bear children when there is no land to give to them. It was observed that lack of land to pass on to children is a key factor in whether men use FP or support use by their wives.

Other economic reasons include the increasing cost of health, food, and education, declining job opportunities and increasing unemployment of highly trained personnel. All of these have 
lowered the quality of life of every citizen and have perpetuated poverty, frustration, and feelings of worthlessness. The implications of increased poverty and sense of worthlessness run deep. Education is increasingly being treated as a replacement for land in the list of things that can be handed over to children. Although not everyone has land to pass on to children these days, everyone can send children to school if they have the means to do so. Through education, parents provide their children with tickets to a better life than they have had. However, given the increasing cost of education in Kenya, families have concluded that the fewer number of children the better. In other words, poverty and frustration associated with declining real wages and quality of life are increasing the motivation among men to utilize FP information to raise the number of children they can feed, clothe, house, and educate. Economic reasons also determine the use of certain methods. For example, data showed that men use condoms because they are cheap, easy to use, convenient, and easily available.

Health reasons include the need to protect oneself from sexually transmitted diseases as in the use of condoms in casual relationships. There is awareness that the condom can also prevent unwanted pregnancies although most of the time the condom is not used with that reason in mind. The married respondents cite another health benefit: adequate spacing between births enhances both maternal and child health. Periodic abstinence and withdrawal are discussed in this context. Most men use these methods because they are ìgoodî, home-based, and have no side effects or costs. All that is necessary is the cooperation of both partners. Almost all the married respondents agreed that these methods were the healthiest but the most difficult to practice.

Data revealed that FP gives emotional and psychological satisfaction to men by increasing love between couples. According to discussants, having fewer toddlers and babies means more free time for couples to experience ìfreedom when having sexî as they are not worried about unwanted pregnancy or young children who could disturb them. The more children a couple has, the more time is spent in child rearing, and the less time the couple can devote to themselves and to developing conjugality and oneness. One respondent in Kakamega said that there is need to teach girls how to have sex and fewer children. She pointed out that women should be taught that child bearing is not the sole objective of marriage and that a woman who iis good in bedî will have peace of mind in that her husband will love her and will not stray into ìother handsî (extramarital relationships) or get diseases.

The common reasons for non-use of FP among men were fear of side effects, high failure rates of some methods and fear of unfaithfulness among partners. Other reasons include cultural beliefs, religious convictions, lack of confidentiality and privacy at health centers, and fear of contracting HIV from some methods. The participants discussed the role of traditional beliefs, customs, and practices as obstacles to FP. One key tradition is sex preference. The desire to have sons who could inherit the homestead often encourages many men and women to postpone FP until they have achieved the desired gender composition of children. Another traditional practice is polygyny. Competition for children among the co-wives is likely to decrease the likelihood that the husband would use FP. Others include naming practices which require that ancestral names be kept ìaliveî through children; pressure from the extended family members, especially grandparents and parents-in-law; and the persistence of the notion that a womanís job is to give birth to as many children as possible. 
Men and women were also concerned with old age security. In particular, women earn social security, esteem, and respect from having many children; and the need to bear many children especially if the husband or wife came from a small family is a major constraint to family planning. Some typical responses are stated below:

Ö We have those who believe they should get children and name their grandfathers and forefathers who died long ago. So they say that before I have my ancestors who died long ago, I cannot plan my family (Kabras, married, male, formal).

Ö Because before a woman has had five children, she does not belong to that home (her marital home). So when you want to prevent her from having children, she thinks that you have another intention. So she usually would like to have many children so that even when you want to terminate your marriage (divorce), the children become a stumbling block. That is why a woman uses children as a shield to show that she belongs to that home (Kakamega, married, male, informal).

Most men believe that when a woman comes, she comes to give birth. And these old women, when they see a woman delaying to give birth, they start asking him (spouse) why you are not getting pregnant Ö So he starts to have that belief that a womanís work is to give birth Ö And the old women make sure that when they see a child being carried on the back, that is the time to have another pregnancy. So the old woman would now tell her son to be in the house every day so that the wife has no time to leave the children and go roaming (Mumias, married, female, informal).

Lack of information about method side effects has tended to discourage use. Most participants argued that the condom reduces pleasure and they prefer ìflesh to fleshî or ìskin to skinî. They added that the lubricants used in condoms affect the user. Others argued that condoms are porous, can come off during use, break, or disappear in the woman (necessitating an operation) and therefore are ineffective in preventing diseases. Almost all male participants said that it is difficult to know the expiry dates on condoms, especially those from health facilities, and that expired condoms have a high rate of breaking. The fear of using expired condoms further discourages men.

Many participants, mainly men, alleged that condoms are laced with the HIV virus. However, many participants also said that some fruits and vegetables have been injected with the virus that causes AIDS. It is therefore uncertain whether the association between condoms and HIV constitutes an obstacle to use or whether it is basically an expression of the frustration with the high prevalence of HIV/AIDs in the area. This high prevalence may have led people into thinking that it must have come from food or condoms.

Trust is a key consideration in whether or not condoms are used in relationships. The young unmarried males said that condom use thrives when a relationship is young and/or partners do not trust each other. Once the partners develop mutual trust, they throw the condoms away. Trust is partly why many married women find it difficult to broach the subject of condom use with their spouses. As indicated in the following quote: iWhen the woman suggests the use of a condom, the man may judge it to mean that she has been unfaithful and this becomes a very sensitive issue Öî (Kakamega, single, male, youth). Drunkenness and traditional dances often encourage men to ìfelanga (feel) freê̂ and not use condoms because of associated momentary excitement and freedom. 
The data also revealed that condom disposal is a problem in almost all the communities studied. Most respondents stated that there are no appropriate places to put used condoms and that if you throw them away, children sometimes pick them up and blow them like balloons. Women, in particular, were concerned about children picking condoms that could be dangerous to them; women also feared that children might use them to initiate sex early.

Vasectomy is generally associated with castration or loss of oneís manhood and is unpopular in the area. Most male respondents were concerned with what happens to a manís sex life once he gets a vasectomy. They said that vasectomy ikills erection, stops ejaculation, makes a man fat like a bullî; it is associated with loss of sexual urge and frequent sickness. According to some discussants, ìvasectomy is impotenceî.

Other men and women were concerned that if there is an accidental loss of some or all children, vasectomy would make it impossible to sire children and their lineage would then become extinct. Fear of the unknown is therefore a major reason for the opposition to vasectomy. This relates to death of children or failed marital relations as in separation or divorce. In any of these cases, husbands want to make sure that the wives will not be able to sire children from other men. They therefore force their wives into TL or completely refuse vasectomy. One male respondent said: ìIt is better the wife to be the one to ëcloseí and you will be there on ëstandbyí in case of a natural calamityî (Kakamega, married male, formal). 
FP among married persons in the area is associated with prostitution. People said that there is a general tendency for persons using family planning to become promiscuous because contraceptives remove the fear of unwanted pregnancy and its consequences. Because of the association with prostitution and the negative perceptions of vasectomy, men acquire vasectomies secretly so that their wives may not talk about them to other people. They also fear repudiation from friends and family.

The young unmarried men said that vasectomy is a painful operation. They also fear getting an infection from the operation and cited examples of those who suffered several health problems from surgical contraception (although most of the examples were TL cases). Others said that it is against Godİs law to be sterilized because God said Ïgo and multiplyÓ. One young unmarried male respondent in Kakamega said, İI donİt like it because if you die without children, you wonÌt go to heaven.Ó Tubal ligation, on the other hand, was associated with general body weakness. Some argued that the woman might be infected if the operation is performed in non-sterile conditions. The women who had experienced some problems from the operation also discouraged others. One said: ÏThere is one of us : work-mate, who used this method. They stitched but it did not heal or it became a wound $\div$ She had to see a doctor. She wasnìt encouraging others to go for the sameÓ (Mumias, married, female, formal).

The pill was associated with various side effects. Among them were long and heavy menstruation; still births; infertility; general body malaise; deformities in children; goiter; prevention of milk production in nursing mothers; peeling of the womanİs outer skin; perforation of the uterus. Interestingly, most young unmarried men seemed to know more about the side effects of the pill than the women themselves. Others said that pills affect fecundity and that women who use them continuously may not be able to have children even after they have stopped using the pills. The married men and women said that the injectable contraceptive causes menses to disappear altogether; it also causes severe backache, headache, dizziness, shortness of breath, fatness/thinness, vomiting, diarrhea, and infertility. Most female respondents said that women become sexually unresponsive although a few said their sexual urge increases. One female respondent said: $\ddot{I} \div$ I have heard them complain that if you go for injection, it usually makes you lose the urge for sex, even if you meet with your husband you canİt feel anythingÓ (Mumias, married, female, informal). The IUD (coil) is associated with heavy and long menstruation and swelling of the body. Use of spermicides (foaming tablets) is inhibited by high failure rate. One man narrated his experience: $\ddot{\mathrm{I}} \div \mathrm{I}$ have had an unpleasant experience. I used to use these foaming tablets. $\div$ but last year she [wife] became pregnant $\div$ at the age of $41 \div$ They were not effective. I had tried for a period of 8 years successfully but you see later on they didnİt workÓ (Kakamega, married, male, formal).

Periodic abstinence and rhythm are also known to have high failure rates and are difficult to practice. Rhythm is highly dependent on the womanÌs monthly cycle and that any menstrual irregularity would affect its efficacy. These methods are of limited applicability among people with little of no education (since such individual may find it difficult to follow the calendar method), when men are Ïyoung, hot and activeÓ or where there is alcoholism. According to the younger men, beer and groundnuts act as sex stimulants that could even lead to bestiality. Abstinence is impractical when there is a lot of drunkenness or alcoholism as pointed out in the focus groups:

There are times you will eat stimulants such as groundnuts and changİaa [a locally prepared liquor]. These ones will excite you sexually. There are some types of changİaa which can even send you to a cow [practice bestiality]. So when I knock that one, it is a must that I go with my wife. Even if the timetable says no sex today, I will not read the timetable that time (Kakamega, married, male, informal).

It is difficult $\div$ because you can agree but when the man drinks he comes in the mood of having sex so the wife has no other alternative (Mumias, married, female, informal).

The younger men added that it is difficult for men to abstain for long, arguing that it is important that men İempty themselves of semen from time to time.Ó

Another constraint on abstinence is sleeping arrangements which encourage body contact. The sharing of a bed by a couple as opposed to the traditional arrangement in which a husband and wife slept in different rooms or beds makes the temptations to have sex very high. Some men argued that 
abstention increases the chances of keeping Ïoutside partnersÓ. In the process, men may end up with more children than they wanted.

Married women, in particular, pointed out that, nowadays, abstinence increases tension between couples and increases the likelihood that a woman will be suspected of foul play. They said that spouses are always suspicious that the other may have had extramarital affairs or contracted a disease whenever abstinence is suggested. Another side effect of periodic abstinence, according to the participants, is that it destroys the therapeutic function of sex. Sexual intercourse, they said, is like a peace-making weapon that can be used to resolve conflicts between couples in that spouses can use the occasion to Ïtalk overÓ their problems and reconcile their differences. Abstinence makes it difficult to make amends during spousal differences. Lack of sex further strains the relationship.

The withdrawal method was not popular among men because it has a high rate of failure due to premature ejaculation and the difficulty of withdrawing at Ïthe climaxÓ. Most male respondents said that at the peak of excitement, one almost loses sense and it becomes too difficult to withdraw. The men said that they can even Ïdie, faint, or get a heart attackÓ from practicing it. One male respondent said: ÏIt is like chewing meat and spitting it out when ready to swallowÓ (Mumias, married, male, formal). Another added, ÏThat one is hard because that time people have held each other very tightly $\div$ She will not allow you to withdrawÓ (Kakamega, married, male, informal). Other male respondents said that their wives or partners did not like the withdrawal method because it insults women. Many respondents complained that withdrawal is dirty; it messes bed sheets. The young unmarried males said that girls value sperms as nutritious and that men fear that they may lose their girlfriends if they use the withdraw method.

Consistent with the views expressed by the men, women also stated that men do not like to withdraw because the Ïsweetness of sexual intercourse is in pouring in, not pouring outÓ. Some women said that men sometimes intentionally ejaculate into them after they had agreed not to do so and then apologize. One FGD group discussed what women do in order to prevent such unwanted sperms from developing into an unwanted pregnancy. One female discussant explained: ÏYou wait for him to sperm and then press your stomach and push them out. Sometimes you can buy aspirin or panadol and you say you are sick and when he just finishes you go and swallowÓ (Mumias, married, female, informal).

\section{How to Increase MenÌs Use of Family Planning}

The researchers investigated ways to increase menİs use of FP and their support of such use by partners. The answers were invariant by age, residence (whether rural or urban) or sector of employment. Most respondents suggested that health education about family planning and prevention of STDs/HIV/AIDS is the key as revealed by the quotes below:

People should be educated so that they know because I think if we have enough education, everyone will know the goodness of FP (Kabras, married, male, informal).

The major issue here is lack of information because in earlier days, FP methods were mostly meant for women not men and people developed a culture of thinking that FP is just a womenIs issue. So it is now upon the FP planners to make sure that we actually have a serious campaign to reach many men, and also in rural areas, not only in town. Because you find that in town most people would already be having information on FP issues. But when you go to rural areas, they just know family planning is just the work of women and nothing else (Kakamega, married, male, informal).

Channels that can be used for community education, according to respondents, include seminars, newspapers, radio, film and video shows, magazines, booklets, posters (charts), and public fora such as schools, churches, chiefİs meetings (barazas), funeral gatherings, ${ }^{6}$ other social meetings, and house-tohouse campaigns by community-based educators.

One group of married women suggested that women should educate their husbands or partners because women are the ones who bear children. They also have greater access to FP information than men do. Some other participants advocated the use of male role models in community education campaigns as a way to reach men with FP information and commodities.

Most respondents said that the available male methods are too limiting and should be increased beyond condoms and vasectomy. The participants stated that the addition of injection and oral contraception to the method mix would increase choice, which should in turn increase contraceptive uptake by men. More information and education on FP should be provided in the rural areas. Such 
increased proximity and access to services could be achieved by building more service delivery points and using mobile clinics. Couples and partners should be encouraged to go for FP counseling together. If men and boys deliver services to their peers, FP will appear male-friendly. Massive campaigns and service delivery strategies could increase condom use among young men; health officials could promote knowledge by demonstrating condom use. Other suggestions are to create more aggressive advertisement of FP methods on T-shirts and caps; use incentives to attract men to use methods (such as giving free T-shirts, bags or caps); use government force such as legislation aimed at forcing men to use FP; put contraceptives in manufactured foodstuffs; and lower prices of condoms.

The participants stated that efforts to increase condom use should focus on youth as they are the critical group. Such efforts should concentrate on finding private and strategic points to deliver condoms to younger men. They argued that condom dispersers placed in open places are not appropriate. Men and especially adolescents are ashamed to collect condoms from these dispensers or health centers because of the association of condoms with casual sex and promiscuity.

In sum, the data reveal high awareness of FP and methods but little knowledge of side effects and method contra-indications and how methods work. This gap in knowledge has encouraged misconceptions about FP which have tended to discourage contraceptive use. Access to information is important to increase the use of FP.

\section{The Dynamics of Contraceptive Use}

Unwanted Pregnancy

The interest is to investigate whether respondents make the connection between unwanted pregnancy and FP. In other words, does the risk of unwanted pregnancy increase the odds of using FP? If yes, at what point do couples decide to use FP? Is it before or after the occurrence of an unwanted pregnancy? In order to answer these questions the respondents were asked what men do if they find that their wife or partner has an unwanted pregnancy. The views differed by age, sex, and marital status. Respondents defined unwanted pregnancy as unplanned or that occurring from contraceptive use failure. Data revealed that abortion is a common recourse for unwanted pregnancies. Youths considered abortion the most pragmatic solution, although the sentiments and likelihood of using abortion differed depending on whether the pregnancy occurred within an established union or whether it was in casual sexual relationships. The same is true of married men. However, youths not in regular union are generally more likely to say that they will abort an unwanted pregnancy than married men or women.

Most of the married male respondents said that they would accept the pregnancy if it occurred within their marriage. This response cuts across all subgroups: residence, age, employment. While some claimed divine reason for their behavior, i.e., abortion is sinful and immoral, others were concerned about the health of their wives. Some said:

$\div$ I know that I am responsible, and I was not expecting a child $\div$ and I know that it is my pregnancy, I would accept because there is no other way, I know it is mine (Kakamega, married, male, formal).

That one $\div$ has come accidentally. Now that it has come, you are supposed to let the child be born, then you can know how to plan. But some people take this pregnant woman and have her take a lot of medicine (overdose) so that she can remove this child. When she removes that child, it becomes a sin to God $\div$ It is better she gives birth, after giving birth then you can know how to plan. If it is planning let them Îcut the uterus and turn it $\div$ (Mumias, married, male, informal).

Abortion is good, many do abortions but at other times it is also dangerous. Sometimes a mother can unexpectedly go for abortion, $\div$ and she loses her life. So many $\div$ just leave and give birth $\div$ Ó(Kakamega, married, men, informal).

Many expressed the sentiment that the child could be a future president and that by aborting, couples would have deprive themselves the opportunity of becoming a presidentİs parents. A few men said that they would keep the pregnancy even if they knew that they were not responsible for it and that the wife may have got it from an extramarital relationship as long as the wife recognizes him (the husband) as the father of the child. Some put it this way:

You know in a home, there are your own children and others from outside (due to unfaithfulness) $\div$ but the mother herself knows much. There can be a wife who gets ten children. Out of those maybe only two are yours. The remaining eight belong to your compound but they are other peopleÌs children $\div$ Let her give birth provided she gives the title, Îchild of Joash Amukung $\div$ I find wives to 
be tricky. According to Luhya customs, if a woman is carrying another manÌs pregnancy, she will take her husbandİs under-shirt and put them on and when she gives birth, the child will just resemble you [the husband] (Kakamega, married, male, informal).

However, some said that they would first need proof that they are responsible for the pregnancy, such as the date of last intercourse or last menstruation, before they can agree to keep the child. It was clear that unwanted pregnancies or closely spaced children are not easily acceptable. Most of the discussants stated that they would go for FP after the birth of the child in order to avoid future occurrences, arguing that the escalating problem of Ïstreet childrenÓ in Kenya is probably caused by unwanted births. Abortion is an acceptable way out of trouble for those groups of men. Participants in four married male groups suggested abortion as a cure for unwanted pregnancy if it is gotten from extramarital relationships in order to avoid conflicts which could ensue if their wives found out. Others said they would go for an abortion if the pregnancy interferes with their development plans such as when the woman is in college, the man is trying to establish a career, or it is not economically viable. Some discussants said:

If it is an outside partner, $\div$ what would run in my mind first will be abortion. I will remove it (Kakamega, married, male, formal).

I feel we must accept abortion because $\div$ you will bring in the child to suffer forever. If a woman gets pregnant and at about one month you agree and the doctor checks and finds it is all right, it is better to abort earlier. Because if you accept the pregnancy the child will later on suffer and blame you for it. If the womanIs life is not endangered, I will agree to an abortion. (Kabras married, male, informal).

Some decide to have an abortion $\div$ In some ways it is acceptable because the pregnancy has come at a time when they had not expected and depending on their plans they see that $\div$ an abortion will give room for them to complete their plans. And there are women who may have plans of going to college $\div$ the only solution is to have an abortion. (Kakamega, married, male, informal).

There were considerable disagreements between men and women in how men respond to unwanted pregnancies. In contrast to what men said, women stated that most of their partners were not supportive of unwanted pregnancies. Some deny responsibility for the pregnancy, neglect or blame their wives, or become harsh in the home. Some women are abandoned in the hospital after delivery or chased back to their parentsÌ homes. Some men desert their wives and go for ÏoutsideÓ partners. Some husbands suggest an abortion and others over-indulge their wives in frequent and aggressive sexual intercourse in order to induce an abortion. Only very few married women concurred with the married menÌs view of just carrying on with the pregnancy. Typical responses are quoted below:

There will be misunderstanding, quarrels and anger. He will ask you why you did not go for FP. They just feel annoyed. (Kakamega, married, female, informal).

Love decreases in the house. If you ask your husband for anything he becomes harsh and takes you $\div$ like a dog. (Kabras, married, female, informal).

Others will say that the pregnancy is not his; that you conceived from outside. He will say I told you not to give birth $\div$ He sends you to your parentsì home. He wants you to leave the child in your parentsì home (Kabras, married, female formal).

They will just desert you and leave you in the house. (Mumias, married, female, informal).

To cope with their partnersÌ and husbandsİ reactions to unwanted pregnancies, the married women said they sometimes secretly go for an abortion or adopt a contraceptive method (without husbandİs knowledge) after delivery. Others said that some women decide to run away to their parentsì home if the situation becomes unbearable or behavior is violent. Here are some typical responses:

What you do when you have got an unwanted pregnancy, you accept to give birth to that child but before you come out of the maternity, you should take a FP method which is better than removing the child. You know they do not accept to have you remove the baby and secondly, removing that baby is risky. You might decide to remove and you die and now you will leave behind the other children. It is better you just stay with that pregnancy and accept the quarrels. (Kakamega, female, informal, married). 
Some women decide to disappear with the small baby and leave the others behind. She goes to her parentsİ home. (Kabras, female, informal, married).

When one woman in one of the groups said that some men let their wives give birth and then ask the service providers for a FP method, there was sharp disagreement from the other discussants who said that men seldom ask for FP. The women added that men believe that women are there to give birth to as many children as possible.

There were no major differences in how younger men and women said they would respond to unwanted pregnancies. The never-married female youths stated that they would do any of the following: decide on an abortion if she is still in school or college; give birth and kill the infant by throwing it into the toilet or onto a rubbish heap or by strangulation; give birth and force oneself to marry the man or force the child on the man; commit suicide by taking an overdose of medicine, hanging or drowning (that is if rejected by the man or parents); run away from home due to fear of parents. They stated that most young men deny responsibility: ÏIn most cases, the young men Îjumpİ; they refuse.Ó Only a few women said they would give birth and stay with their parents or marry the man if he initiates the move.

The male youths cited a host of ways to deal with unwanted pregnancies, ranging from acceptance, denial, abandonment of both the baby and the mother, to the use of force in order to coerce the woman to run away or hold another man responsible. Most stated that they would recommend an abortion to their partners, either by buying them medicine or taking them to a doctor, citing unpreparedness for family responsibilities. Although abortion is not considered a method of family planning in the populations studied, it is nevertheless accepted among the younger men and women as one way of dealing with unwanted pregnancies.

Unwanted pregnancy has different consequences for women and men: women are likely to suffer the most from it. Although the married men stated that they will Ïjust acceptÓ, women said they face tremendous consequences which include rejection, deprivation, violence, and even separation. However, married women are less likely to say that they will use abortion than unmarried women or men because of the risks to the womanIs life, although many agree that it is one way out of trouble.

One key issue is whether respondents make the connection between unwanted pregnancy and FP and whether the risk of unwanted pregnancy increases the odds of using FP. It was found that the respondents perceive that contraceptive use can prevent unwanted pregnancies. Also, the risk of unwanted pregnancy appears to increase the odds of using FP among the respondents. Many women (including younger unmarried ones) tend to suffer the consequences of one or two unwanted births or abortions before they decide to use FP. In the end, it is the woman who has to protect herself. In other words, contraception is like a resolution women take after birth or abortion to prevent future occurrences. This is an obvious case of unmet need that can be addressed by programs. Married men understand that contraceptive use can prevent unwanted pregnancies but they do not consider contraceptive use their own responsibility; it is a womanİs job.

\section{Patterns of Contraceptive Use Among Men}

The respondents, men and women, were asked whom men use contraceptives with and the method used in each context. It was quite clear from the married men and women that different types of contraceptives are used in different types of relationships. Since vasectomy is not popular among the men, the discussion centered on the use of condoms. The data revealed that among married men, condoms are used with Ïoutside partnersÓ in casual non-regular relationships. Use in those contexts is mainly to prevent STDs and HIV/AIDS. Although pregnancies are also prevented, men do not make that conscious decision although they are aware of the dual role of condoms. It is the assumed responsibility of the casual partner to protect herself from unwanted pregnancies. Condom use in regular marital unions is for the purpose of preventing unwanted pregnancies, but very few married men use condoms with their wives. Some men use condoms within marriage to guard against infecting their wives if they suspect that they have contracted an STD from a casual relationship. Most married men seem to trust their wives and hence see no need to use condoms with them.

The use of condoms among married couples is often viewed with suspicion because condoms are associated with prostitution and casual sex. These reasons, according to the men, accounted for poor approval of condom use among married women. The married women on their own part stated that men use condoms in outside relationships to protect themselves against STIs and unwanted pregnancies. 
The prerogative to prevent unwanted pregnancy in marriage is the wifeÌs. These views are exemplified in the quotes below:

Husbands prefer the woman to use family planning but not him to use (Kakamega, married, female, formal).

You know when a man wants to use something like a condom, he tries using them with outside women because he is preventing diseases and $\div$ from giving birth to a child outside his marriage. In most cases men donÌt like to use condoms with their wives (Kakamega, married, female, informal).

Instances in which both men and women agree to use condoms for pregnancy protection include cases in which the husband is caring and both partners want to stop or space but the wife is not able to use contraceptives for health reasons as indicated by one respondent: ÏSometimes those women who have Îveinsİ [varicose veins] are told that they cannot use any method so they agree with the husband and he uses condomsÓ (Mumias, married, female, formal).

The never-married respondents said condoms are used mainly with untrustworthy partners and basically to protect themselves from STDs and prevent unwanted pregnancies. Lack of trust is a key factor in condom use among all categories of men. Once trust has been developed, whether between a married man and his outside partners, or between single persons, condoms are not used. Similarly, both male and female groups of the never-married youths stated that condoms are only used with new or unfaithful partners and mostly for disease prevention. Female oriented contraceptives are used to prevent pregnancies. It was obvious that in an established relationship condoms were not used. A few of the younger men said that they would use a condom to prevent a pregnancy if they suspected that they themselves may have contracted an infection. Some respondents said: İA few, those that one does not know wellÓ (Kakamega, unmarried male youth), ÏFor those that there is some bit of doubt, he automaticcally has to use at least a shield [condom] $\div$ Ó (Kakamega, single, male, youth), and ÏThose girls who like walking carelessly [are promiscuous] and the one whom they think might have a certain diseaseÓ (Mumias, single, female, youth).

In conclusion, it was evident that trust is central to the use of condoms. In regular relationships, men do not use condoms because they trust that they are the only partners. Women will not ask husbands to use condoms for fear of being distrusted. Men too will not use condoms with their wives because the wives may begin to worry that the husband is Ïmoving aroundó, is infected or both. Similarly, in non-marital relationships that endure for some time, partners began to build trust and perform sex without using condoms. Use of condoms is, therefore, a measure of how much trust partners have for each other. This is one area for intervention. As long as partners think that condoms connote distrust, use will continue to be low.

\section{Family Planning and Sexual Behavior}

One subject that has been tossed around in the literature and in FP circles is whether family planning efforts influence sexual behavior by increasing the urge to have sex. Many studies indicate that the fear that women may become promiscuous is one reason why some husbands do not support contraceptive use among their wives. This assumption has had significant impact on programs because it has encouraged many stakeholders, most of whom are men, to oppose family planning efforts, including information, education, and issuance of methods at the household and community levels. It has also hindered program efforts to aggressively promote family planning issues within communities.

In order to investigate the assumption that FP efforts promote sex, we asked respondents whether knowing about FP influences a personÌs sexual behavior and why. The hypothesis was that men who think that FP effort increases the urge to have sex are less likely to use or support the use of methods among their wives. This study reveals a widespread perception that knowledge and use of contraception affect behavior. Depending on the method used, contraceptives can either increase or decrease the urge for sex. For example, it is believed that knowledge and use of condoms encourage premarital and extramarital sex among men because it offers dual protection against pregnancy and STDs, including HIV/AIDS. Here is a typical response: ÏPeople are no longer afraid of pregnancy as there is protection, but the fear of HIV/AIDS is overwhelmingÓ (Kakamega, single, male, youth). Abstinence, surgical contraception, pill, coil, and traditional methods are perceived to encourage sex by making the body ÏhotÓ. Some respondents said: ÏAbstinence makes husbands to have lots of extramarital affairs because their blood becomes too hotÓ (Kabras, married, male, informal). Others stated: İTablets like (pills), they $\div$ make the body Îhotİ. You can even grab someone outsideÓ (Mumias, 
married, female, informal); and ÏI have just heard that the coil increases the sex desire a lot. You can even climb a treeÓ (Kakamega, married, female, informal).

Injectable contraceptives are believed to reduce sexual urge. Almost all the female respondents said that women become ÏcoldÓ to their partners when they are on the injections. This usually creates tension between partners so men look for other partners outside. According to the women:

Some FP methods like the injectables make you not to desire to be with your husband. You donIt even want his odor near you. The body is normally cold [no desire for sex] (Mumias, married, female, formal).

Women lose the urge because of the injection. It is us who feel cold. The man will just bear you up

$\div$ (Kakamega, married, female, informal).

In sum, the data reveal that the association between contraceptive use and sexual desire is widespread in the area. Knowing about $\mathrm{FP}$ is also believed to affect individualsì perceptions of sexual autonomy. The perception that FP affects sexuality is also one of the reasons why some men do not encourage their wives to use FP. Most of the male discussants said that women get a free ticket to promiscuity if they use FP methods. However, such promiscuity is allowed if men are the ones involved because, according to the respondents, African culture is permissive of menİs premarital and extramarital relationships and multiple partnerships. None the less, the findings indicate that programs oriented towards increasing access to FP information and services should not be inhibited by the latent effect of affecting sexual behavior of the target population.

Furthermore, data revealed that husbandsİ fears that wives will become promiscuous if allowed to use contraception is predicated on the fact that women who use FP to achieve reproductive targets often remain sexually desirable and attractive because they have not been weathered by frequent child bearing. Contraceptive use reduces the frequency of child bearing, enabling women to retain their youth, physical attraction, and beauty while frequent child bearing causes women to age fast. This assumption, rather than a direct observation, probably underlies menİs perception that women who use FP become promiscuous. Indeed, data indicate that the desire to reduce wivesİ physical attraction is one major reason why husbands want to make their wives pregnant often. The husbands argued that serial pregnancy and child bearing reduce womenİs attractiveness, making them less appealing to other men. Also, pregnancy is treated as a penalty for womenİs assertiveness. As men in some FGDs said, Ïlf your wife talks too much, is affluent, or goes out a lot, make her pregnant so that she can be in the house and be more quiet.Ó Pregnancy is like a weapon in the hands of men to subordinate women or cause them to accept male supremacy by reducing their personal autonomy.

\section{Summary}

Although the findings reveals widespread awareness of FP and clear statements of why men are or are not using methods, there are differentials in access to information between the rural and urban areas. Men in rural areas are disadvantaged in that they have limited access to information about FP and knowledge of how FP methods work. Programs therefore have a major role to play in improving access to information and services in rural areas. Increasing access to information and services is also important because lack of knowledge has encouraged the negative perception of FP, and some men and women hold tenaciously to the idea that contraceptives have side effects which are bad for their bodies. For instance, the men said that vasectomy decreases a manİs sexual ability and makes a man fat like a bull. Although most of these statements of side effects have been discarded in the literature as mere myths and rumors, men and women in this study really believe in these myths and rumors because they know people who have experienced side effects. Program developers need to accept what people readily believe and find ways to instill the correct information and condition people to accept the truth. Otherwise, program effect will continue to be attenuated by these same myths and rumors.

It was observed that there is lack of commitment on the part of men to use contraceptives or support use of FP by their spouses. Some of the opposition to FP by husbands is based on the notion that contraceptive use increases promiscuity among women. According to the data, it is perceived that use of contraceptives increases the urge for sex although a few methods are believed to affect sexual behavior negatively by making women "cold". It is also commonly believed among men that women who use contraceptives are able to retain physical attraction and youthfulness. More importantly, FP is perceived to take away 
worries of unwanted pregnancies, worries which men consider important in order to subordinate women by engaging them continually in reproductive roles. It is this desire to control wives' sexuality, sometimes expressed as a concern for women's health and at other times as a concern for women's weakness (the notion that women will become promiscuous if allowed to use contraception), that often motivates men to oppose contraceptive use among their wives. Therefore, programs which seek to improve women's objective condition could increase women's ability to negotiate contraceptive use in order to implement their fertility goals. 


\section{Chapter 3}

\section{Knowledge, Perceptions, and Concerns about STDs}

Local community perspectives on STDs were investigated in order to understand the association between knowledge of STDs, preventive strategies, utilization of services, and practice of ÏhealthyÓ behavior. A review of studies on male reproductive health indicates that knowledge, awareness, and approval of reproductive health ( $\mathrm{RH})$ services are high in Kenya but the practice of low risk behavior is low (NCPD 1994; Ndeti 1989; NCPD et al. 1993). The assumption is that if menİs knowledge of ways to prevent STDs is high, then there should be greater use of services and practice of safe sex behaviors that can reduce the risk of diseases. We investigated this assumption by studying menİs beliefs, perceptions, and concerns about STDs and in particular menİs knowledge of STDs, including types, symptoms, transmission, prevalence, perception of risk, management, and prevention. (Note that this chapter does not discuss HIV/AIDS.) To understand local perception of the association between knowledge and behavior, participants were asked to discuss what individuals in their area do to prevent risk of STDs. This investigation is important because the design of services which are attractive to men and encourage them to support their partnersÌ reproductive health must begin with an understanding of menİs points of view and their needs for information and services.

\section{Types, Symptoms, and Transmission}

There was a high level of awareness of STDs in the areas studied. Most participants, men and women, were able to name the common STDs which affect people in the area and to discuss their symptoms. The commonly identified STDs were syphilis and gonorrhea. They also reported pubic lice and a symptom which they called Ïland cruiserÓ (sensation of something moving under the skin) as common problems which they perceived to be sexually transmitted. In addition, a few respondents, mainly younger men and women with higher education, some medical training, or in formal employment, identified other types of STDs: herpes, hepatitis, chancroid, candidiasis, scabies, and Treponema vaginitis (most of the latter being found in women rather than men).

Participants were able to identify the symptoms of STDS although they were not able to match these symptoms with specific types except in the case of syphilis and gonorrhea. Some of the symptoms identified by the respondents include: ulcers (amakaha amkonzo), strings (worms, kamba nane or luusi) coming out of the penis, urethral discharge, painful urination, genital itching, passing of pus, general body weakness, fever, stomach/lower abdominal pains, exhaustion, swelling on the body and around the groins, bubos, boils, or inability to walk. Syphilis is associated with painful urination and passing of blood. Gonorrhea is associated with passing of pus in large quantities and this pus sometimes causes the penis to stick to the clothes. In order to prevent this stickiness, men who have this disease sometimes wrap their penis with paper before wearing their undergarment. Another symptom of gonorrhea, according to respondents, is the passing of threadlike substances or worms.

Many of these symptoms and names are identified in the local (Luhya) language, indicating the extent of the respondentsİ knowledge and awareness that many of these diseases are Ïhome grownÓ. The respondents stated that a man has an STD when he begins to experience one or more of the symptoms which may begin to appear as early as two days after infection. However, infection takes much longer (up to 3 months) to mature in women. Some men also go for diagnostic tests in health facilities when they are in doubt of their STD status.

There were significant differences in knowledge of STDs, including types, symptoms, and origin, by place of residence and type of work. Men who live in urban areas and work in the formal sector (who coincidentally are also better educated) have significantly more knowledge about types and symptoms of STDs than their counterparts who are rural and work in the informal sector. Knowledge is also significantly higher among men than women across all subgroups, including residence, age, employment, or marital status.

Knowledge of transmission of STDs cuts across all subgroups. Most of the respondents identified unprotected sex as the main mechanism for the transmission of STDs. Some respondents added that it is not just unprotected sex per se that increases vulnerability to STDs but a selected type of unprotected sex, such as sex with animals, unhygienic persons (e.g., prostitutes), and truck drivers. 
Another means is the sharing of unsterilized needles (injection). Although the majority of participants are accurate in their knowledge of how STD is acquired, there are a few who display wrong knowledge or misinformation about transmission. These respondents identify the following channels for STDs: sharing seats, bedding, clothes, toothbrushes, bath water, bathing sponge, or towels with an infected person; picking coins; kissing; lack of good genital hygiene; and swimming or standing in water. The latter is said to be most characteristic of fishermen. These wrong channels were more commonly mentioned in rural areas by younger women than in urban areas or among older women or men. The limited knowledge of STD transmission in rural areas and among young women provides an opportunity for intervention.

The respondents also identified certain conditions or factors which enhance the spread of STDs. Widow inheritance increases the risks to both the inheritor and the inherited (these are discussed further in the next chapter in the context of HIV/AIDS). Another element is funeral ceremonies that enhance the transmission of STDs because of the concentration of a large number of sexually active people in one place and the freedom of being away from home. According to respondents, this freedom encourages sexual liaisons that may otherwise have been impossible.

Vigorous traditional dances, especially when performed in the night and under the influence of alcohol, increase the urge to have sex and, most of the time, unprotected sex. The participants stated that alcoholism causes people to lose control over their own feelings and action, leading to irresponsible behavior such as unprotected sex.

The participants also stated that sex with several partners increases the risk of STDs since each partner is likely to have different sexual histories and multiplier effects. The menstrual flow is considered ÏdirtyÓ or Ïbad bloodÓ, and sex within the menstrual period is considered an important factor in the spread of STDs. Respondents in one focus group stated, $\ddot{I} \div$ when you are in your monthly period, in most cases when you go with a man ...it can cause you to get infected with that disease.Ó

\section{Prevalence of STDs and Concerns About Risk}

We investigated participantsÌ knowledge of prevalence and their concerns about risk. In order to have a rough estimate of prevalence, respondents in every group were asked to estimate how many men out of ten would have contracted an STD in their communities within the past year. The data revealed that the incidence of STDs is perceived to be almost equally high in urban and rural areas. However, there are gender differences in estimates of prevalence in urban areas. While men estimated that only three out of ten men might have suffered from an STD condition within the past year, women estimated that seven out of ten urban men may have suffered from STDs. In rural areas, the rate is $6 \mathrm{O} 7$ men out of ten on average. The study revealed that availability of services and information makes a big difference in local perceptions of risk and prevalence. Areas (whether rural or urban) with better access to information and services are estimated to have a lower STD prevalence than rural areas with poorer access. However, many respondents stated that it is difficult to estimate the level of prevalence of STDs in the area because many people hide the disease and go for treatment secretly. One participant said: ÏWhen people contract them [STDs] they treat themselves so secretly that you cannot identify those who have itÓ (Kabras, married, male, formal).

Although many of the participants in the area expressed concern for their health, an STD is not considered a major threat to peopleÌs health mainly because of the outbreak of HIV/AIDS and partly because treatment and information are available for STDs. In fact, many respondents stated, ÏAIDS has swallowed up STDsÓ and that STDs no longer presents any major challenge to men in the area because STDs are curable. There are differences by residence in the perception of risk of STDs. The risks for both men and women in urban areas are said to be moderate and declining due to the availability of information and treatment. However, the risk is perceived to be considerably higher among young unmarried persons than older persons who are in union. Women are more likely to perceive a higher risk for men than men are apt to do for themselves. Children ${ }^{7}$ are considered to have little or no risk except if raped by older men. In rural areas, both men and women are considered to have a high risk of contracting STDs but children are considered to have low or no risk at all. However, rural areas with access to information and services (e.g., Mumias) are less worried about STDs than those who have minimal access.

The reasons for the high risk among men and women are different. Among the men, the high risk is said to be due to promiscuity, high income (which enables them to support many partners), and plenty of free time. The following quote is a typical response: ÏThe environment surrounding them ... they are not busy, they have time for chasing girlsó (Mumias, married, female, informal). Another said, ÏIt is high because he can stay with a girl here and again tomorrow he meets another oneÓ (Kabras, unmarried, female, youth). In Kakamega, one participant said that the practice of riem when a man decides to have sex with a woman because he saw another man with her increases the chances of contracting AIDS 
among men. They added that women could not approach men for sex and that this restriction reduces womenİs promiscuity and chances of contracting STDs.

Poverty and poor access to opportunities are cited as the main reasons underlying the risk of women getting STDs. Limited access to opportunities reduces their power and ability to negotiate safe sex. As respondents in one focus group said, ÏWomen do not carry condoms as men.Ó Poverty also increases promiscuity by women. The participants stated that poverty forces many women to engage in illicit sex in order to make ends meet. One respondent said: ÏThe standard of living of women $\div$ women live in not very good conditions. If she gets a man to uplift her she gives in and helps in the spread of the diseaseÓ (Mumias, married, female, informal). In rural areas, men stated that prostitution among young unemployed women who, most of the time, engage in unprotected sex increases their exposure to infections. The risk among younger girls is also attributed to their poor economic condition; they engage in sex to raise money for clothing and schooling.

Some respondents blame lack of family planning among families with large numbers of children for the incidence of poverty, which, in turn, aggravates womenİs economic dependence and their vulnerability to STDs. According to participants, parents who have many children are unable to cater adequately for them. This lack of economic support causes some young women to turn to prostitution as a means of raising money to meet their basic needs. One participant said:

The thing which makes the disease to spread a lot is that someone has failed to plan his family, the children are many, he cannot sustain their needs $\div$ when they go to school, those children are not necessarily bad, but their desire to meet needs for school or clothing press them to go with men with money and those people with money are also those with AIDS $\div$ lust for money makes these children go with these men (Kabras; married, male, informal).

\section{Knowledge About Management of STDs}

Researchers investigated how people in the area manage STD infections. The knowledge of how STDs can be managed is relatively high. Seeking prompt treatment was the most cited manner of management of STDs. However, whereas those in formal employment or resident in urban areas usually are likely to seek treatment from hospitals or local health centers, those resident in rural areas or in informal employment used a combination of modern and traditional medicine in treating STDs. Others engage in self-medication; they buy medicine, mainly antibiotics, from chemists; others get medicine from quacks or Ïbush doctorsó. Yet others seek help from friends who may have been infected in the past and thus suggest medication. Younger men, not in union, are significantly less likely to seek treatment from health facilities than older men for fear of being discovered by their relatives or peers. While married women are afraid that their husbands may find out about their STD status, it is commonly perceived that husbands are the source of the STD in their wives. Treatment of wives is, most of the time, initiated by the husband (and most of the time without the wife knowing what she was being treated for) in order to prevent re-infection. Fear of husbandİs reaction may not constitute major roadblocks to married women who want to use STD services as it does if they wish to use FP (Biddlecom and Fapohunda 1998). ProviderÌs unfriendly behavior encourages self-medication and use of traditional doctors who are considered friendly and sympathetic. Data collected from the facilities serving the communities studied indicated that infected persons do not seek care because they are afraid that they may be discovered or seen by their friends or relatives. STDs are associated with immorality so men often find it difficult to admit their infection. Avoidance of shame and stigma therefore discourage men, young or old, from seeking prompt care before their infection reaches an acute state, creating a gap between knowledge of management and practice.

\section{Prevention and Behavior Change}

Local knowledge reveals ways to prevent STDs or steps which individuals take to reduce their chances of contracting STIs. In particular, researchers investigated the association between knowledge and behavior and whether persons who know their risk of STD do something about it. The literature indicates that knowledge of risk is not necessarily associated with change in behavior in that most of the time there is lag between the acknowledgment of risk and individualİs preparedness to change behavior in order to reduce the risk of STDs.

The respondents considered STDs preventable and are knowledgeable about ways to prevent them. Most of the identified prevention routes are behavioral, corroborating the view that the respondents recognized that STD is a behavioral problem. The most cited ways to prevent STDs and reduce personal risk of infection include the use of condoms, abstinence (especially among younger unmarried persons), being faithful to an uninfected partner, sticking to one partner (Ïzero grazingÓ), avoiding sex with an infected partner, seeking prompt treatment, educating the community including young adults on sex and STDs, and screening pregnant mothers for STDs to prevent infection of unborn babies. 
There is evidence of behavior change in the communities studied. The data revealed that the fear of HIV/AIDS has forced some men and women to take steps to reduce exposure to STIs. Some women stated that their husbands no longer come home late in the night. Safe sex through using condoms, reduction in alcohol intake and zero grazing are some of the steps men have taken to reduce their exposure to STDs. However, it is not known how widespread or profound these behavioral changes are in the communities. For instance, some participants expressed serious doubts about the ability of men to control their sexual urge and to be faithful to one partner. One participant said: İA man is only yours when he is in bed with you otherwise if he steps outside the gate heÌs got another woman. You part at the gate and meet in bedÓ (Kabras, married, female, informal). Also, there is minimal change in cultural practices such as widow inheritance which provide structural support for the transmission of STDs.

The data reveal further that respondents believe that efforts to stem the spread of STDs in the area have to transcend individualsì efforts. Respondents suggested that the government should pass legislation to discourage behaviors and practices that increase the risk of STDs. These include widow inheritance, traditional dance, indiscriminate sex and premarital sex which expose young persons to diseases. There is consensus among almost all groups that there is need to educate youths on how to protect themselves against STDs. They suggested that the government, church leaders, parents, and teachers should collaborate in creating and increasing awareness of risk reduction strategies in order to minimize the incidence and risk of STDs in the communities.

\section{Summary}

The data revealed differential knowledge about STDs by sex and residence. In general, women and those resident in rural areas are less knowledgeable about types and symptoms of STDs than men or those resident in urban areas. Most respondents believe that all STDs, with the exception of HIV/AIDS, are curable; hence, some men tend to underestimate their risk. They say that HIV/AIDS has swallowed up STDs. This type of attitude tends to encourage behaviors that further endanger men. It is known from the medical literature that some STD conditions (e.g., herpes) are not curable and cause long-term health problems. There is a knowledge gap that can be addressed by programs and policies.

There are also differences in perceptions and concerns about risk. Men in urban areas are more likely to perceive little risk to themselves than women or those in rural areas, but younger men who are not in union are perceived to have the highest risk of contracting STDs in both rural and urban areas. In rural areas, the risk of STDs is perceived to be equally high among men and women though for different reasons. While promiscuity, money, and power were identified as factors increasing menİs risks of STDs, poverty was identified as the major factor in womenİs risk status in both urban and rural areas. Poverty, induced by structural inequality in access to income and opportunities among the sexes, predisposes women to engage in illicit sex in order to meet basic needs. It also reduces their ability to negotiate safe sex. The occurrence and implication of such behaviors are much greater among younger women, especially women under 20, single and/or employed than other categories of women.

Overall, opinions regarding availability of services and information make a big difference in concerns about risk. Men and women who live in areas of better access to health services and information are more likely to say that STD constitutes a minor threat to them than those who live in areas with minimal access.

There is evidence of behavior change in the area. Focus groups said that some men have begun to engage in practices (safe sex, sticking to one partner, abstinence) that reduce their risk of STDs. However, it is not clear how widespread or profound these behaviors have been in the communities. Many of the participants stated that men do not take STDs seriously. The exception is HIV/AIDS. However, even in the case of HIV/AIDS (see Chapter 4), many men have adopted a carefree attitude, arguing that campaigns about STDs are propaganda and that none of it matters. The laissez-faire attitude to STDs in Kakamega poses a major challenge to behavioral change, including the utilization of services and practice of safe sex, behaviors that can reduce risk. It also has a significant implication for programs and policies created to induce change. Therefore, there is need for increased information and education about the dangers of STDs. Residents also need to know that HIV/AIDS is an STD and that the existence of an STD condition increases the risk of HIV/AIDS. 


\section{Chapter 4}

\section{Knowledge, Perceptions, and Concerns about HIV/AIDS}

Knowledge, perceptions, and concerns about STDs are further elaborated by looking at HIV/AIDS. HIV/AIDS is singled out for further examination because Kakamega District has one of the highest rates of HIV infection in Kenya (National AIDS and STDs Control Programme, 1996). Knowledge of HIV/AIDS has wide ranging implications for peopleÌs attitudes, especially with respect to utilization of information and services, and the practice of safe sex behavior. As in the previous chapter, the hypothesis is that knowledge shapes behavior. If we understand opinions, perceptions, and beliefs about HIV/AIDS, it may be easier to predict behavior and design programs that can reduce exposure to STDs. We investigated knowledge about HIV/AIDS, including general knowledge of what it is, transmission routes, beliefs and practices regarding management, prevention strategies, and behavioral change initiatives.

\section{What is HIV/AIDS?}

In order to examine local knowledge of HIV/AIDS, a simple question was asked: What do people in this community know about HIV/AIDS? Answers revealed differentials in knowledge by access to information, services, and education. Participants with formal education from Mumias or Kakamega Municipality, the two areas that are better served with information and services and with considerable FPAK presence, are better able to give accurate descriptions of AIDS than those from Kabras. They are also less likely to cite incorrect channels of transmission compared to the participants from Kabras. The limited knowledge about the disease in all three communities has fueled myths about the transmission and/or denial of the reality of HIV/AIDS.

HIV/AIDS was variously described as a disease that has no cure; a fatal disease without boundaries; a disease that depletes human immunity/cells; one that has come from the urban areas; a disease that has come from overseas (brought by the white men) in order to decimate African populations; a natural disaster; or a disease sent by God as punishment for sexual promiscuity. Elaborating on the latter, many men said that AIDS is a sign of the last days, a symbol of the end of the world, something that has been predicted in the Bible. Others characterized it as Eshinjero or Eshinranda $\hat{U}$ a disease associated with serious protracted illness and weight loss, a disease planted by the government in order to reduce adultery. Here are some typical responses:

\footnotetext{
In this community, people know that AIDS is a disease that cannot be treated, and even if you treat it, you will lose a lot of money and it is a must that that person will die (Mumias, married, male, formal).

$\div$ it is a discipline from God because in the days of Noah, people died in water and when it came to Sodom and Gomorrah, they died by fire. On our side, it looks our time is ready, and it is for disease (Mumias, married, male, informal).
}

Because there is a lot of promiscuity God brought gonorrhea and people found medicine for it and also other diseases and people got medicine for them. Then God had to bring a big cane or stick so that even if people try, they cannot cure (Kakamega, unmarried male youth).

$\div$ the government has tried castrating men and women in vain until they brought up this threat of death, so some people have taken it that lets do what we want, if death catches on us, too bad $\div$ (Kabras, married, male, informal).

Some in the urban areas characterized HIV/AIDS as Ïjust another diseaseÓ, like small pox, an accident, or bad luck, and nothing to be feared. Yet others, especially men, expressed the view that AIDS does not exist. They characterized AIDS as the figment of doctorsì imaginations, a ploy to cheat innocent people, or propaganda that exists only on the radio. Unlike these men, most female participants from urban areas described AIDS as a reality and not a lie or witchcraft.

There is a common belief among the rural participants that AIDS is an urban disease that is not common in the rural areas. Those who have traveled to urban areas are most at risk. This perception is consistent with the available statistics which indicate that urban prevalence rates are higher than rural 
rates. Although the local population may not be aware of this statistic they none the less hear of fatalities due to the disease in urban areas. However, it is believed that rural prevalence levels are catching up with the urban levels. Also, data indicated that many infected persons in urban areas retreat to rural areas for sexual escapades which significantly increase the risk of the disease for rural populations.

\section{Beliefs About Origin and Causes}

In the rural areas, most respondents are not certain about the origin of HIV/AIDS. One respondent said, ÏWe in the reserve, when we hear such incidences, itİs like a dream, we donİt know how AIDS came.Ó Most respondents say that white men brought AIDS with the purpose of controlling African populations. Others say that the government created it. Many participants think that it is foreign to their societies. Most said that Uganda is the immediate route from where the disease came into Kenya and that Ugandan men and women who work in cities and rural areas of Kenya are the carriers. Local names given to the disease in the communities studied corroborate the hypothesis that the disease is foreign to the communities studied. These include ÏslimÓ, scheme (related to promiscuity), slow puncture, manila (nylon thread)Ó, odume (bull), Ïletter NneÓ (four letters), Nnane Nnane (8), Ï7+1Ó, ${ }^{8}$ ÏT9Ó, İJimmyÓ (the name of a dog), obwetsa (Ïthe one that has comeÓ), Ïit is the oneÓ. The names also suggest that the disease is of recent origin.

The view that the disease is foreign and of recent origin is contradicted by reports from a few respondents who stated that they have learned from older men that AIDS has been in existent for a long time and was known as Eshinherechere, Omukhongo, Omuyeka, or Ishira. ${ }^{9}$ For example, a few respondents from Mumias stated that only half of the population in Mumias believe that AIDS is a new disease.

Many of the rural populations associate HIV/AIDS with witchcraft. Some male participants said that witchcraft is a preferred explanation for AIDS in the rural areas because people do not want to accept that they have the disease even when they have been scientifically proven to have it or that it exists in their area even when they know or have seen someone who died from it. By attributing AIDS to witchcraft, many victims and their families are able to avoid the ostracism and shame associated with the heavily stigmatized AIDS. Belief that AIDS is witchcraft is more common in Kabras, perhaps because of greater access to information and services in Mumias. It could also be because Mumias is more developed and urban than Kabras. However, the belief that AIDS is a punishment for breaking taboos, including incest or sex with fatherÌs wife or concubines (described as Ishira or curse), by God or the ancestors is common in all the communities studied. As some participants from Kakamega stated: ÏYou get a person sleeping with his mother, his sisters etc. Now the gods $\div$ are annoyed and that is why they bring those diseases.Ó

In both rural and urban areas, persons of low education are less likely to believe that there is AIDS or accept that people are dying or can die from it. AIDS is a heavily stigmatized disease and sufferers experience considerable ostracism. Some stated that it is this stigma that has made AIDS impossible to control because most people hide once they think that they have the disease. Others engage in increased sex in order to create the impression of well being. In the process, a man distributes the virus to many others.

In general, men in rural areas, especially in Kabras, complained about a general lack of knowledge of AIDS (what it is and how it is manifested). The same is true of the urban areas among persons with little or no education. People say no one has died of AIDS but people die of other diseases such as malaria, tuberculosis and diarrhea. People in both urban and rural areas are not aware that AIDS increases susceptibility to these opportunistic diseases, and hence it is difficult for them to believe the information on HIV/AIDS and to modify their behavior based on that information. Therefore, it is necessary to intervene and increase knowledge about AIDS.

\section{Knowledge of Transmission}

All respondents were asked to discuss how the disease is acquired in their area. The most popular transmission routes identified by almost all respondents are sex with multiple partners or prostitutes, use of unsterilized needles, circumcision knives, sharing of razor blades, blood transfusion, and perinatal transmission. Other routes that were mentioned mostly by women in rural areas include kissing, shaking of hands; sharing of toothbrushes, bathing water, cooking utensils such as spoons; eating of vegetables (spinach) and/or fruits (such as oranges), overeating of different types of foods at the same time, and condoms. The latter is mentioned mainly by male respondents who believe that condoms are laced with HIV/AIDS (see Chapter 2). There is a common belief in both rural and urban areas that vegetables and fruits have been injected with AIDS. It was pointed out in Chapter 2 that the notion that local fruits, vegetables, and condoms are laced with HIV is probably due to the prevalence of the 
epidemic in the district. The high prevalence may have led many to associate HIV/AIDS with food, sex, and condoms.

Some of the practices identified as increasing the transmission of HIV/AIDS in the area include circumcision, widow inheritance, polygyny, and sex with school-age girls. Except for circumcision, the mechanism by which these practices increase the spread of HIV/AIDS is through sex. Sex with schoolage girls (some of whom are paid as little as KSh 40 for their services) is practiced by men who consider these girls to be too young or innocent to have HIV/AIDS. However, most respondents said this belief is no longer popular and that men now prefer married women because they think that married women are free of AIDS.

Widow inheritance is considered an important route. However, the belief about widow inheritance is not as common in the urban areas as in the rural areas. One participant from Mumias stated: ÏIt spreads because you might find that so-and-sol̀s husband died of AIDS and people donÌt believe it. So now, your husband comes and inherits her. When he comes back from there, he infects youÓ (Mumias, married, female, informal).

Polygyny enhances the transmission of HIV/AIDS because inability on the part of some polygynous men to satisfy each wife sexually increases the tendency, among those women, to seek sexual gratification from extramarital relationships, which in turn, increases exposure to HIV/AIDS. Also, the number of women/persons who are simultaneously infected by a polygynous man is higher than in monogamous marriages.

When asked whether these practices were good or bad for their communities, most of the respondents were selective in their answers. Practices such as widow inheritance and extra- or premarital sex with young school-age girls were condemned, but circumcision was not. Sex with young girls is believed to increase their exposure to STDs. The respondents suggested that the government should pass legislation that will enable society to punish those who engage in such practices. Responses on polygyny follow gender lines. While most men think that the practice is not inherently bad, most women said that polygyny is bad and should be banned. Although the majority of the participants suggested that wife inheritance is bad and should be discouraged, many women stated that the practice should be preserved because of the protectionÛemotional and financialUit gives women and their children. Thus it was suggested that, rather than abrogate the practice, widows and their inheritors should undertake an HIV test, and if either is seropositive, they should be counseled on safe sex behavior. Others argued that widow inheritance reduces infection because uninherited widows develop sexual liaisons that extend beyond her traditional compound, increasing the risk of infection to herself and other sexual partners.

Researchers also investigated local knowledge about the symptoms of HIV/AIDS. Respondents were asked: How does a person know if he or she has AIDS? Most respondents said that the only way to know oneÌs HIV/AIDS status is through a blood test in a hospital. Some participants stated that this procedure is not foolproof because the testing kit could give false results if faulty and some doctors could lie about it. One respondent said that the machine is like a computer: it will show whatever is fed into it, and someone who does not like you may say that you tested positive whereas you really tested negative. Another woman said that the test result depends on oneÌs state of health. If one has a cold when the test is taken, the result could be opposite once the cold clears.

Other ways a person can determine HIV/AIDS status is if a sexual partner has tested positive for AIDS or has had a blood transfusion in the past. Others, when they suspect that they may be having the virus, decide to have a baby with the hope that if the child survives the first two years of life, this confirms that they do not have the virus.

Most respondents said that it is difficult to know oneÌs HIV/AIDS status because most people go to the hospital only when they are sick with full-blown AIDS. Some of the symptoms of AIDS are associated with other diseasesÛmalaria, tuberculosis, skin diseases. Most respondents in the rural areas have difficulties identifying the symptoms of AIDS. However, participants from Kakamega Municipality identified the following: continuous headaches, stomach aches, chest pain, diarrhea, vomiting, weight loss, general body weakness, coughing, genital sores, reddening of lips, hair loss, and skin rashes.

\section{Concerns About Risks}

In order to obtain perceptions of risk of HIV/AIDS in the communities, men and women in focus groups ranked the chances of men, women, and children in their communities getting AIDS as high, medium, or low and explained why. Most respondents, men and women, from Kabras and Mumias divisions stated that the risks for men and women are high but low for children. The reasons for the high risks are different for men and women. While male participants stated that promiscuity among men and women is the main reason underlying their risk, the women stated that husbandsİ promiscuity is the key factor in womenİs HIV/AIDS risk as shown in this quote: ÏThey [men] cut sugar cane and after that they get the 
money, they make love with girls with that money, $\div$ when a man comes from there and enters in the house, he will ask you [for sex], you cannot refuse him, and when you give him, when he has that disease, he will infect youÓ (Kabras, married, female, formal).

Also, menİs denial that there is anything like HIV/AIDS increases the risk to the wife or partner. Others blamed the lack of self-restraint among husbands for the high risk of HIV/AIDS among wives. This response from one of our participants sums it all up: II- when men go out there to drink, when they get in the bar, he gets carried away and when he sees those girls that serve him well and maybe at home the wife does not treat him like that, they get carried away and they stop giving a damn $\div$ they feel even if I die, so what?ó (Mumias, married, female, informal).

Married women whose husbands have moved to urban areas for employment are considered to be at a greater risk than those who live with their husbands in the rural areas. The argument is that those husbands may contract HIV from urban areas and infect their wives when they return to the rural areas. This view is consistent with the widespread notion in this area that HIV/AIDS is an urban disease and that those who live in urban areas are more at risk than those who live in rural areas.

In Kakamega Municipality, opinions are divided as regards the relative risk of the disease to men and women. While some men say that the risk is high, others say that the risk is low. Those who say that the risk is high cite widespread promiscuity among men and women and alcoholism among men to support their claim. According to our respondents, alcoholism and ÏcarelessÓ sex go hand-in-hand: $̈$ of course he knows there is AIDS but after taking about three bottles, he starts coveting the ladies next to him, then he goes with themÓ (Kakamega, unmarried, male, youth.

Others, especially those living near the major inter-country highways, cite the frequent presence of truck drivers in their area as increasing the risk to women. Another reason is Ïsugar daddyship.Ó Younger women who befriend sugar daddies for money are said to be highly vulnerable to HIV/AIDS. Promiscuity among women is attributed to poverty and lack of information about safe sex. Poverty is a double-edged missile in that it increases the tendency to sell sex and at the same time reduces womenÌs ability to negotiate safe sex in both casual and regular sexual relationships.

Those who said that the risk of HIV/AIDS is moderate to low cite the decline in number of casual sex partners and infrequent visits to the bars as the main reason. The bar is seen as the storehouse of HIV/AIDS in the communities because, according to the participants, most bars are staffed with single girls or prostitutes from Uganda. Most of them are believed to carry the virus that causes AIDS. Thus, many people believe that sex is safe as long as it is not with any of those women. However, all women in the focus groups stated that the risk to men in urban Kakamega is high.

There is a consensus that the risk to children is low or nil, but participants with medical background stated that inadequate supplies such as gloves, shortage of personnel (especially in maternity wards), and poor disposal of used surgical needles increase the exposure of young children to the risk of HIV/AIDS. However, girls in their teens are believed to be at very high risk because many are sexually active, being used by older men for sexual gratification.

\section{HIV/AIDS Infection Management and Behavioral Change}

The study also sought to determine local knowledge about management of infection, symptoms, prevention, and behavioral change. Data on management of AIDS are scant, perhaps because of the newness of the disease or the lack of understanding of its symptoms. Data revealed that management strategies include proper dietary practice (balanced diet), use of traditional medicine, and counseling.

Prevention strategies were discussed at two levels: micro and macro. At the micro-level, respondents discussed what individuals are doing or can do to reduce their risk of HIV/AIDS, while discussion at the macro-level focused on what the government can or must do. Individuals can practice safe sex behavior such as sticking to one partner, avoiding sex with distrustful partners, using condoms, avoiding non-sterile needles; and using one circumcision knife per client. Only one male group in Kabras mentioned the use of condoms as a preventive strategy. Some precautionary measures are suggested for medical practitioners such as use of gloves when taking delivery of new babies, screening blood before transfusion, and being careful when handling open wounds. Other precautionary measures include community education and sex education for children in order to increase the awareness of the disease in the area, and HIV/AIDS screening for potential couples and would-be sexual partners.

Preventive strategies at the macro-level include the seclusion of seropositive persons, removing prostitutes from the street, outlawing polygyny, encouraging marriage at younger ages in order to reduce the number of unattached young adults, and routine screening for those planning marriage. Other suggestions touched on what the government can do to increase access to risk-reducing information and services. These include community education to change risk-enhancing beliefs and practices. It was suggested that such education should be extended to school-age children because education oriented to changing behavior must begin at an early age. 
Further discussion revealed that although there is lots of concern about contracting HIV/AIDS, real change in behavior has been minimal. A few individuals have reduced alcohol consumption, time spent in bars and number of partners. A few individuals planning a long-term relationship now agree to prenuptial AIDS screening. Some are abstaining. Some patients now carry disposable needles to the health centers in order to avoid injection with non-sterile needles, but these are very few. The majority, according to the female respondents, does not care.

To further explore this ÏdonÌt careó phenomenon, respondents were asked why those who know their risk and ways to prevent HIV/AIDS do not always engage in behavior that will reduce their exposure to infections. There were no major differences in responses across socio-economic strata. One major theme that emerged from female respondents is that people, especially men, have adopted a laissez-faire attitude to the question of HIV/AIDS. Data indicate that many do not believe that AIDS exists. As one respondent stated, $\ddot{\mathrm{I}} \div$ they take it as a joke $\div$ they do not care.Ó Others say that AIDS is like an accident: anyone can get it. Others argue that their immune system is strong, while others believe that they have to be in the same blood group as their sexual partner in order to contract HIV. Others simply say: $\ddot{\mathrm{I}} \div$ even if AIDS does not kill you, stagecoach will kill you, malaria will kill you, cancer will kill you $\div$ it is just death and you cannot resurrectÓ (Kakamega, married, male, informal).

The question then is: Why bother to change behavior? These men need to be taught that death by AIDS can be prevented. The lack of behavioral change among women is attributed to poverty among those who sell sex for money. Another reason is frustration. Some individuals are frustrated with life, and HIV infection provides a route to die, a sort of suicide some people undertake to end their frustration. Such people persist in reckless behavior in spite of their knowledge about risk and prevention. There is the belief in uncontrollable sexual urge. This relates to the myth of Ïhot bloodÓ in some people who have insatiable appetites for sex. For these people, knowledge does not always have any effect on their behavior. One man stated that one has to be a eunuch or moralist in order to prevent HIV/AIDS infection. For some there is the fear of Ïdying aloneÓ. Some people engage in intentional transmission if they know or suspect that they are HIV seropositive in order to create company in death. These people are motivated by the desire not to die alone. Such individuals are reckless in their behavior no matter their knowledge of HIV/AIDS and preventive strategies. Some believe that increased sexual activity can rid the body of the virus that causes AIDS. Therefore, rather than reduce their sexual activity, many seropositive men increase it. Another reason is suspicion of seropositivity. Some people suspect that they may already be carrying the virus because they know that someone whom they had sex with in the past has tested positive or died of AIDS. Others engaged in risky sexual behavior before they knew about AIDS. Most of these people are not motivated to engage in risk-reducing behavior. As one person said, ÏIt is because AIDS was discovered recently and there are some who have already rioted (promiscuous) $\div$ have already got it $\div$ so they say, let me just continue riotingó (Mumias, married, male, formal). Alcoholism and peer influence are additional reasons. The prevalence of certain traditions and beliefs about divine causation or witchcraft have increased the spread of AIDS. Some engage in fatalistic rationalization regarding death, that it is Godİs plan and that it does not matter how it comes. Such beliefs lead individuals to resign to fate. The argument is that these forces are transcendental and omnipotent and cannot be manipulated. High prevalence of AIDS encourages inaction and fatalism among those who think that they will get it no matter how much they try to avoid it. Many of these reasons can be summarized as due to alcoholism, poverty, peer influence, and fatalism.

\section{Summary}

Although there is low overall knowledge of HIV/AIDS, including symptoms and prevalence, knowledge is much higher in urban than rural areas. Also, there is considerable misconception about origin and causes of HIV/AIDS, gaps that can be filled by programs that focus on improved and increased knowledge about HIV/AIDS. Although most of the participants have the correct information regarding transmission routes, misconceptions and misinformation about transmission are widespread, especially in the rural areas. Places with better access to information and services (that is, urban areas) have more correct information about the reality, origin, causation, and prevalence of HIV/AIDS than those with poor access to services and information.

There is considerable concern about risk of acquiring AIDS, although differences exist in the perception of risk by sex and residence. However, this fear has not translated into profound changes in behavior. Nevertheless, there is evidence that a few men are undertaking preventive strategies such as sticking to one partner, reducing alcohol intake and nights in bars, and undertaking safe sex behavior. The study reveals that gaps in people's knowledge about HIV/AIDS, its reality and prevalence as well as poor availability of services and 
information contribute to persistent behaviors that enhance the risk of HIV/AIDS in the communities. 


\section{Chapter 5}

\section{Spousal Roles in Reproductive Health}

The study investigated different dimensions of spousal responsibility and roles in maintaining own reproductive well being and that of the spouse. These dimensions include spousal discussion of FP and STD/HIV/AIDS infections and treatment and response to own or spouseÌs infections and notification. Each of these dimensions is crucial to understanding the dynamics of spousal negotiation and decision making about FP and disease prevention. Another objective is to develop some insight into how spousesİ responses to own or partnerİs infections could inform programs on how best to intervene in order to promote the health of the family.

\section{Family Planning}

Spousal Discussion of FP

All the focus groups were asked if spouses in their communities found it difficult or easy to talk about FP or ways to avoid or delay a pregnancy. The responses were similar across sub-groups. Almost all discussants agreed that it was usually difficult to initiate talks on FP and that men were generally opposed to its use. The female groups, in particular, said it was very difficult for them to initiate talks on FP use with their husbands or partners. The reasons are discussed below.

Men think that women are the obstacles to spousal discussion of FP. They argued that many wives are concerned that their husband may be planning to marry another wife, increase the number of casual sex partners, reduce marital coital frequency, or raise children from extramarital relationships. Additionally, women are worried about their marital security, given the prevalence of polygyny in the area. They consider a large number of children as obstacles to multiple marriages since the man would have to think about the financial implications of additional children. In view of this, women are not receptive to FP discussions until they have raised the number of children they consider sufficient to guarantee their marital and economic security. In view of this, men avoid discussing issues of FP with their wives in order to avoid suspicions. These views are expressed in the following quotes:

The difficulty is that the moment you tell a woman that we use FP, she may think that you want to reduce the number of children you are having with her so that you can marry another wife. Secondly, she thinks that using FP leads to a reduction in the number of days you are going to have sexual intercourse. Also, she thinks that you are reducing here (at home) to increase outside (casual relationships). You see $\div$ when you do FP, she sees it as a reduction in the number of children that you are going to have $\div$ (Kakamega, married, male, formal)

$\div$ As a community worker, I have observed that issues on FP are difficult because a woman believes that if she goes for FP, and stops giving birth, her husband will marry another wife $\div$ (Kabras, married, male, formal).

Some men attribute the reluctance by women to engage in FP discussion with the spouse to the persistence of traditional and Christian beliefs which criminalize FP, reducing its acceptability in local conversations. One participant stated: ÏI feel it is a bit difficult because many women in this area go to church. And these are churches with a lot of traditional beliefs in regard to the Bible, that God said Îve multiplyİ $\div O$ (Kabras, married, male, informal). However, women seemed to think differently as one woman from Mumias stated: ÏHe tells you that if you do not want to give birth I will marry another one,Ó indicating a real fear that a husband could be planning to marry another wife when broaching the subject of FP. This view is supported by the following quote:

It is difficult $\div$ In this community men are used to marrying many wives. So when a man tells the woman to control birth, she will accuse him of wanting to marry a second wife, causing disagreements. If the woman gave the suggestion, the husband accuses her of having another man outside and that is why you did not want to give birth. It therefore becomes hard for these people to agree on FP. Very few accept easily, but the rest end up in arguments (Mumias, married, male, informal).

Participants in most groups stated that men are not ready for FP; they believe that it is womenIs business. Many men are opposed to contraceptive use. Broaching the topic of contraceptive use with them could result in disagreement or even violence, as a female participant stated, ÏMen do not take 
care of children; they take care of numbers.Ó Others are also concerned about the sex composition of their children. The following quote summarizes these perspectives:

\begin{abstract}
$\div$ Men are not ready for FP, because they believe that FP is for women $\div$ We have got those who do not realize the importance of taking care of children. He only thinks of numbers. Lastly, it is giving birth to different sexes of children. There is one who may have given birth to only girls, now if you tell him to go for FP, he will say he wants a boy. He will give birth to boys even until he reaches 30 children. There is another who may have given birth to boys only. Maybe he can say, ÎI am just looking for at least if God can give me a girl child.Ì He will continue giving birth and if you tell him about FP, you cannot convince him. Because I have tried ... I have even been in an FPAK seminar and I have walked in communities as a CBD $\div$ Trying to tell them (men) to go to Kholera House (FPAK male clinic) is difficult (Kabras, married, male, formal).
\end{abstract}

Some men also pride themselves in being able to make a woman pregnant. It is like establishing control and hegemony over the woman. As our participants stated, when a woman stays for a long time without becoming pregnant, people conclude that the man is weak or impotent. When a woman is pregnant, it shows the man is potent. As one man said: ÏIt is difficult because $\div$ some men praise themselves when they get many children and if a woman stayed for long without a pregnancy, they conclude that the (man) is weak. To them (men), when a woman is pregnant she has been disciplinedÓ (Mumias, married, male, informal).

Misconceptions and misunderstandings about FP among men also contributed to limited spousal discussion about ways to prevent unwanted pregnancies. Many men think that wives who remain beautiful and attractive may be taken by another man. This reality often results in suspicions, accusations, and counter-accusations when a spouse raises the issue of FP. Infrequent childbearing is believed to enhance the chances of women to look good and attractive as the quotes below indicate:

I think they find it difficult particularly here in Ekero because men and women have a lot of misunderstanding about FP (Mumias, single, male, youth).

I know that there are some men who have married women and they donIt trust each other $\div$ Some men think that if I donÌt make her pregnant $\div$ she will be followed (seduced by other men). So he sees that if a woman just stays nicely without a pregnancy $\div$ other men will Îenvyİ her and they will grab her if she uses FP and comes back on fashion (becomes youthful) $\div$ So we have to make her pregnant all the time so that she becomes too old (Kakamega, married, male, informal).

The desire to avoid suspicions, accusations, and counter-accusations of infidelity, secret marriage plans, and/or disagreement often lead spouses to avoid discussing FP matters. Participants stated that only a few spouses are able to discuss and agree on FP issues. The majority often end up in marital feud because people have not adopted the idea that marriage is not just about having children but is also for companionship, friendship, and love.

Another reason is the limited education among some spouses and/or gaps between amounts and time periods of spousesİ education. These factors often reduce the potential for couples to understand each other as revealed in this quote: III think it is according to the level of education $\div$ Those ones who find it difficult to talk with spouses are mostly primary school and probably secondary school dropouts $\div$ Ó (Kakamega, unmarried, male, youth).

Spousal discussion about use is associated with contraceptive uptake. Factors that inhibit use of FP also hinder discussion about whether or not to use it. These include traditional beliefs, customs, and practices such as sex preference (the desire to have at least one son who could inherit oneÌs homestead) lineage immortality, old age security, polygyny, naming practices (which require that ancestral names be kept ÏaliveÓ through children), pressure from extended family (especially grandparents and parents-in-law, and the persistent emphasis on womenİs reproductive rather than productive roles (see Chapter 2).

Only a few participants in four groups said that spouses find it easy or acceptable to discuss about FP. They argued that economic hardship high cost of food, clothing, education, and healthÛhas made men more receptive to FP. Others stated that mass education increased individualsI awareness of FP and the disadvantages of frequent child bearing.

Spousal FP Decision Making

The desirability of joint spousal FP decision making in the area was examined. Specifically, we were interested in finding out whether men and women want their spouses involved in reproductive decision making. The data revealed that respondents considered it desirable for both the husband and the wife to be jointly involved in reproductive decision making. This view cut across every subgroup regardless of age, sex, residence, and sector of employment. Various reasons are given for this response. Firstly, child bearing is the responsibility of both partners in a couple and as such the woman and the man 
should be jointly involved in decision making about family size or contraceptive use, including who should use (husband or wife) and which method to choose. The increasing cost of child rearing also makes it necessary that spouses plan family size together as a couple. Secondly, joint spousal decision making facilitates the selection of a suitable contraceptive method, an opportunity often missed when spousal resistance, real or perceived, leads women to use contraceptives secretly. Thirdly, it helps to avoid violence which could ensue if the husband finds out that the wife had taken a unilateral decision to use contraceptives, especially when the side effects of a method cause contraceptive use to show. If spouses jointly decide on use, then both partners understand and assist each other when one is suffering from harmful side effects as revealed in this quote: ÏA fight might break up in the house because he never wanted it. So it is better for you to discuss and agree and then you go. And sometimes you can go and you get side effects. When you fall sick he will dump you and say you went without my knowledge $\div$ Ó (Kakamega, married, female, informal). Finally, joint spousal decisions increase love between couples.

To further examine the dynamics in decision making on family planning, researchers asked men whether they need spousal permission to use FP. All the male groups emphatically and spontaneously said, İNoÓ. The male groups said that the man is the head of the household and the overall authority with regard to all household matters including reproductive decisions. Men could discuss with their spouses but do not have to seek permission. Asking for permission was seen as a reversal of the locus of power in the household. There was a consensus across all subgroups that a woman must follow a manİs decision and that the husband has the final say, as the following quote reveals: $\ddot{\mathrm{I}} \div \mathrm{A}$ woman is a person who has been married into another home. So when you explain to her, she will accept $\div$ because she must obey the rules that I will provide $\div$ I am the driver (decision maker) in issues of family size $\div$ Ó (Mumias, married, male, formal).

A few men in four groups indicated that men should ask for permission from their wives or partners because family planning decisions involved both partners, and furthermore, joint decisions reduced unfaithfulness and suspicions between partners. However these views were dismissed by other group members who argued that only men who are ÏweakÓ or have been Ïsat onÓ by their wives would ask for their permission to use family planning. In other words, asking for the wifeÌs permission in order to use family planning is a sign of weakness.

We also asked women if their husband seek their permission in order to use contraceptives. Consistent with the male responses, most women said that husbands do not consult wives with regard to contraceptive use unless they are considering a female method. The women added that men generally use condoms with outside partners, a view that was also confirmed by the men. A typical response is: ÏWhich man will come to you for permission? He is the boss. He is the king post of the house. He is the decision maker. He is the head of the house. He is like the president and so the overalló (Kakamega, married, female, formal). Another woman said, ÏHe will ask you whether that homestead is his or yoursó (Mumias, married, female, informal). However, almost all female discussants said that their spouses should seek their permission to use contraception because FP should be a joint spousal responsibility and that such discussion would also deter men from extramarital child bearing.

Spousal Disagreement and Conflict Resolution

As evident from the analysis presented above, joint decisions are often not realized because reproductive decisions tend to be dominated by the husband. Respondents stated that conflict is common when spouses cannot come to an agreement on one or many reproductive issues. Various examples were given as common grounds for disagreement.

\section{Divergent Desire for a Certain Number and Sex of Children Between Couples}

When either the husband or the wife has not achieved the desired number and sex of children wanted, joint decision regarding contraceptive use could result in a fight. However, data reveal that it is the menÌs desire that is often problematic. Available data reveals considerable concordance in the fertility preferences among couples in Kenya and where there is a divergence, the men are more likely to want more children than the women (Bankole and Singh 1997). Data also reveal that women are the ones who use contraceptives, not the men. An example is cited:

There are cases where the wife wants to plan but the husband is opposed to her use of FP. They also disagree over the number of children they should have. In cases of wealth, the parents would want their son to give birth to several male children to inherit the wealth. But if they have $\div$ only one son and several daughters, the wife may want to use FP but the husband will be opposed (Mumias, single, male, youth).

\section{Disagreement on Who Should Use or Which Method to Use}

This disagreement is most often associated with menİs resistance to FP. The participants attributed this resistance to ignorance or lack of correct information and gender gaps in formal education levels 
between spouses as shown by the following response: ÏConflicts come from men because women $\div$ are the ones who use those methods so much. So I think the men of this community do not favor so much the idea of family planning. So the difficulty comes from the menÓ (Kakamega, married, male, formal).

\section{Side Effects and Failure of FP Methods}

Disadvantages of FP can be grounds for disagreement as the following quote shows: ÏYou can go for a FP method which can make you ÎhotI and another that can make you like Îsour milkÌ (reduced sexual desire). Even when the man asks for sex you refuse completely because your body is Îcoldİ. So that is when a quarrel starts in the houseÓ (Kabras, married, female informal).

\section{Distrust, Unfaithfulness and Lack of Commitment}

Suspicions between spouses can prevail. If suspicious about outside partners, women will fear that their husbands could marry another wife if they stopped bearing children or underwent TL. Related to this are instances in which the husband forces the wife to go for FP when he has ulterior motives; for example, a husband asks the wife to go for TL and he turns around and marries another wife as indicated in this quote: ÏSometimes husbands force their wives to go for FP with a wrong motive so that the wife stops giving birth and thereafter he marries another one. He might be intending to marry three wives so that each woman gives birth to two children $\div$ Ó (Kabras, unmarried, female, youth).

\section{When the Husband Discovers That the Wife is Using Contraceptives Secretly}

Some wives resort to secret use when it becomes difficult to convince a husband of the need to plan their family. One participant narrated an incident which occurred in the area:

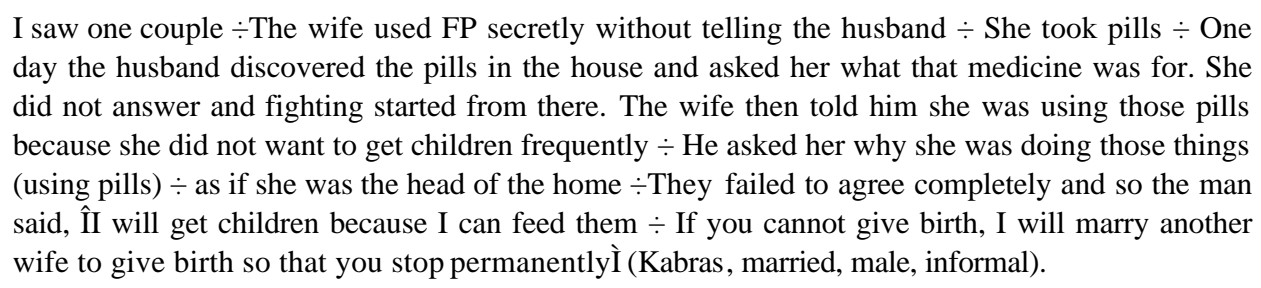

Other reasons that were cited as common grounds for conflict include prevalence of traditional beliefs and practices, pressure from extended family members, competition among co-wives in the number of children, different religious beliefs, practices that are supportive of large family sizes, and different spousal concerns about childrenÌs future and welfare.

The discussants were asked how conflicts or disagreements about whether or not to use FP were solved. The responses did not differ among the various subgroups. The main method for resolution is third party intervention by a family member (elders, parents, brothers, aunts, uncles), friends, family planning counselor, religious leader, or local administrator such as the chief, assistant chief, village headman. It is interesting to note that family planning providers are sometimes brought in to advise the dissenting partner. This finding is consistent with data from the health facilities.

Sometimes there is the use of force if the woman refuses to acknowledge the husbandİs authority. Most female participants stated that the husbandİs decision prevails and would always be followed by the woman whether she agreed or not because the man should decide and it is the wifeÌs role to accept what the husband decides. Some women said they would just continue to give birth if that was the desire of the spouse. A few men said that they would use persuasion or Ïsweet-talkÓ to convince the wife. Other couples Ïleave the decision to GodÓ, saying that experience will teach the disagreeing spouse a lesson. One participant stated: $\ddot{\mathrm{I}} \div$ Some couples just leave the problem to be solved naturally, $\div$ When they find that children have no clothes, do not go to school $\div$ they then decide to use FP when life becomes difficult $\div$ Ó (Kabras, married, male, informal). If a conflict arose from harmful side effects, the couple could simply change to another method or go for counseling. But if the woman is using FP secretly, continuation becomes problematic if method side effects cause secret use to show. Some women use secretly in order to manage the husbandİs resistance. In extreme cases, such as when there is total resistance by the husband, the conflict is resolved through separation or divorce.

\section{STD/HIV/AIDS Prevention and Management}

Spousal Discussion about STDs

Spousal communication on reproductive health issues was further explored by examining whether it is easy or difficult to discuss STD risk and prevention. There were no subgroup differences in the responses. Almost all the participants, men and women, stated that STD matters are almost never discussed between spouses. The lack of such discussion hinges on the fact that STD touches the heart of marital relationshipUtrust. The data indicated that STD connotes unfaithfulness and challenges 
marital trust in that it indicates that one of the spouses is involved in an extramarital relationship, a reality that neither men nor women want to confront. Although it is generally believed that men engage in extramarital affairs and are likely to contract STDs and infect their wives, men do not want this reality acknowledged or discussed. Therefore, they avoid the discussion of STD issues in order to avoid the possibility of being directly accused. Even though male infidelity carries no penalty, except of course if the man acquires AIDS, it is, however, not socially acceptable.

Data revealed that although trust is the foundation of marital relationship in the communities studied, it is the wife who has to be trusted, not the man. In general, men said they trust their wives and so thought that they were not at risk. Women do not trust their husbands but are afraid to say so. In order to explore this issue of trust further, the team asked whether married men and women in the area have outside partners or visit prostitutes and whether this practice is acceptable in the community. There is unanimity among all respondents that extramarital and premarital partnerships are unacceptable but that they are common among men. Although some married women engage in extramarital relationships, the prevalence is much lower than among men because women receive punishment, including public humiliation, abuse, violence, divorce or separation for sexual transgression. Furthermore, society frowns on extramarital courtship among women. However, society is permissive of such courtship among men. This permissiveness and the absence of punishments for men gives the impression that male infidelity is socially acceptable. It suggests that women should be pious but that men can continue in their sins.

Some men described the absence of sanctions against male infidelity as an expression of societal powerlessness to control male behavior. However, the key factor in the differential treatment of male and female infidelity is unequal access to power and decision making. Men are the custodians and enforcers of traditional norms and mores. Therefore, it is their prerogative to determine which norms to enforce.

There is also the fear that the wife may retaliate by engaging in extramarital relationships. For instance, among educated spouses, one of the reasons why the husband will not discuss the issue of STD is the fear of creating suspicion about his own behavior which could in turn motivate the wife to retaliate. In fact, many of the participants stated that the motivation to retaliate accounts for infidelity among women.

In general, wives and other women in regular relationships are reluctant to broach issues of STD with their husbands or partners because they do not want their credibility to be in doubt. Husbands could become suspicious that the wife is engaging in an extramarital relationship or become violent because the wife is suspecting him. Therefore, the fear of being accused or suspected of engaging in illicit sex is a major constraint to the discussion of STD and HIV/AIDS risk and prevention among many couples. By remaining mute, couples avoid accusations and counter-accusations that could cause violence or destroy marital bliss. These views are captured in the following quotes:

It is difficult $\div$ it depends on the man. Because, it is mostly assumed that the men are the ones who have outside partners. So if you know that you probably have outside partners, you would not like a thing like that to come up at all (Kakamega, married, male, formal).

As a woman you will ask why he has decided to tell you about STDs. You will start suspecting that he has an STD (Mumias, married, female, formal).

It is like touching electricity (discussion of STDs). If you tell her it will be like telling her you are unfaithful $\div$ Most families lack harmony. If a wife starts the topic, she will be rebuked and asked to explain why she suspects he is unfaithful (Kabras, married, male, informal).

No, it is not easy because they believe they are faithful to each other $\div$ So we do not talk about STDs (Kabras, married, male, formal).

The lack of discussion of STD issues has a cultural dimension to it. Culturally, sexual relations were always taboo topics and were never discussed among men and women, irrespective of marital status. However, in the past, there were also structures in place to punish sexual transgressions. For instance, when a husband infected the wife, she was free to report the matter to her own parents (it was rare to find a wife infecting the husband). The issue was then tabled in the committee of elders and if the husband was found guilty, he was fined one cow that had to be paid before he was allowed to have his wife back. Repeated infection of oneÌs wife could result in divorce, with the wife returning permanently to her parents. So, even though sexual matters were not discussed among couples, there were ways in which a couple could seek redress if life was endangered. Such mechanisms no longer exist today, yet people hold tenaciously to the culture of silence on sexuality. This persistent silence in the absence of a framework for punishing sexual transgression makes it difficult, if not impossible, to discuss STD 
matters. Some husbands use violence in order to keep the wife quiet. Furthermore, the participants said that spouses discuss respectable issues, not nonconventional subject such as sexual matters. It is very difficult to discuss sexual matters as captured in these quotes:

$\div$ Going back to past ages since the time of our ancestors and grandfathers, if the man brought STD to his wife you gave a certain fine which was to serve as a punishment to the man and if it was the woman, there was also punishment which was given $\div$ But these days even if you bring a disease in the house, you become harsh $\div$ (Kakamega, married, male, informal).

Here women have been told we cannot command men on how to behave outside. So we are told to Îwalk wellì but they themselves can ÎwalkÌ the way they want. It is never easy to get a couple seated and the wife telling the husband please let us ÎwalkÌ properly (Kabras, married, female, informal).

Other reasons for poor discussion of STD matters among couples include low levels of education among couples and lack of information, knowledge, and opportunity. Some men stated that poorly educated persons lack the knowledge and skills to engage in discussions of STD risk and prevention.

Some men also consider discussing RH matters with their spouses as relinquishing power to them, and most men do not want to be seen taking advice from women. Some women would like to discuss STDs but the opportunity does not present itself. When the husband is not confrontational, he is not available: if not at work, he is at the bar. As participants said, $\ddot{\mathrm{I}} \div \mathrm{I}$ think women or wives prefer to talk about STDs but husbands take it as nonsense. Men are very proud and they cannot accept any advice from their wivesÓ (Kakamega, unmarried male youth); and İIt is hard because we have some men who will not come to the house after work. He will go to drink alcohol. He comes drunk and leaves early for work. So the opportunity does not avail itself $\div$ Ó (Mumias, married, female, formal).

The respondents identified some circumstances under which STD issues are broached, such as when there is love, trust, and respect between the partners, or when both spouses are educated and aware of the risk of STDs. In this case, STD prevention is discussed as an issue of mutual interest to both partners. Discussion may occur when there is a strong suspicion that one of the spouses is unfaithfulÛmost likely if the wife is being suspected or when the wife has some information that the husband is engaging in an extramarital relationship. In such cases, high degree of mistrust often triggers the discussion. Communication here takes the form of one spouse warning the other to apply caution. When the wife is the one giving such warning, she is likely to be educated and have a formal sector job. The men usually respond by being harsh, confrontational, and at times violent, believing that if they allow discussion it is the same as accepting that they had extramarital affairs. So, although the issue may be broached, it is never really discussed. Formally educated couples who have access to information about STDs from multiple sources find it easy to talk about them. Discussions will occur when the spouses are concerned about the risk of HIV/AIDS.

There is a notion that STDs are not a serious problem since they can be treated. This notion contributes to the lack of discussion of STD in the area. Some discussants perceived discussions of STDs to be of no consequence in their sexual relationships and so never gave it much thought. Furthermore, to the majority of discussants, STDs are not a major problem but HIV/AIDS is. To explore the issue of spousal responsibility for and roles in partnerÌs reproductive health further, we investigated how individuals responds to own and spouseÌs STD and HIV/AIDS status.

Individual Response to STDs

Participants were asked what they would do if they found or suspected that they have an STD. The reaction was different for HIV/AIDS and STDs. In the case of STDs, the male participants said that they would seek treatment from a hospital or health center, apply over-the-counter medication or traditional herbs, or seek information about appropriate treatment from a trusted friend who had suffered an STD before. Some said that they would avoid sex with their wife until cured, become very harsh or quarrelsome, or go for a journey in order to avoid having sex with the wife. A few men said that they would secretly go for treatment and later on accuse their wives of infidelity since the spouse would not have had any treatment. The major constraint for obtaining treatment is the fear of providers in public health services and the high cost of treatment at private facilities. The participants stated that female providers, especially those in government health facilities, are abusive of men seeking STD care. When the infection is serious and very painful, treatment is sought from health facilities, mistreatment and punitive costs notwithstanding.

Many discussants said that some men usually increased their coital frequency by engaging in sex with several partners. This is because these men believe that more sex helps the man get the disease out of his body faster. One male participant from Kabras stated: ÏWhen men get that one (STD), many decide to transmit to others and some believe that if they transmit it, they will get well $\div$ Ó This belief could also account for the tendency among some individuals to continue sexual activity even after they 
have tested positive for HIV/AIDS. Most men said that they would ensure that their wives are treated in order to prevent re-infection, but they would not disclose the nature of the treatment to the wife in order to avoid arguments. Many said that they would coerce their wives to go for treatment or take the husbandİs over-the-counter medicine. Although STD does not seem to be a problem among women, they too said that they would seek treatment from the health center if they suspected or found that they were infected.

Once treatment has been obtained, most men said that they would try to establish the cause of infection. There is a consensus that casual sex is the source of most STDs in men, but the husband is the most likely route for wifels infection. However, many men said that if they were faithful to their spouse, and it was established that the wife infected him, he would beat her. In a few cases it was said to be the basis for a divorce. If a casual sex partner is the source, the men said that they would encourage or coerce her to go for treatment and then terminate the relationship. Others said that they would force the casual partner to go for treatment if they liked her. Some wives said that they would report the matter to the elders so that the husband would be fined or reprimanded. Most women said that they would encourage their husbands to go for treatment and ensure that they get it.

Response to HIV/AIDS

While people are less worried about STDs because they are considered curable, responses to HIV/AIDS infection were different. The most immediate response is to spread the disease through sex, mostly commercial sex. This response is more widespread among men than women. There was a consensus in many of the focus groups that on learning about their HIV/AIDS status, most men would sell their property or take a loan and squander it on drunkenness and promiscuity, particularly with an aim of getting the ÏHIV fluidÓ out of the body. In the process, they may infect unknowing people. People adopt an ÏI cannot die aloneÓ attitude. One participant narrated a real life story from his area:

One immediate thing $\div$ is like an experience in my area where one person knew that he had AIDS. So what he did he got a loan, and he was now really moving because $\div$ he did not want to die alone. Five hundred shillings $\div$ So he really spread the disease $\div$ Even ... we had a woman in Eldoret who lost her husband. She was young and beautiful. She really went for men. The other one is people become worried and then begin losing themselves, what we may call wasting too fast $\div$ (Kakamega, married, male, formal).

It was observed, however, that menİs desire to spread HIV/AIDS is partly motivated by the need to protect themselves from suspicion and stigmatization by community members. The men said that it is easy for people to suspect that one is suffering from HIV/AIDS if one does not move with many partners at the same time. When one is seen to be active, with multiple partners, then people are less likely to suspect oneÌs HIV/AIDS status. Among the women, the desire is to retaliate. For both men and women, there is an additional desire of not wanting to die alone, that is, to create company in death. However, some men said that, rather than deliberately spread the disease, they would consider castration so that they no longer attain erections.

Other people go into a state of shock, depression, self-rejection, denial, withdraw from society, hopelessness, mental torture, or commit suicide, as the following quotes reveal:

One becomes worried, anxious, loses sense of belonging and sees himself as dead. His reaction makes him lose appetite and hope in life (Kabras, married, male, formal).

Some plan to commit suicide (Kakamega, unmarried, female, youth).

Some normally become depressed and they decide to disappear from their homes. They do not stay with people. They stay in isolation $\div$ (Kabras, unmarried, male, youth).

A few participants, men and women, said that they would plan for their families knowing that death is near. Most women said that they would be more accommodating, composed, re-adjusting to the new condition and pretend that all was well. Others said that they would go to the hospital or to traditional healers to look for drugs and improve their diet so that they could prolong their lives by a few more years.

Others would attribute HIV/AIDS infection to witchcraft and would consult traditional doctors for treatment or blame other people for their problems. Other reactions mentioned by one or two groups include: plan for the upkeep of their families, particularly children; adopt new dressing attire so that their emaciated bodies and other symptoms of HIV/AIDS infection could not be easily recognized; or go to church for prayers. Only a few participants (male and female) said that they would go for blood screening to confirm whether they, in fact, had the disease.

Response to Spouse's STD or HIV/AIDS 
The study also sought discussantsì views on what they thought people do when they suspect or discover that their spouse or partners have STD or HIV/AIDS. In addition, they were asked what they would do if their partner informed them that they had an STD or HIV/AIDS. The purpose of this question was to determine how men perceive their responsibility for their spouseÌs health. There is a consensus among participants that it is not easy for a spouse or partner to tell the other about having an STD because revealing such information would bring worry and disharmony to the household. If by any chance a wife informs the husband that she has an STD, and the husband can establish that he is not the route, most men said that they will beat the wife, and in extreme cases, it could cause separation or divorce. Furthermore, most say that they will avoid sex with the wife until she is cured but will satisfy their sexual desires elsewhere. However, the data indicates that husbandİs reaction to the wifeÌs STD is constrained by the perception among most men that husbands are the sources of wivesİ infection.

In reaction to spouseÌs STD, the women said that they would encourage their husband to seek treatment, follow him to the health center to ensure that the treatment is fully administered, and/or avoid sex until he fully recovers. A few said that they would go to their parentsì home in order to prevent the man from forcing them to have sex: III would not have sex with him $\div$ even to our place (her parentsİ home) I will goÓ (Mumias, married, female, informal).

The single males said that their response to a partnerÌs STD would depend on the extent of bonding and intimacy between them. If a close friend, they would have her treated and advise her to be careful. If not a close friend, he would help her get treatment but shun her afterwards and advise his friends to stay clear of her.

However, the reaction is different if the spouse was found or suspected to have HIV/AIDS. Most men said that they would go for blood screening. If tested negative, most said they will divorce, separate from the wife, or if they have to stay together, will live in separate houses. One participant said that he would bury the wife alive. Here are two examples of how men would react to news about wifeIss HIV/AIDS: ÏIf I am the one, and my wife is HIV positive while I am not, I will send her back to her people to be taught manners. I will then proceed to marry another wifeÓ (Kakamega, unmarried, male, youth); and $\ddot{\mathrm{I}} \div$ The relationship will end $\div$ Ó (Kakamega, married, male, informal). A few men in formal employment said that they would encourage the wife to live positively and seek professional counseling on how to live with the disease. Some of those men said that they would initiate such care and accompany their wives for treatment. But if they (the husband) too have the disease, then almost all the men said that they would stay with their wives, console each other, and jointly work out ways to manage the illness in order to prolong their lives.

Most women said that they would stay to take care of their husbands if they found that the husband has HIV/AIDS. However, they would avoid sex with him, and if they must have sex, a few (mostly educated ones) said that they would demand that a condom be used. Others said that they would go into a state of shock, worry, and eventually succumb to death. None said that she would abandon the husband.

The single males said that they would just end the relationship if they found that only the partner was HIV/AIDS positive. If both of them were positive, they would decide to get married but ensure that they agree not to spread the disease to other people.

Spousal Notification of STD or HIV/AIDS

The dynamism of spousal responsibility and roles for each otherÌs reproductive health were further investigated by asking participants whether they will notify their spouse if they had STD or HIV/AIDS. There is a consensus across all subgroupsÛirrespective of residence, employment, gender, or marital statusÛthat it is neither necessary nor expedient to inform a spouse about oneÌs STD status. They argued that although STD is a common illness in the area, it is nevertheless a delicate issue and could cause tremendous problems because of the notion that STD is associated with illicit sex. Notifying a partner about STD status could break up a relationship. Some married men were afraid that their wives could spread the news about their STD status because (as they say it) women cannot be trusted with secrets. Most men said that they would not tell their spouses or partners but would seek treatment secretly, coerce wife (using open force or deception) to undergo treatment, avoid having sexual relations, or feign some more acceptable sickness until cured. Some men said they would take their partners for STD treatment but package it as medication for a different disease after prior arrangements with the doctor. Here is a typical response: İYou will sneak for treatment without telling her, but if she is already infected, look for a way of taking her for treatment without her knowing the sickness but talk about another sickness which she usually complains ofÓ (Kakamega, married, male, informal). A few men said that they would instead turn around and blame their partner for infecting them in order to cover up. This accusation will force the wife to keep quiet and to accept treatment.

However, a few educated men in formal employment said that they would tell their wives so that they can stop bothering them (the husband) for sex, protect themselves from infection, understand why the husband is not responsive to her sexual desires, facilitate treatment of the husband. Men wished to 
avoid conflict that may ensue if the wife is allowed to find out by herself or because it is difficult to hide an STD. One participant said: ÏMe I will tell her so that I caution her not to move near me $\div$ But if I hide from her and her sexual urge goes up, and I refuse to fulfill her desires, according to our custom, she can report me to her people and then it becomes an embarrassing caseÓ (Mumias, married, male, formal). Because of the difficulty in breaking such news, one participant said he would tell his spouse indirectly by giving her a letter from the doctor showing that he had an STD and that the wife was required to go for treatment.

A few men said that it depends on the type of wife you have. If the wife is nice, easy going and understanding, you will tell her, but if she is tough and stubborn, then it is not advisable to tell her. One participant said: IIIt depends on how your family is. If the woman is the type who fusses and jumps around making noise, you will not tell herÓ (Mumias, married, male, formal).

Among single men, the consensus is that they will not tell their partners because women are hard to trust with secrets and that telling a woman such a secret is bad practice. According to one participant: ÏIt is not good for you to tell secrets to a lady. There are things you have to do secretly. And if you tell her that you have the STD, she can easily leave you and go and tell her friends. And you know, with ladies, the message will go flying all over. Where will you get another one?Ó (Kakamega, unmarried male youth).

The question of partner notification did not elicit much discussion among the female participants because it seemed that it is an uncommon problem among them. However, most of the women said that it was important not to notify the husband in order to avoid accusations of infidelity and/or violence. Women gave other possible courses of actions such as going for treatment secretly (most popular), talking about the symptoms but not admitting infection, feigning a more acceptable disease in order to get treatment, or finding an excuse to go to parentsì home until cured, as indicated in this quote: $̈$ İ If I walk outside there [had an outside partner] $\div$ and I see that I have that disease $\div$ I will tell him, let me go to see my mother. And I will pass through the hospital, they treat me and I $\div$ go homeÓ (Kabras, married, female, informal). If all avenues to get treatment fail or the woman knows that she acquired the STD from her spouse, she will tell her husband.

The groups were almost equally split as to whether or not they would inform their spouses if they had HIV/AIDS. Those who said that they would notify their partners were concerned about their childrenİs future and the health of their spouse (they do not want spouse infected), especially where one partner was HIV/AIDS negative.

The men who said that they would not notify their partners were afraid of desertion; they said that their partners would worry a lot, commit suicide, or spread the news about their health status. Women, in particular, feared that their husbands could become violent. However, participants who work in the formal sector, have higher formal education, or have greater access to reproductive health information and services are more likely to say that they would inform their spouses if they had HIV/AIDS. Their counterparts in informal employment or with low or no formal education or little or no access to information and services would not. This difference is attributable to the superior knowledge of benefits and costs of spousal notification in the context of HIV/AIDS among persons of higher socio-economic groups.

\section{Summary}

Two key dimensions of spousal responsibility and roles in reproductive health were explored. These are spousal involvement in decision making about family planning and spousal responses to STIs. Issues covered under decision making include spousal discussion of STDs risk and prevention, and FP, marital conflicts and resolution. The study found that issues of FP were difficult to discuss but STD issues were hardly if ever mentioned within the household. Avoidance of accusation and counter-accusations of infidelity, a reality which couples are often unwilling to confront, accounts for the limited discussion of STD issues among couples. However, there are conditions under which STD issues are broached. These include when there is love, trust and respect between spouses, when there is a strong suspicion or knowledge that one of the spouses is unfaithful, when spouses have higher formal education or access to RH services and information, and when spouses are concerned with their risk of HIV/AIDS.

Factors inhibiting discussion of family planning include divergent preferences for the number and sex composition of children; different perception of cost of child rearing by men and women; the desire to subordinate women; low education levels among the majority of spouses; knowledge gaps between those who are educated and the associated dependency; little awareness of the benefits of family planning; the persistence of beliefs and practices that promote male domination, including naming practices; pressure from in-laws; polygyny; and gender division of labor which emphasizes the reproductive rather than the productive roles of women. In particular, concerns for marital and economic security reduce womenİs receptivity towards FP discussions. However, couples who have higher 
formal education, are in formal jobs, and have access to FP and RH services and information are more likely to find it easy to discuss FP and some STD matters than other categories of respondents.

The study reveals that spousal involvement in decision making is desirable but rarely achieved. Men make most decisions about FP. Men and women expect wives to abide by their husbandsì decisions. Consistent with this perspective, women are not expected to give any views regarding contraceptive use by men because (as the women themselves say) men are the ÏbossÓ, Ïking postÓ, ÏpresidentÓ, and Ïoveralló.

Decisions regarding STD services rarely involve the wife, and both men and women are discreet about use of STD services. However, men are likely to initiate treatment for their wives or partners or take steps to reduce their exposure when they themselves have contracted an STD. This indicates that men are willing to take responsibilities once they understand the benefits for their own health and the consequences of failing to take action. This finding presents an opportunity to include men in programs targeted toward improving the reproductive health of women.

Issues of spousal decision making and negotiation regarding healthy behavior were further investigated in womenİs responses to own and spouseÌs STDs. The findings are variant.

If a spouse/partner has an STD:

Ô Most men seek cure secretly. However, most also initiate treatment of their pouses (usually without the knowledge of the wife in order to avoid arguments and accusations of infidelity).

Ô Most women will also seek treatment covertly without the husbandİs knowledge and not initiate such treatment in their husband for fear that they could be beaten, chased back to their parents, or divorced.

Ô Many men practice intentional transmission because of the belief that more sexual intercourse helps rid the body of STD fluid.

Ô There is avoidance of sex. This is used mainly by married men in order to avoid infecting their wives.

If it is the spouse's STD:

Ô Most men will beat their wives, or it could lead to separation or divorce.

Ô Most women will advise spouses to seek treatment and will ensure treatment follow through and follow up.

Ô Most men and women will avoid sex with the spouse in order to avoid infection.

Ô A few women said that they would demand that condoms be used if the husband insists on having sex.

If a spouse/partner has HIV/AIDS:

Ô There would be intentional transmission. This is used mostly by men to create company in death, rid the body of the HIV/AIDS fluid/virus, hide HIV/AIDS status in order to avoid societal suspicion, and/or retaliate. Many men tend to increase sexual activity when they know/suspect their HIV/AIDS status. Many innocent persons are deliberately infected in this process.

Ô The person goes into a state of shock, hopelessness, mental torture, self-denial, self-rejection; some withdraw from the society or commit suicide.

Ô The person wears new dressing attire to hide the AIDS impact.

Ô Persons seek care and counseling from modern health facilities, herbalists, and traditional doctors.

Ô Women improve diet in order to prolong life.

Ô Most women plan for their families, become more accommodating, re-adjust to the condition, pretend that all is well, and wait for death.

If it is the spouse's HIV/AIDS:

Ô Most men would end the relationship, live in different buildings, or marry another wife if they themselves are seronegative. If seropositive, most men said that they would stay with their wives and jointly work out a management plan to prolong their lives. Almost all the single men in the sample said they would end the relationship.

Ô A few men in formal employment said that they would encourage their spouses to seek professional counseling and support the wife in the process.

Ô Most women said that they would stay to give care to their husbands and avoid sex. If they have to have sex, a few said that they would ensure that condoms are used.

- $\quad$ Most men and women said that they would not notify the spouse if they discovered that they have an STD. Men said that they are worried about the impact of such news on their wive's health because (according to them) women are weak and do not have the heart to bear bad news. However, the women were concerned that such news could create a tremendous amount of violence within the household. If the infection was HIV/AIDS, a few women said that they would notify their husbands for the sake of their children. 


\section{Chapter 6}

\section{Perspectives on Male-Friendly Reproductive Health Services}

The study assessed knowledge of services, including where they are obtained, whether men are satisfied with the existing services, and if not, the attributes they expect to find in a facility catering to menİs reproductive health. Researchers examined provider perspectives on menİs reproductive health needs and the extent to which these needs are met within the existing service delivery facilities.

\section{Type and Sources of Services Offered to Men}

All the FGD participants were asked about their knowledge of the type and sources of FP, STD, and HIV/AIDS services that men were offered in their communities. There were slight variations in responses by gender and major differences by place of residence. The major types of services, provided in the urban areas are, according to the male participants, issuance of condoms, vasectomy services, and information on family planning and HIV/AIDS. Condoms are provided at the health centers serving the communities visited, at FPAK clinics, in condom dispensers, by CBD agents and in the market shops. Other services provided in the urban area include STD diagnostics and treatment.

There is very little knowledge regarding the availability of HIV/AIDS services, including screening, counseling and care and management among either male or female respondents. Only three male groups mentioned that HIV/AIDS screening and counseling are available from Kakamega Provincial Hospital, St. Maryİs Mission Hospital (Mumias groups) and Mukumu Mission Hospital (Kabras groups) but predominantly for in-patient care.

Most men in rural areas (Kabras and Mumias) stated that the only service provided in their area is issuance of condoms. The men were aware that condoms can be obtained from health centers located some kilometers away but most of the participants stated that men obtain condoms from shops in the market. One group of single males in Kabras mentioned condom dispensers as a place to obtain condoms. As in the urban area, most participants from rural areas said that there are no HIV/AIDS services provided in their locality, but STD diagnoses and treatment can be obtained from the Provincial General Hospital (PGH), Kakamega, St. Maryİs Mission Hospital, and a few health centers located in the area. A few participants were aware that PGH offers some HIV screening services. Some of the male participants from the rural areas (Kabras and Mumias) also mentioned the FPAK male clinic as another place where a vasectomy can be obtained. However, almost all the men said that family planning services are provided predominantly to women in their area. As one of the male participants from Kabras stated: ÏBut the family planning that is here is for women.Ó

Women in rural areas are more likely to say that there are no services for men than those in the urban areas. However, they are aware that condoms are available at the local health centers and that a vasectomy can be obtained from facilities in Kakamega, Kisumu, Bungoma, and Nairobi. Women in urban areas identified similar sources and types of services as the men.

The participants stated that information on FP, STDs and HIV/AIDS are available through the mass media: print and audio, advertisements (Trust condoms), billboards, and from CBDs. Other sources, mentioned to a lesser extent, are TV, maganga (traditional birth attendants), community outreaches, churches, films, seminars, and chiefİs barazas (mainly by men). The health centers were rarely mentioned among the male participants as a place to obtain information about FP or STDs. Almost all male participants decried the inadequacy of information on FP, STDs and HIV/AIDS to men and the poor access of the critical segment of the population, including adolescents and older children, to reproductive health information and services.

\section{Are Men Satisfied with the Services Provided?}

The study investigated whether men were satisfied with the services that are currently provided for them within their communities. All the male participants said that they were not. Most female participants found it difficult to assess menİs satisfaction since most of the men do not have access to FP services, and STD services are never discussed but are obtained secretly when needed. A number of reasons were given for the lack of satisfaction among the men.

Services Are Not Accessible

Most health facilities are located several kilometers away from participantsÌ locality, especially rural residents. Participants from Kabras Division stated that there were no services in their local areas. 
Provider behavior complicates accessibility problems. Providers in public health facilities are described as unfriendly, unhelpful, and cold. Most do not attend to clients swiftly but waste considerable time.. The discussants complained that waiting time is too long in government hospitals and some clients sometimes give up and return home without obtaining the services they wanted. One female group in Kakamega said that the staff at the public facilities were too slow, chat away and do their own things rather than attend to clients, making clients wait endlessly for services they may end up not getting. One female participant added that providers need to serve clients quickly because men do not like sitting for long. The younger participants said that service providers are particularly unfriendly to youth. Those seeking STD services are treated with disgust and disrespect. Both male and female respondents strongly criticized the reception accorded to them by some service providers, particularly women. Some male groups in Mumias reported that the service providers in local hospitals are rude and use abusive language, referring to men who come for STD services as Ïthese men of AIDS from BookersÓ. The women from Kakamega also reported that sometimes health providers in public facilities maltreated them. They said that if side effects occur from an IUD or Norplant implant, the doctors would demand a bribe of KSh 3,000 to remove it. If they did not part with the money, they would be told to stay with it until the device expired. They also mentioned that they were never told of side effects of the various FP methods they used; hence, FP was very unpopular with their spouses and partners.

Lack of Privacy and Confidentiality

The men argued that current facilities are too open, not private. This was the most cited reason by almost all male and female groups. The older men complained that most $\mathrm{MCH}$ clinics cater to women and children and that men are shy of being mixed with women and children or being seen by other community members at the $\mathrm{MCH} / \mathrm{FP}$ clinics. The younger men gave similar reasons: they are shy of obtaining STD and FP services alongside their own parents, older relatives, or community members. Furthermore, the men said that the concentration of services on women has left men out and that FP programs are not responsive to menİs health needs. The women stated that because of lack of privacy, men use trusted health facility workers to get them condoms, and in cases where men go to get condoms themselves, they do it secretly so that they are not seen. Data indicate that men use FP services secretly because condom use and vasectomy are stigmatized in the area. Therefore, services that meet menİs requirements for secrecy and privacy are likely to attract the most participation from them.

A related problem is the lack of confidentiality at local health centers. The participants, men and women, claimed that providers do not treat clientsİ records with respect and integrity. The male groups said that some providers revealed a clientİs health status to the community and therefore everyone knew who uses FP (condom/ had a vasectomy) or has an STD. The following illustrate their views: ÏMen are not satisfied because family planning is a secret affair and should not be so open as it is nowÓ (Kabras, married, male, informal); and ÏYou know men generally want privacy but they believe if they go to the hospital, when they come back from there, everyone gets to know that they went there. So there is no secret $\div \mathrm{I}$ donlt know how you will mange it but that is also making them shy away from the $\div$ hospitaló (Mumias, married, female, formal).

Cost of Services

The cost of services was another commonly cited reason by most groups. Both male and female groups said that the cost of methods sometimes prohibited individuals from procuring condoms or vasectomy in both private and public health facilities. They suggested that FP methods should be provided free. One woman said, ÏThey [men] are not satisfied. There are financial constraints. You may want this method of being cut (vasectomy) and you donIt have the money, it is not free. So you will not go. And also affording the condoms, sometimes it is hardÓ (Kakamega, married, male, formal); a man said ÏThe only problem is lack of money. Since they have started the issue of money (charging a fee), this is the time we have started moving backwards. But if they said it was free-we would have gone to be cutó (Kakamega, married, male, formal).

Lack of Choice of Methods

Most respondents said that the limited range of male methods to choose from is a problem for participants who may want to use FP services. As discussed in earlier chapters, both vasectomy and condoms are stigmatized and not generally acceptable in the area. Participants suggested the provision of injection and pills for men; for example, ÏMen require more methods $\div$ If they can get pills for men, that would work welló (Mumias, married, male, informal); $\ddot{\mathrm{I}} \div$ It would be fair if men can have injections for a particular period to avoid pregnanciesÓ (Kabras, married, male, informal).

Inadequate Information on FP, STDs/HIV/AIDS

Most male groups stated that there is not enough information on FP and STDs, including HIV/AIDS, for men and that those in the rural areas are worse off because they have limited access to the mass mediaÛprint, audio, audio-visual, or electronic. Most information is provided in health facilities for women and usually during antenatal and postnatal care. They argued that men rarely go to health 
centers except when they are sick or accompany their wives to give birth. Some facilities use the opportunity to give information to men but it is usually a matter of too little too late. According to one participant from Kakamega: III see that FP services should not be left until your wife is going to deliver and then after asking how many children she has, they start telling her Îclose conceptionİ or do like thisó (Kakamega, married, male, formal).

The youth also complained that lack of information hindered their ability to use the available services. There is lack of any articulate efforts to inform men, especially younger men, about FP or HIV/AIDS. Here are typical responses: ÏInformation about AIDS are poor $\div$ information about AIDS in this area is found only on the billboards at the hospital $\div$ only oneÓ (Kakamega, married, male, formal); and ÏThese sides [rural areas] are still behind. There should be an increase of seminars in the interior rural areas. Because those who are in town get seminars but we in rural areas get nothing. Few have heard about FPÓ (Mumias, married, male, formal).

Others complained that the mode of disseminating information to the public is bad. Some said that radio and television advertisements of FP methods, especially condoms, was embarrassing to those with children, and that putting vasectomy posters in the waiting room can scare away potential clients. They suggested that radio and TV advertisements should be scheduled for periods when they cannot be viewed by children and that vasectomy posters should be put in the operation room (theater) where it would be difficult for a client to change his mind. It was also suggested that efforts should be made to reach men, especially those in the rural areas, through seminars, billboards, posters, public health films, and community-based education on FP and STDs, including HIV/AIDS, in order to increase patronage and service acceptability. They also suggested the use of male providers, vasectomy success stories, and human models of real-life cases of HIV/AIDS to educate men in the communities and at their work places.

There were a few male participants who said that they were satisfied because condoms are easily available, simple to use, relatively cheap. There are also indications, though not widespread, that a few providers are friendly, helpful, trustworthy, and efficient.

\section{Men and WomenÌs Perspectives on Male-Friendly Services}

Given the dissatisfaction with available service delivery systems, participants, men and women, were asked to describe the qualitative characteristics of a service delivery model which meets menIs $\mathrm{RH}$ needs. This information is important to develop programs that truly meet menÌs needs and to integrate them into reproductive health. Various dimensions of a model clinic were explored, including organization; staff composition; range of services; convenient hours; privacy, confidentiality, and security considerations; and appropriate provider-client relationship.

All categories of male and female groups in all three divisions of Kakamega gave similar responses. Mumias male groups concentrated most on privacy and confidentiality. One group of men in informal employment in Kakamega gave an elaborate description of the type of clinic men would like. Some participants from Kabras gave views akin to male chauvinism and domination of all women.

The key concerns in the discussions of choice of services are confidentiality and privacy. As stated above, clients are concerned about the way clinic staff reveal a clientİs health status in the community. This practice jeopardizes clients who are using FP covertly or attending clinics for STD care. This concern for privacy and confidentiality is often expressed in different forms: as separate clinics for men and women, separate clinic days for men and women, locating clinics in a remote or busy part of town where the identity of clients can be hidden.

The discussion of male-friendly reproductive services is situated within the quality of care framework developed by Bruce (1990) and specified by Jain et al. (1992). The framework identifies six key attributes of quality that should be addressed in programs providing reproductive health services. The six attributes are choice of methods, information given to users, technical competence, interpersonal relations, mechanism for continuity, and the appropriate constellation of services acceptable to men. This framework is applied in this context as an organizing framework rather than an analytical algorithm.

Choice of Methods

As stated above, the availability of only two modern FP methods for men limits choice, accessibility, and participation by men. The men suggested increasing the mix by providing injectable and oral contraceptives. Investigations conducted in health facilities serving the communities also revealed that providers are concerned about the availability of limited methods for men. The small range of male methods, according to the providers, limits the clinicÌs preparedness to meet the RH needs of men. They suggested that a wider range of methods should increase uptake of FP and participation in RH by men. Increasing the method mix is important for meeting health needs and preserving continuity. As Bruce (1990) stated, having a choice of methods has practical and philosophical benefits; it reaffirms the programİs goal of providing services that meet individualsİ needs, and by so doing encourage longer 
term use as individuals settle on methods which, in the local expression, Ïrhyme with their bodiesÓ (see also Rutenberg and Watkins 1997).

Appropriate Services

The investigation of convenient and acceptable health services from the clientİs perspective considers physical structure, composition, organization, type, and operational characteristics. The preferred organization is one that ensures confidentiality and privacy. This requirement is expressed in a range of service delivery models that vary in the degree to which they separate services by age and sex. Participants suggested six service delivery types:

Ô Separate but equal services for young and old men located far apart;

Ô Same clinic for both young and old men but located far away from womenÌs clinic and the general public (very private);

Ô Male-only clinic with separate sections or different clinic days for young and old men;

Ô Mixed clinic but with separate sections for men and women;

Ô Mixed clinic but with separate clinic days for men and women;

Ô Same clinic for men and women with no distinction in service areas.

When men elaborated on why they preferred a particular model, they expressed concern for confidentiality, described those from whom they wanted to hide use of service, and gave reasons for wanting to hide service utilization. For example, older men want to hide use of services from women (wives), younger men, or other community members. Men complained that women are too talkative and that if a woman sees you at the clinic, everyone in the neighborhood will hear about it. They said, ÏWe (men) should be separate from women. We men should have our clinic for FP and women theirs. Women should not know the FP method you have used $\div$ because if they know, they will start spreading words that so-and-so has been operated (vasectomy) $\div$ Ó (Mumias, married, male, formal); and ÏIt should be for men only. Because men should be free $\div$ they should not meet with women because men donÌt want to be seen going for FPÓ (Kabras, single, male, youth). Additionally, men consider it demeaning to wait in the same line for services with men who are the age of their sons. They also worry that younger men could spread rumors about those who have undergone vasectomy. Some younger men also suggested having a youth-only clinic in order to maintain secrecy. They too do not want to wait in line for services with persons the age of their parents. Youth are also concerned that such individuals may find out why they have come to the clinic and report to their parents. The following quote sums up these views: ÏThey would prefer it separate for boys and men. Young men will shy off if they have STD because of the presence of older men. They cannot explain in detail how they got it in order to be treated properlyÓ (Mumias, married, female, formal).

These views were corroborated by the women who stated that men are shy and would not want their wives to see them queuing for services. The desire to hide service is also motivated by the communityİs poor opinion of male FP methods. Similarly, STDs are regarded as ÏsecretÓ diseases and one should not be seen receiving treatment in the open. Men said that separate clinics for men and women would allow partners to obtain services secretly when suffering from an STD; if a clinic is mixed, the couple may meet each other in the clinic and that could cause conflicts in the home.

Others simply argued that it is Ïpayback timeÓ: women have always been given prominence in FP issues and program activities, and it is now time to give men some attention and priority. One group of men in Kabras chauvinistically said, ÏMen are more important than women. If you put bulls together, they represent cows also, so if you give health services to a man, it means even if you leave the woman, she is already catered forÓ (Kabras, single, male, youth).

Those who advocated for a service delivery center where both men and women are served gave a number of reasons for their preference: (1) Setting up the same clinic for men and women is the best way to cater for the needs of couples, especially if the care that is being sought requires that both be treated. Married couples should show a good example to the youth by going together for joint service without fear. (2) Setting up different clinics would be costly and time-consuming. (3) Setting up separate clinics for men could suggest that something sinister is going on; wives could worry that their spouses are up to something bad due to lack of understanding of the philosophy of male-only clinics. However, women suggested that a joint clinic for men and women should be divided into sections because men are very rough and push a lot while waiting for services and they may hurt pregnant women in the process. Sectioning would ensure privacy and confidentiality; it would prevent men from meeting people that they are not comfortable with, such as in-laws and other relatives.

The participants described other features necessary for a clinic to meet menÌs RH needs. There should be a signpost at the main road to indicate the location of the clinic as well as a gate, fence, and watchman for tight security and privacy. Doors should not have labels such as ÏSTD roomÓ or ÏFP RoomÓ but should have numbers or other labels that do not reveal the type of services being provided in the room. This will help maintain privacy and confidentiality and build patronage. One participant put 
it as follows: ÏI feel on the doors, they should not indicate that people with STDs enter here or $\div$ FP people enter here. That would bring a lot of problems $\div$ because someone might go and spread word that I was seen entering that roomÓ (Mumias, married, male, formal). Privacy is also a major consideration at the reception. While some suggested one reception area for men and women, others suggested different waiting areas. Those who suggested separate reception areas for men also wanted a male secretary or receptionist who is mature, knowledgeable, respectful and well informed about FP issues. It was suggested that the waiting room should be set up to educate and entertain clients. It should also have curtained windows that people cannot see through. It should have comfortable seats, television (used for educational music, entertainment and announcements), video films on FP, STD, HIV/AIDS and other health issues, and an educator. It should also have condoms, pamphlets, posters, and educative reading materials that clients can take away with them. The preference is for separate waiting rooms for men and women in a mixed facility. Again the key reason is privacy. There are differences of opinion regarding whether there should be one consultation or examination room for both men and women, but the key requirement that participants want is privacy. Most wanted treatment and consultation to take place behind closed doors so that the client is assured of confidentiality. Some respondents suggested having a separate pharmacy for men and women in order to maintain privacy, but most thought that one is adequate since few are likely to know the type of medicine being collected. The consideration for privacy and confidentiality also emerged regarding the laboratory. While the majority suggested one lab for men and women, since it is not easy for anyone, other than the technologist, to detect the type of test that is being performed, others suggested that it would still be necessary to have separate lab in order to maintain privacy. A few participants argued that it is necessary to have a follow-up room where continuing FP clients or those who have come for a review of their health status can be served. They said, however, that such a room should be located close to the reception or inquiry area so that clients who come for follow up are not seen repeatedly inside the clinic. An operating theater was suggested as necessary for a service delivery center catering for men so they do not have to travel long distances to obtain a vasectomy. The men suggested that administrative facilities are necessary for complete functioning of any service delivery center but that there should be separate toilets for men and women in order to maintain privacy.

As mentioned earlier, the key consideration to men in both the organization of service delivery and the physical structure of a facility catering to men is privacy and confidentiality. The motivation to achieve privacy and confidentiality (badly missing in current systems) encouraged participants to demand that all levels of service be partitioned by sex and age. Some participants also suggested locating services that cater to men in remote or busy business centers so that community members do not see clients. Others suggested that providers should live far away from the communities and facilities they serve. The data indicated that the issues of privacy and confidentiality pose behavioral, attitudinal, and service management problems. While the latter can be corrected by re-organization, behavioral and attitudinal changes can only come from information and educational programs which wipe away stereotypes in the community and increase respect for professional ethics among providers. Partitioned services that do not deliver on privacy and confidentiality are not likely to attract men in the communities studied; however, a mixed service delivery model that guarantees privacy and confidentiality is likely to enjoy high patronage and acceptability.

Types of Services Expected

Again, the participants suggested a whole spectrum of services that should be provided in any facility catering to men. These include:

Ô FP service only;

Ô FP and STD, including diagnostics and treatment;

Ô FP, STD and HIV/AIDS, including screening, counseling, care and management;

Ô FP, STD, HIV/AIDS and treatment for minor ailments;

Ô FP, STD, HIV/AIDS and treatment for minor and major ailments.

Again the key element in these suggestions is privacy and confidentiality. Another theme that also begins to emerge is effectiveness in service delivery. The most popular suggestion was a facility providing FP and STD services along with diagnosis and treatment. Most participants stated that these two types of services are sufficient, arguing that overloading the model clinic with other types of services will lead to overcrowding, reducing privacy and effectiveness. As one participant stated: ÏIf you want to discharge services effectively, it should just be for those two services, FP and STD. But if we overload it with other services, it will not give out services wellÓ (Mumias, married, male, formal).

Those who suggested the last three service facilities expressed the need to maintain privacy and confidentiality and believed that providing a wider range of services beyond FP and STD would facilitate seeking FP and STD services covertly. A few others suggested that such a system would 
ensure comprehensive care in that people could obtain all their health care in one place; children could also receive care while the mother is receiving counseling about family planning.

Staff Composition

Most of the participants wanted facilities catering to men to be staffed with male providers who will attend to men and, by implication, women who will attend to women. They argued that men Ïfear womenÓ and do not want their nakedness to be seen by female providers; men are freer with fellow men. One female participant from Kabras said, ÏWomen staff should not be in a menİs clinic because a man does not like a woman touching his buttocks $\div$ Ó It was stated that female doctors have no secrets and can expose oneÌs health status in the community. Others argued that women ask irrelevant questions such as ÏHow did you get an STDÓ when they know it was obviously through sexual intercourse. A few participants argued that such a clinic should be staffed by both men and women, arguing that a doctor is a doctor, and that some women providers have very persuasive language and some men listen to them more than they do male providers.

Time

The key in the timing of service is convenience. Men want flexible hours so that services are available when they need them. They suggested that services should open in the evenings and on weekends so that those who work can benefit. Again privacy and confidentiality were key considerations. For example, it was suggested that services should not be open on market days because many women are around then (some of the existing facilities are located near the market). One male participant from Mumias suggested expanding service to cover the evening hours because $\ddot{I} \div$ when you leave home people think you have gone for a strolló. Another said, Ïothers would prefer late hours so that they are not seenÓ (Mumias, married, female, formal).

All FGD groups said that Ïtime is moneyÓ and that waiting time should be short in order to avoid boredom and ensure privacy. Others stated that people have a lot of commitments and need the time for other activities. Some others stated that a clientİs health problem could require immediate attention.

Mechanism for Continuity

The most discussed elements of continuity in this study are information and cost of services. Information needs were discussed above. None of the participants made a distinction between the different types of cost Ûwhether it is consultation charges, or payment for commodity, transportation, or drugs. There is a consensus that cost is a hindrance to service uptake and continuity, especially in the rural areas. Therefore, the participants suggested that services should be either free or affordable. For example, some men stated that the new condom (Rough Rider) is too expensive and should be made more affordable. However, they made a distinction between what should be free and what should be affordable. For instance, most participants suggested that FP services should be free in order to entice men but they should not be completely free or too cheap because people would then undervalue them. Most participants stated that STD services should be moderately priced to encourage safe sex behavior; they said that high prices drive people to quacks for health care.

Provider Behavior and Competence

Almost all respondents were concerned that providers extend high quality competent service and exhibit cordial, friendly, and helpful behavior. They described the qualities they would like to see in their providers. For example, providers should be knowledgeable in FP methods and other health issues. They should be willing and able to discuss any health issues with clients; they need to be good communicators. They should be morally upright in the community and viewed as role models whom clients can copy. They should use FP and have a small family of not more than four children. They should be friendly, helpful, patient, polite, persuasive, and social in order to win clientsİ trust and confidence. One participant from Kakamega said, $\ddot{I} \div$ he must be friendly to his clients if he has to get any information from him that would enable him (staff) to assist the client.Ó Providers should be confidential and trustworthy. They and should not hide or sell medicines and health supplies meant for clients, as was believed to be the case in government health facilities.

Type of Information Expected

There are considerable misconceptions regarding the side effects and contra-indications of contraceptive methods just as there is lack of knowledge of STD/HIV symptoms, transmission, and prevalence. The study participants suggested the model clinic should provide information on both FP and STDs, including HIV/AIDS. They suggested that FP information should include range of available methods, instructions on how to use the method selected and how to choose the best method that rhymes with the clientİs body. There should be full explanations about the risks, side effects, and contra-indications, including the impact of method selected on sexual behavior and viability. Advantages and disadvantages of methods should be described. There should be information about what clients can expect from service providers regarding continuity, advice, support, supply, and referral to other methods and related service if there are harmful side effects. 
Regarding STDs and HIV/AIDS, clients expect information which will diffuse misconceptions regarding transmission. They need to know that HIV/AIDS is not just another disease; it is not witchcraft or an act of God but the result of a behavioral problem that can be prevented. People need to be informed that there is no safe haven for risky behavior. In other words, AIDS is not an urban disease; it could be acquired in the rural areas if one is exposed. People want information about the origin, causes, and symptoms of HIV/AIDS and prevalence of STDs; information about availability of services, including screening, counseling, and care for HIV/AIDS. These services should include systematic periodic community education to increase awareness and knowledge.

\section{Provider Perspectives on MenÌs Service Needs}

Various qualitative attributes emerged as necessary in a facility providing health care for men. These are choice, privacy, confidentiality, and convenience, responsiveness to client, effectiveness, efficiency, timeliness, information, comfort, as well as competent and congenial providers. Utilizing data from the health facilities serving the communities studied ${ }^{10}$ we investigated the ability of existing facilities to meet menİs expectations for services. Comparing data on clientİs expectations, prevailing services, and gaps we identified interventions that could increase acceptability of health care services to men and in so doing increase patronage among men and women.

Information, Access, and Continuity

Access to adequate information about services is one of the attributes of quality service identified by the participants. The five facilities studied provide services to men but only three actively inform men about FP and STDs. Many of the providers stated that health centers do not provide adequate information to men on FP and STDs, including HIV/AIDS. Only two of the facilities visited had brochures, posters or pamphlets about FP and STDs, including HIV/AIDS, in any part of the facility. Only one of the facilities provides vasectomy and, by implication, is capable of providing information about vasectomy to clients.

The providers identified a number of hindrances to menİs access to information. One of the ways providers get information to the husbands is through their wives. Lack of support among men for wivesI use of FP and STD needs limits this channel. Other factors limiting access to information and (safe) services include lack of skills (in two of the five sites studied), personnel, equipment, supplies, and other infrastructure such as vehicles and finance. Some staff members cited the predominance of female providers and client overload as additional constraints.

In two of the facilities, providers said that they do not have sufficient guidance, updates, and backup to provide safe FP and STD services. In one of the sites, the providers said they had received seminars to improve their skills in providing STD services in the past, but it is not known whether they received comparable updates on FP and contraceptive methods. Only three of the facilities had qualified clinicians available for consultation and complications.

Data revealed that all five facilities lack supply of some contraceptives, including condoms, diaphragms, and Norplant. In two sites, providers complained of not having adequate equipment and supplies to provide STD services. The lack of proper equipment, supplies, and skills means that clients seek treatment from private facilities if they can afford it, find other solutions which could include living with the disease until it reaches an acute stage, or, if FP, discontinue the method.

Flexibility and Affordability

Flexibility refers to whether the hours of service at the local facilities are convenient and acceptable to men. Affordability refers to whether the cost of services is within the clientÌs reach, including consultation charges, the price of commodity or drugs, and transportation. Providers from four of the five sites felt that services are affordable for their clients. However, in one of the sites, the provider stated that consultation charges and the price of drugs or commodity are beyond the means of some clients and suggested that some type of waiver be developed for those who are not able to pay for services.

The data obtained from the five facilities are consistent with those obtained from the communities that the hours of service are not convenient for men. Most of the facilities open between 8.00 am and $5.00 \mathrm{pm}$. Only one of the clinics opens to clients for a few hours on Saturdays. None are open on Sundays. Most are not open for FP and STD counseling or issuance of methods in the evenings. The providers themselves stated that hours of service are not flexible enough to accommodate the majority of men, especially working men, who may want to use the services.

Choice

Choice is one of the key attributes of quality from the respondentsì perspectives. Data from the community indicate that lack of informed choice on the range of contraceptive methods and STD services available is a major constraint to service utilization. Some of the men complained that some wives are basically coerced to accept whatever is available even if they prefer another method. In order to obtain provider perspectives on informed choice, researchers asked providers to assess their 
facilities on a number of choice-related subjects. These include the range of services provided especially to men, whether these services meet the menİs sexual and reproductive health needs, and whether men who come to the facility receive the method of their choice.

Most of the service providers felt that their facilities do not offer a range of contraceptives which meet male clientsİ sexual and reproductive health needs. Although the providers attributed this problem to the limited range of male methods, the unwillingness of a provider to offer a vasectomy in facilities equipped for that service is also a key problem.

Confidentiality

Confidentiality is another major concern to the men in the communities. Participants (men and women) said that once an individual is diagnosed with an STD, the clinic staff spreads the information all around the community. The cost of this breach of confidentiality is high as the individual could suffer tremendous social retribution and even ostracism if community members think that the disease is HIV/AIDS. In order to obtain providersÌ perspectives on clientsİ right to confidentiality, the providers were asked to assess their facilities on a number of issues, including management of clientsİ records and partner notification in case of clients diagnosed with STDs.

Most of the providers said that clientsI information is kept with utmost confidentiality and that access to clientsI records is strictly controlled. Staff at two of the sites said that confidential issues are frequently discussed and staff are reminded, from time to time, of the need to maintain the highest professional ethics. Because of provider commitment to keep the integrity of clientsİ records, providers stated that information about clients is never released to any spouse unless the client has consented. In some cases, providers said that they have had to lie to a husband in order to protect a woman who is using FP secretly. When asked how they deal with partner notification for clients who have an STD, all the providers who participated in the study said that they ask the client to bring their partner for treatment. To encourage compliance, clients are counseled on the merits of bringing their spouse in order to prevent re-infection. However, if the client is diagnosed with HIV/AIDS, it is only a doctor who breaks the news to the affected person, and the partner, after counseling.

Nonetheless, a few providers confirmed that providers do not always keep clientsÌ records confidential. In one of the sites, it was learned that some providers reveal information about people diagnosed with STDs. One staff member narrated a case of a client who came for STD treatment at the facility. When he was leaving the clinic, a staff member who had seen his treatment card started telling others, pointing a finger at the client. While she was still pointing at him, the man happened to turn back; he became very furious and returned to scoff at the nurses. He swore never to return to the health center if that was the way clients were treated. Experiences such as this one were frequently described by clients in the communities as major constraints to accessing FP/STD services. These data contradict what most providers said regarding their respect for clientsİ records and confidentiality.

Privacy, Convenience, and Comfort

Related to confidentiality is the issue of clientÌs privacy and comfort. As stated above, the data revealed that these two attributes should be present in any facility providing services to men. The facility-based data reveals that privacy is a concern in three of the five sites visited. In many of the clinics, the waiting area is an open space where clients are not shaded from either rain or sunshine. The toilets, where clients are expected to give urine, are dirty and unkempt. Many of the health centers are busy and crowded, with little space to accommodate clients. Rooms are not closed off during counseling or examination, and in some of the sites, service providers examine clients behind a narrow cloth screen with other clients watching. In three of the sites, providers complained that the door handles and locks are bad; in others, the locks are good but are just not used. In one of the sites, the examination room is also used for handling medical emergencies. In only one site did staff say that their doors have locks and that they are used during counseling and examination. However, almost all providers said that it is difficult to prevent interruptions during counseling because there are no signs on the door to show that counseling is in progress.

Dignity and Comfort

The providers were almost equally opposed on whether they maintain the dignity and comfort of their clients during examination. The majority of providers said that men are not comfortable receiving treatment from them. They attributed the discomfort to the predominance of female providers, arguing that men feel comfortable receiving treatment from their fellow men. These views were consistent with the opinions expressed by the clients.

The facility-based research revealed additional factors that may play key roles in clientsİ discomfort. For instance, over half of the providers said that staff do not explain to the client what type of examination is being done. They argued that staff have no time to explain anything because of client overload and because service providers try to spend as little time as possible with each client in order to reduce waiting time. Some providers intentionally withhold information from clients because some run away when told that they are being tested for STD for fear that they could be screened for 
HIV/AIDS as well. Some providers assume that clients have undergone similar tests in the past and hence know what is happening.

Provider-Client Interaction

How friendly are the providers to clients? Data from the communities indicate that some providers are unfriendly, unhelpful, and cold. Consistent with this view, in a discussion of the hypothetical facility delivering services to men, the participants stated that provider-client interaction should be friendly, cheerful, and helpful. Researchers obtained providersI assessments of client-provider interaction in the prevailing services, and most providers said that the relationship of their staff to clients is good. However, some providers stated that lack of space and seats was a problem. Because of lack of space, providers cannot offer clients a place to sit or the necessary privacy when they come to the facility. Client overload also may have contributed to hurried interactions. Where number of clients is large, providers find it difficult to interact at the level that the clients want. Additionally, it was discovered that providers have no systematic way of finding out about clientsI satisfaction or suggestions for improving services. This hampers their capacity to structure services in a way that responds to clientsİ needs.

Waiting Time

Consistent with data obtained from the communities, most providers considered waiting time too long and consultation time too short. The long wait and short consultation time is attributed to shortage of staff and clinic case overload in many sites. For example, some providers stated that counseling for FP and STDs is scantily done due to these problems. Yet clients do not consider themselves as cases but as unique individuals with health needs requiring attention. The implication is that many clients go home unsatisfied and with very little helpful information or understanding of the treatment or contraceptive method received.

Provider Needs, Competence, and Service Readiness

Providersİ perspectives on their needs, competence, and readiness to provide services to men were investigated. We also examined their access to information, staffìs knowledge of the field and whether they have access to good management, supervision, training, and update. Questions on access to information focused on whether providers are familiar with the various regulations governing reproductive health service delivery to men. We also wanted to know whether they follow the rules and regulations. All service providers said they were aware of the $\mathrm{MOH}$ rules and regulations regarding $\mathrm{RH}$ service delivery (including FP and STI prevention and treatment) but that they are barely understood and seldom used.

Four main management and supervision issues were examined. Service providers were asked whether their management emphasizes and is committed to the provision of quality FP services, particularly to men. They were also asked whether any headquarter organization gives them support for providing services to men. The third concern was whether the existing system of supplies enables the provision of quality services to men. The final dimension deals with whether the providers have any mechanism through which they can discuss RH issues with community-based distribution workers.

All service providers from the five health facilities said that their management is committed to the provision of quality FP services, particularly to men. In one of the sites, a family planning nurse is placed in all the male admission wards to offer services, both counseling and issuance of methods. In four of the sites, providers said that they receive sufficient support from headquarters and that this support always meets their needs for providing services to men. However, providers at one of the sites complained that the existing system of supplies does not enable them to provide quality services to men. They pointed out that condoms are often in short supply.

All service providers said they have mechanisms in place through which they can learn about the reproductive needs of men in the communities. Such information is obtained from CBDs. In one of the sites, CBDs report to the facility every week. In others, the staff rely on the weekly information gathered from Maendeleo ya Wanawake (a womanİs organization). In another, the facility-based workers meet with CBDs monthly. One of the sites has no such mechanisms. In those that have, it is not clear whether such information is fed back into the system in any systematic way to improve services.

The ability of providers to give quality service depends on how much knowledge they have about FP and STD services as well as the timeliness of that knowledge. We investigated whether service providers regularly receive updates and in-service training to keep them informed and competent in providing FP and STI services to men, including skills in resolving marital conflicts. Research at the community level revealed that couples who disagree over whether or not to use FP often consult staff at the local health center for resolving those conflicts. Thus, the providerİs job includes more than clinical services but also involves family management and conflict resolution. Since conflict resolution between couples is important in the use of FP, it was necessary to find out whether providers felt that they have sufficient knowledge and information to deal with marital conflicts. 
In three of the sites, providers said that updates and regular in-service training are provided to keep staff well-informed and competent in providing FP and STI prevention and treatment services to men and women. In two of the sites, providers said that they have not received such updates or regular inservice training. However, the providers said that most members of their staff know enough to give basic FP and STD services to men, but that some are deficient and need additional training or updates.

Most providers said that they have handled marital conflicts at some point in the past. In two sites, the providers narrated how they resolved two cases. In one of the sites, they narrated the case of a woman who had an IUD inserted without her husbandİs knowledge. The husband got very furious when he found out and brought the woman to the health center and demanded that the IUD be removed. The nurses said they tried to pacify the man but he wouldnIt listen. The nurses took the woman in, removed the IUD, and showed it to the man. As soon as the man left, they took the woman back in and inserted a new IUD for her. The man did not come back to complain and the wife never reported any incident. In another site, a provider resolved such a conflict by helping the woman to hide the method. The provider narrated a story of a woman who wanted to use family planning but her husband was against the idea. This generated a significant amount of trouble within the family. In order to ensure that the wife did not use FP behind his back, the husband accompanied her every time she visited the clinic, be it for headache, knee injury, or their little babyl̀s immunization. The woman was wise. Every time she had to visit the clinic, she claimed that the baby was not feeling well. While at the clinic, she would receive the injectable contraceptive secretly and the nurses covered up for her. At the end of the visit, she returned to her husband outside the clinic with some packs of panadol for the baby; everyone was happyÛwoman, her husband, baby, and nurses. The nurses said that they were able to resolve a major conflict in that family by giving the woman secret support to use family planning. Other forms of conflict are resolved through counseling and education. However, many providers suggested that some additional training is needed on spousal conflict management as regards use of FP and treatment for STDs and prevention in order to equip staff to provide quality reproductive health services for men and women.

\section{Summary}

A comparison of clientsİ expectations with prevailing services reveals significant deficiencies in the way reproductive health services are being provided that could account for the limited utilization of services by men and the lack of support for partners who may want to use services. The mix of services currently provided is limited. Beyond the issuance of condoms, men have limited access to information on other FP methods, STD prevention and treatment, and HIV/AIDS screening, counseling, management, and behavioral change. Enhancing menİs access to services calls for improvements that would make services male-friendly. This section describes required interventions and suggestions of the type of improvements that could be implemented.

Men need to be informed through community awareness and education campaigns that are available in their area. They need more information and knowledge about the merits, side effects, and contraindications of FP; types of contraceptive methods, and STDs, including HIV/AIDS services. Suggested ways to improve menİs access to information and services include use of male community educators, persons who have successfully used vasectomy, and real life examples of persons suffering from HIV/AIDS. Because radio advertisements of condoms are offensive (see Chapter 2), enhancing menİs access to that information will require scheduling adverts for periods when they will not be heard by children.

Choice is problematic partly due to the limited range of male methods and partly because adequate information is not provided to clients about available methods. More information is needed on the two male methods available (condom, vasectomy) and other female methods so that men can make informed choices and decisions. An appropriate constellation of services that provides effective service and guarantees consumer confidence, convenience, privacy, and comfort should be available.

There is considerable concern among men about being discovered receiving a vasectomy, condoms, treatment or counseling for STD/HIV/AIDS. This concern derives from the stigmatization of vasectomy, condoms, and STDs in the area. Evidence presented above indicates that prevailing services do not meet clientsİ expectations for confidentiality. One way to minimize the problem is through community education and awareness campaigns targeted towards removing stereotypes and stigma associated with male methods of family planning and STDs/HIV/AIDS. At the clinic level, providers need to take steps that protect the integrity and comfort of their clientsÛlocking doors during examination and counseling, describing to clients the type of services they are receiving, and protecting the integrity of clientsİ records. Clients want male-friendly health centers to provide a range of services.

Findings indicate that the provision of evening and weekend services would significantly improve utilization by men. Waiting time also needs to be shortened, and providers need to spend a bit more consultative time with clients than is currently the practice. Part of the discomfort experienced by clients 
at the clinics is attributed to the predominance of female providers. A long-term solution will require hiring of more male staff to care for male clients. In the short term, available staff can be re-organized such that male providers are allowed to care for male clients while female providers attend to female clients. In the event that this is not possible, clients must be given the option of seeing the available provider or be allowed to come at another time when the provider of choice will be available. Information about this possibility should be made available to the clients, men and women.

Data indicate that although management and supervision is good, staff, especially those in the rural areas, need updates and training in providing safe services to men. These include updates on basic skills in the resolution of marital conflicts regarding use of methods and treatment for STDs. Data from health centers and the community indicate that providers are increasingly being called upon to resolve spousal conflicts regarding FP problems. Such updates should also include training in client management and professional ethics in order to improve provider-client interactions.

Lack of space, and indeed, male-friendly space, is a problem in most of the facilities. The providers stated that this problem limits their ability to treat their clients in a humane way and to attract men to their services. Therefore, there is a need to provide new space in existing facilities and to organize existing space in order to maximize the utility. Community, government, and health administration representatives would have to work together in order to achieve this objective.

9 Malava Health Center is the main health center serving the Kabras population, but this is located about $11 \mathrm{~km}$ away from Mahira and Kakunga, the communities studied in Kabras. In Mumias, the population lives within closer proximity of a health clinic. 


\section{Chapter 7}

\section{Policy and Program Implications}

There is an explosion of interest about incorporating men in reproductive health programs. Their exclusion has been noted as a key factor accounting for the limited use of reproductive health services among men and women. However, to be successful, efforts have to be based on broad understanding of menİs views, including their perceptions, concerns, and practices regarding reproductive health (including FP and STDs, HIV/AIDS and other male health needs) and an appropriate constellation of male-friendly services in these arena. In order to contribute to this understanding, this study investigated the perspectives of men, women, and providers about menÌs needs for information and services regarding family planning and the prevention of STD. In particular, we explored menIs knowledge, perceptions, and concerns about FP, STDs/ HIV/AIDS, spousal roles and responsibilities in the context of STDs and HIV/AIDS prevention, and the characteristics of male-friendly services.

The study utilized data collected in communities and health facilities in three administrative divisions of Kakamega DistrictÛKakamega Municipality, Mumias, and Kabras. Data were collected using a combination of qualitative and participatory approaches, including FGD among participants in the communities and self-assessment by providers in health facilities. The participants were recruited using a purposive sampling technique. We expect that the findings are valid for other settings with similar characteristics as the study area, that is, rural or small towns with limited access to services and a strong patriarchal society. However, they can not necessarily be generalized universally.

\section{Ideological and Practical Obstacles to MenÌs Participation in Reproductive Health}

One key reason for the limited use of services among women is lack of partner support or husband disapproval. Many scholars have interpreted this problem as the outcome of infrequent verbal communication or discussion about family planning and sexual health between partners. This finding has also formed the basis for the call for greater spousal discussion and dialogue by program experts. According to this school of thought, promotion of spousal discussion and dialogue should engender spousal cooperation and supportive partnerships which should, in turn, increase service utilization among men and women. However, is this relevant to situations and programs seeking to increase utilization of service for the reduction of unwanted pregnancies and STDs and HIV/AIDS in Africa?

While recognizing the important association between spousal discussion and contraceptive use and the role that spousal dialogue may play in service utilization, policies and programs oriented toward promoting spousal discussion and dialogue are not likely to engender supportive partnership or spousal cooperation without carefully articulating and dealing with problems which have prevented that dialogue and discussion. They are even likely to engender violence and subordination of the weaker partner, who in this case is the woman. The policy with the most potential therefore is one that addresses the ideological and pragmatic obstacles to menIs participation as both clients and supportive partners.

A number of those ideological and pragmatic obstacles have been articulated in this report. These include gender gaps in access to resources, poor male access to reproductive information and services, and operational problems regarding service delivery. The latter include range of services provided; the lack of choice, space, privacy, comfort, convenience, confidentiality, skills, personnel, supplies; and poor provider behavior. Operational problems in service provision have been discussed in detail. In this section, discussion focuses further on the aspects of gender disparities in access to both productive and reproductive resources, particularly in the context of spousal cooperation. Policy and program recommendations for addressing some of these obstacles are discussed below.

\section{Expand Information About Family Planning}

There are considerable misconceptions about the side effects of FP, such as the ÏhotÓ and ÏcoldÓ blood effects on a womanİs body and sexuality. These misconceptions are engendered by the lack of factual information about FP. Men also hold a number of beliefs regarding FP which are obstacles to their adopting it themselves or supporting the use of FP by their partner. For example, men believe that contraception is womenİs business, that there is an association between condoms and HIV/AIDS, that there are side effects of contraceptives, that contraceptives affect womenÌs sexuality and physical appearance, and that there is a stigma about some male methods. For example, most men believe that use of some methods increases promiscuity among women by increasing their urge for sex. Other methods are believed to make women unresponsive during intercourse. It is also commonly believed 
among men that women who use contraceptives are able to retain physical beauty and youthfulness. More importantly, FP is perceived to take away pregnancy worries, worries which men consider important in order to continually subordinate women to reproductive roles. Consequently, some husbands block their wivesİ access to contraceptives. Many wives resolve the conflict and implement their own reproductive goals by using FP covertly or undertaking abortion when unwanted pregnancy results from unprotected sex.

The desire to control wivesİ sexuality contributes to the limited support for partnerÌs use of contraception among men. Misconceptions regarding family planning also hinder menİs readiness to use FP or to support their partners who may want to use these services. Therefore, there is need for policy and programs that would increase education and awareness of the role of family planning among men in communities. Such efforts should also:

Ô Emphasize that family planning is for everyone: women, men, and adolescents.

Ô Mount large-scale public awareness campaigns to change community perceptions about FP;

Ô Engage men in the formulation and implementation of community-based reproductive health education programs, including use of vasectomy success stories and real life examples of HIV/AIDS;

Ô Advertise reproductive health technologies through the mass media and village-level channels such as chiefİs barazas and funerals.

\section{Improve MenÌs Physical Access to Services}

Another major constraint to the utilization of services is the poor physical access to information and services, especially in the rural areas. Men in rural areas cannot avail themselves of the opportunity to utilize services because services are located several kilometers away from the communities. Physical access to those services are further hindered by lack of good roads and transportation network. Another dimension of the poor physical access to FP services by men is the gender disparity in access to reproductive resources: women have better physical access to reproductive health services since, as configured, FP services are provided within the maternal and child health $(\mathrm{MCH})$ framework. Programs should aggressively seek ways to expand service provision to men. One way to do this is to build more facilities especially in the rural areas. Another strategy is to attract men to services through promoting STD treatment. This study showed that men will not only go to obtain care if they know that they have acquired an STD but will also initiate treatment in their wives in order to prevent re-infection. This presents an opportunity to include men in programs targeted toward improving womenİs reproductive health. Programs that attempt to improve service utilization among men can begin with the provision of STD services and then move into FP. In other words, an STD/FP configuration may have the best application in a system targeting male clients rather than the current constellation that is predominantly $\mathrm{MCH} / \mathrm{FP}$ based. An STD-based configuration of service delivery could also provide avenues for reaching men with FP because men who come for STD treatment can be educated about ways to protect themselves from diseases and unwanted pregnancies.

\section{Introduce Interventions to Promote Gender Equity}

Spouses seldom discuss STD prevention, and FP issues are broached with considerable difficulty. Avoidance of accusation of infidelity is the main reason these subjects are seldom discussed. Other inhibitions to spousal discussion of FP include spousal preference differences for family size and composition; gaps between desired and achieved family size; spousal educational gaps; and the persistence of practices that promote male dominationÛnaming practices, pressure from in-laws for large family sizes, polygyny, and gender division of labor. The latter promotes womenİs reproductive roles at the expense of their productive roles. Given the strong association between spousal communication and contraceptive use in many settings (Bongaarts and Bruce 1995; Bankole and Singh 1998; Drennan 1998), the limited discussion of reproductive health issues in this population may have hindered the use of RH services, especially FP. Therefore, eliminating obstacles to conjugal discussion and decision making could increase use of services by both men and women.

Africans, and especially African men, value womenİs quietness and silence in sexual issues. Even when a woman ÏknowsÓ, she is not expected to say it. When she Ïfeelsó, she is not expected to ÏshowÓ it but to suppress it. Silence and passivity in sexual matters issues are the attributes of Ïgood womenÓ, whereas men are expected to take risks, be expressive, and take leadership in sexual and reproductive matters. Both men and women share this perspective. Higher education for women tilts the balance slightly in their favor as they are then able to Ïknow, feel and, sometimes, say so.Ó Programs which promote womenİs visibility in spousal discussions regarding FP and sexual matters in a culture where that is not to be the case and which do not investigate why lack or infrequent discussion has 
existed and persisted are likely to challenge menİs Ïrightó to control womenÌs sexuality; such programs will breed violence against women. Recent analysis of Ugandan data by Ezeh and Gage (1998) indicates that women are more likely to be beaten by their husbands if they perceive that their ability to control wives is being challenged. If a woman begins to initiate talks about FP and sexual issues, the husband would feel that her Ïeyes have openedó (become over-civilized), and the way to keep eyes closed is through violence.

Indeed, we observed that couples with highly educated wives or with a wife as educated as her husband are likely to develop a loving and trusting relationship which increases the likelihood of spousal discussion of FP, STDs, and HIV/AIDS. This finding has implications for womenİs status and empowerment. It revealed that where there are gender inequities and inequality in access to educational opportunities and decision making, women are likely to lack the ability to negotiate reproductive health matters with their spouses.

A recent study conducted by Biddlecom and Fapohunda (1998) found that women are not only likely to receive their husbandsİ support for contraceptive use if they are highly educated, but they are also more likely to use openly or covertly if they find it difficult to broach such subjects with their husbands. Data in this study revealed that poorly educated women were more likely to passively accept their husbandìs position. If husbands are cooperative but women are poorly educated and/or economically dependent, they would be less likely to avail themselves of the opportunity to use technologies that could help them implement their RH goals. They are also less likely to have the means, including the knowledge to procure RH services. The Kenyan population policy underscores the role of gender inequality and inequities in access to education, economic opportunities, information, and health technologies, including family planning, as major barriers to successful FP programs in the country. Therefore, policies that promote gender equity by increasing womenİs access to high education, specialized training and economic opportunity will reduce womenİs dependence on their partners and improve wiveÌs ability to negotiate partner cooperation and collaboration in the utilization of reproductive health services. Interventions to achieve this objective could include greater focus on womenİs access to higher education, income generation, and adult education that improve skills and knowledge of individuals and couples.

\section{Promote Male Interests in Supporting Family Planning}

It is not problematic to obtain husbandİs cooperation for a childİs immunization. That is because men understand the merits of child immunization in the context of their own interests and the consequences of inaction which could include child mortality. Similarly, this study reveals that husbands are likely to initiate treatment and prevention of STD in their wives if they figured that they themselves have acquired the disease no matter the cost and without the wifeÎs knowledge. Sometimes that could involve collaboration with the area doctor, packaging treatment as something for more acceptable illnesses, lying, using condoms with the wife even when this could cause tremendous inconvenience. In this example, men know the advantages of taking action and the consequences of inaction which could include re-infection, and temporary or permanent loss of wifel̀s sexual, reproductive, and productive capacity if she falls ill or dies.

In the context of FP, the advantages to men are not that clear. Conversely, the disadvantages are highly visible to the eyes: it prevents the birth of additional children and the joy, labor, hopes, and fullness that birth could bring to the family. In African households, the birth of a child is a joyous event whether the pregnancy was wanted or unwanted. This joy, hope, and fullness are reflected in the type of names families often give their children. Family planning prevents the realization of that experience.

\section{Target Youth}

Data presented in this study reveal that services are not friendly to youths. There is need to target youths, men and women, as a special group by creating specialized services solely for them. This could include the use of peer educators, youth centers to disseminate information about safe sex and prevention of unwanted pregnancies, skill improvement programs aimed at increasing job opportunities especially for youth who have dropped out of school. The latter will provide income-earning avenues for youths, especially girls, and reduce the tendency to engage in sex for pay. These services also present important opportunities to change the ways young men and women are traditionally socialized about sexuality and move towards a greater understanding of the negative consequences of those roles and how those roles can be changed. 


\section{Promote Individual and Community Responsibility for STD and HIV/AIDS Prevention}

A key finding is that both spouses maintain secrecy if infected; however, men are more of the problem. The data reveal that both men and women acknowledge the fact that most of the STDs in women are acquired from the husband while men acquire theirs from extramarital relationships. Therefore, if the incidence of STDs among men were reduced, womenİs risks would be significantly attenuated. This is a challenging factor for community education. Another key finding is that very minimal change in behavior has occurred in spite of the widespread fear of HIV/AIDS in the communities. Chapters 3 and 4 discuss the reasons why individuals are slow in changing their behavior. Community-wide campaigns using real life cases of HIV/AIDS sufferers could help individuals see the reality of AIDS. Such a program should also intensify education on local prevention strategies.

Furthermore, there are some harmful practices which enhance the transmission of HIV/AIDS; these include deliberate transmission, using one circumcision knife for multiple clients, widow inheritance, and belief in divine causation (see Chapters 3 and 4). Data revealed that many seropositive men tend to increase sexual activity when they know or suspect their HIV/AIDS status, endangering innocent persons, especially women. This practice is used predominantly by men to rid their bodies of the ÏHIV fluidÓ. Many men believe that one can pass HIV/STDs out of the body in the same manner as urine and that the more sex one has, the more one rids the body of the virus. To change these practices, it is important that RH education contain basic information on the mechanisms by which the virus multiplies in the body and how it affects the immune system. Men need to know that once infected, a person cannot rid the body of the virus by increasing risky sexual behavior, and that AIDS doesnIt go the way it comes. They also need some elementary education on seroconversion.

A third key finding is the notion of ÏAIDS safe havensÓ. These are married women, young girls, and elderly women who are thought to be HIV/AIDS free because they are too young, too old, married, or too robust to have AIDS. Although there is not much evidence about sex with elderly women, a few men said it exists. There is considerable evidence of preferences of older men for younger girls and married women. Sometimes these men use money to lure younger women into having sex with them. There is need, therefore, to educate men that there is no HIV/AIDS safe haven; because a person is married or fat does not mean that the person is not carrying the virus that causes AIDS. It is important to teach men that unprotected sex by seropositive persons endangers innocent women who could be someoneÌs sisters, mothers, or daughters. This could be useful for engineering community mobilization for behavioral change by making everyone feel that they have a stake in preventing HIV/AIDS. Also, policies that increase knowledge of the disease and eliminate or at least minimize retrogressive practices such as widow inheritance and sex with minors should be enacted. Traditional surgeons (referred to as abasebi in Luhya) should be educated about the dangers of using one circumcision knife for multiple clients.

\section{Offer Male-Friendly Services}

Analysis of existing facilities reveals that current configuration of services do not meet male clientsì expectations. The deficiencies in current services include limited choice; lack of privacy, confidentiality, and attention to clientsİ comfort and convenience; and lack of information on range of available services, method side effects, and methods contra-indications. Others include the predominance of female providers; unreasonable waiting and consultation times; shortage of space, equipment, supplies, skills, and staff; and unfriendly provider behavior. Chapter 6 of this report contains detailed discussion of ways to reduce these deficiencies and increase service utilization among men. Suffice it to say that programs which minimize these deficiencies and eliminate misconceptions regarding FP will have significant appeal to men, women, and youth. Such a program will require time and painstaking effort. Nevertheless, in a place like Kakamega where there is considerable resistance to a wife using FP and little readiness among men to use FP services themselves, the engineering of appropriate programs would be the litmus test of efforts to enhance menIs access to reproductive resources and increase their involvement as gatekeepers of womenİs health. The appropriate program should increase knowledge of available services such that individuals are able to make informed choices; such a program would also evolve a relevant constellation of services that guarantees clientsÌ confidentiality, privacy, comfort, and convenience as well as good provider-client interaction.

\section{Implications for Further Research}

One of the findings of this research is the inverse relationship between access to information on the assessment of personal risk of STDs/HIV/AIDS and the negative attitude to FP. This finding can be explored further using the data. It would be interesting to compare Mumias and Kakamega divisions, 
which are very similar in terms of access to health services, with Kabras, which has less information and fewer health facilities. This analysis should provide insights for assessing the effect of FP programs on communitiesİ perceptions of reproductive health and attitude to FP. Such analysis can also provide a preliminary basis for testing the impact of FP programs on fertility behavior and preferences and for evaluating, though in a preliminary way, the role of FP programs in the context of declining fertility in Kenya.

Furthermore, the study revealed little change in behavior despite the knowledge of risk. This study found that the tendency to rid the body of the ÏHIV fluidÓ accounts for accelerated sexual activity among seropositive men. Again, research is needed to determine the prevalence of the practice and its potential impact on HIV/AIDS transmission, including deliberate transmission.

One of the key barriers to condom use among men is the notion of trust. This study revealed that men throw condoms away once they feel that they have established trust. Further research is needed in understanding the following questions: What are the elements of trust? At what point in the relationship is trust established? What are the profiles of partners that are likely to be trusted/not trusted? Do issues of trust carry the same weight among women as they do among men?

Many men in the communities stated that condom disposal is a real problem for users and that because of disposal problems some individuals often refrain from using them. Operations research could also provide insights into current practice regarding condom disposal and identify techniques that could alleviate the problem.

Finally, this study has provided significant insights into men's knowledge, perceptions, concerns, and beliefs about FP and prevention of STDs and HIV/AIDS and their impacts on service utilization. The findings - including the notion that knowledge and use of FP affect sexuality, the reasons for the poor change in behavior in spite of awareness of risk, and the description of services that enhance men's participation-have profound implications for policy and programs. However, the prevalence of these practices across Kenya and beyond is not known. Hence, there is a need to examine these issues in other settings to assess their prevalence and impacts on reproductive behavior. 


\section{Bibliography}

Allen, S. et al. 1992. ÏEffects of serotesting with counseling on condom use and sero-conversion among HIV discordant couples in Africa,Ó British Medical Journal 304: 1605 Ò1606.

Association for Vasectomy and Surgical Contraception (AVSC). 1990. MenÌs involvement in family planning and vasectomy initiatives. Report of a planning workshop held in Nairobi, Kenya, November 14Ò16.

Bankole, A. and S. Singh. 1998. ÏCouplesİ fertility and contraceptive decision-making in developing countries: Hearing the manÌs voice,Ó International Family Planning Perspectives 24 (1): $15 \mathrm{O} 24$.

Benchmark Qualitative Research Services. 1995. Male involvement: Project baseline study. A research report produced for Family Planning Association of Kenya, Nairobi, Kenya.

Biddlecom, A.E. and B.M. Fapohunda. 1998. ÏCovert contraceptive use: Prevalence, motivations, and consequences, Ó Studies in Family Planning 29 (4): 360Ò372.

Bongaarts, J. and J. Bruce. 1995. ÏThe causes of unmet need for contraception and the social content of services,Ó Studies in Family Planning 26: $57 \mathrm{O} 75$.

Brass, W. and C.J. Jolly (eds.). 1993. Population Dynamics of Kenya. Washington, DC: National Academic Press.

Bruce, J. 1990. ÏFundamental elements of the quality of care: A simple framework,Ó Studies in Family Planning 21 (2): $610 \mathrm{90}$.

Central Bureau of Statistics. 1994. Statistical Abstracts. Nairobi: Ministry of Planning and National Development.

Central Bureau of Statistics. 1996. Kenya Population Census 1989: Fertility and Nuptiality (Analytical Report Volume IV). Nairobi: Ministry of Planning and National Development.

Chambers, R. 1992. ÏRural Appraisal: Rapid, relaxed and participatory,Ó Institute of Development Studies discussion paper no.311. Unpublished.

Drennan, M. 1998. ÏReproductive health: New perspectives on menÌs participation,Ó Population Reports, Series J, No. 46.

Ezeh, A. and A. Gage. 1998. The economic and sociocultural context of domestic violence in Uganda. Paper presented at the Annual Meeting of the Population Association of America, Chicago, Illinois, April 1 Ò4.

Ezeh, A.C. 1993. ÏThe influence of spouses over each otherĪs contraceptive attitudes in Ghana,Ó Studies in Family Planning 24 (3): 163 Ò173.

Fakeye, O. and O. Babaniyi. 1989. ÏReasons for non-use of family planning methods at Ilorin, Nigeria: Male opposition and fear of methods,Ó Tropical Doctor 19 (3): 1140 Ò17.

Family Planning Association of Kenya (FPAK). 1996. Annual Report. Nairobi: FPAK.

Fapohunda, E. and M. Todaro. 1988. ÏFamily structure and demand for children in southern Nigeria,Ó Population and Development Review 14: 571Ò594.

Government of Kenya (GOK). 1994. Kakamega District Development Plan 1994Ò1996. Nairobi: Government Printer.

Government of Kenya (GOK). 1996. ÏNational Population Policy for Sustainable Development.Ó Sessional Paper No. 1. Nairobi: Government Printer.

Government of Kenya (GOK). 1998. Kakamega District Development Plan 1997Ò2001. Nairobi: Government Printer.

Isiugo-Abanihe, U. 1994. ÏReproductive motivation and family size preferences among Nigerian men,Ó Studies in Family Planning 25 (3): 149 Ò161.

Jain, A., J. Bruce, and S. Kumar. 1992. Quality services, programme efforts and fertility reduction. In: Family Planning Programmes and Fertility, edited by James F. Phillips and John Ross. Oxford: Clarendon Press, pp. $202 \mathrm{O} 221$.

Juma, M.A. 1996. Male Involvement Project: Baseline survey for training impact evaluation. A survey report produced for FPAK, Nairobi, Kenya.

Kamenga, M. et al. 1991. ÏEvidence of marked sexual behavior change associated with low HIV-1 seroconversion in 149 married couples with discordant HIV-1 serostatus: Experience at an HIV counselling center in Zaire,Ó AIDS 5: $610 े 67$

King, R. J. Estey, S. Allen, S. Kegeles, W. Wolf, C. Valentine, and A. Serufilira. 1995. ÏA family planning intervention to reduce vertical transmission of HIV in Rwanda,Ó AIDS 9 (suppl. 1): S45ÒS51.

Kruger, A. 1998. Developing Questions for Focus Groups. Thousand Oaks, London: Sage Publications.

Mbizvo, M.T. and M.T. Bassett. 1996. ÏReproductive health and AIDS prevention in sub-Saharan Africa: The case for increased male participation,Ó Health Policy and Planning, 11 (1): 84 Ò92.

Mbizvo, M.T. and D.J. Adamchak. 1991. ÏFamily planning knowledge, attitudes, and practices of men in Zimbabwe,Ó Studies in Family Planning 22 (1): 31 Ò38.

Mwarogo, P. and I. Achwal. 1997. Reaching out to men: The forgotten fifty percent. Paper presented at the Men as Partners Workshop, Mombasa, Kenya, May 8 Ò22.

National AIDS and STDs Control Programme (NASCOP). 1996. AIDS in Kenya: Background, Projections, Impacts and Interventions, Third Edition. Nairobi: Ministry of Health. 
National Council for Population and Development (NCPD), Central Bureau of Statistics (CBS), Office of the Vice President and Ministry of Planning and National Development (Kenya), and Macro International Inc. (MI). 1993. Kenya Demographic and Health Survey 1993. Calverton, Maryland: NCPD, CBS, and MI.

Ndeti, K. 1989. Male Motivation in Family Planning Acceptance in Kenya. Research Report. Nairobi: NCPD.

Odhiambo, O. 1992. Men and Family Planning in Kenya: Alternative Policy Intervention Strategies for Reducing Population Growth. Doctoral Dissertation, Florida State University. Ann Arbor: Michigan University Microfilms International, pp. xiii, 263.

PATH. 1997a. STI/HIV/AIDS Education for Worksite (company) Employees. A project report, PATH, Nairobi, Kenya.

PATH. 1997b. STI/HIV/AIDS Education for Security Guards in Five Companies. A project report, PATH, Nairobi, Kenya.

Renne, E.P. 1993. ÏGender ideology and fertility strategies in an Ekiti Yoruba Village,Ó Studies in Family Planning 24 (6): 343Ò352.

Ringheim, K. 1993. ÏFactors that determine prevalence of use of contraceptives methods for men,Ó Studies in Family Planning 24 (2): 87Ò99.

Rutenberg, N. and S.C. Watkins. 1997. ÏThe buzz outside the clinics: Conversation and contraception in Nyanza Province, Kenya,Ó Studies in Family Planning 28 (4): 290 Ò307.

Ryder, R.W. et al. 1991. ÏFertility rates in 238 HIV-1 seropositive women in Zaire followed for 3 years postpartum,Ó AIDS 5: $1521 O ̀ 1527$.

Terefe, A. and C.P. Larson. 1993. ÏModern contraception use in Ethiopia: Does involving husband make a difference,Ó American Journal of Public Health 83 (11): 1567 Ò1571.

Tour», L. 1996. Male involvement in family planning: A review of the literature and selected program initiatives in Africa.ÓA report submitted to the USAID Support for Analysis and Research in Africa, Washington, D.C.

World Health Organization (WHO). 1995. Progress in Human Reproduction Research. No. 35. Geneva: WHO. 